\title{
SIZE, ROLE AND PERFORMANCE IN THE OIL AND GAS SECTOR
}

\author{
R.L. Mansell, J. Winter, M. Krzepkowski, M.C. Moore ${ }^{\dagger}$ \\ The School of Public Policy, University of Calgary
}

\section{SUMMARY}

The oil and gas sector is a key driver of the Canadian and Albertan economies. Directly and indirectly it typically accounts for roughly half of Alberta's GDP, as well as one-third of the country's business investment and a quarter of business profits - and rising global demand will only add to these figures. However, that energy sector is also a changeable place populated by companies of all shapes and sizes, from small Emerging Juniors to wellestablished Majors whose daily production capacities are hundreds or thousands of times greater. The sector's assorted firms have different structures and ambitions, respond in distinct ways to market forces and have unique impacts on the economy. These differences in size, role and performance must be reflected in energy and related economic policies if they are to be effective in achieving policy goals. For example, they must recognize that the smallest firms are not always the fastest growers or the most innovative; that Intermediates are the most highly leveraged, with the highest debt-to-equity ratios; and that while Majors tend to have the lowest average cost per well drilled, they also (along with Emerging Juniors) have the highest operating costs. Despite the industry's critical importance, relatively little hard data has been made available concerning companies' structure, behaviour and performance, based on size. This paper goes a considerable way toward filling that gap, bringing together comprehensive datasets on 340 public oil and gas firms to chart essential patterns and trends, so policymakers and industry watchers can better understand the complexity and functioning of this important sector.

\footnotetext{
† The authors wish to acknowledge the helpful comments of the anonymous referees.
} 
TABLE OF CONTENTS

1 INTRODUCTION

1.1 At Issue

1.2 Study Objectives

1.3 Study Outline

3

2 BACKGROUND

2.1 Role of the Oil and Gas Sector ...............................................................................

2.2 Patterns of Changes in Activity ...................................................................................... 5

2.3 Literature Review on Firm Size, Behaviour and Performance............................................ 7

2.4 Statistics Canada Survey ......................................................................................... 11

2.4.1 Employment and Growth by Size Category ........................................................... 11

2.4.2 Hours Worked and Earnings ………………....................................................... 13

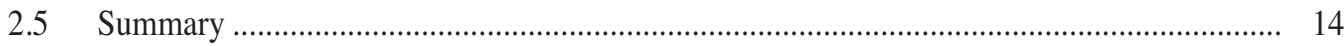

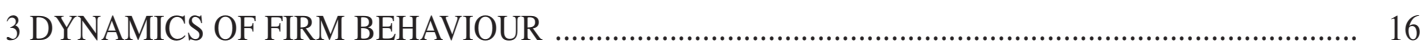

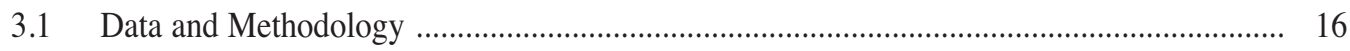

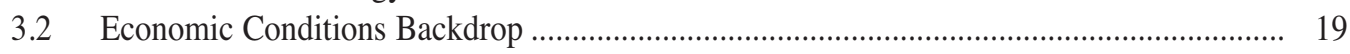

3.3 Entry and Exit Dynamics ………………………................................................. 22

3.4 Longer Term Survival Rates ................................................................................... 26

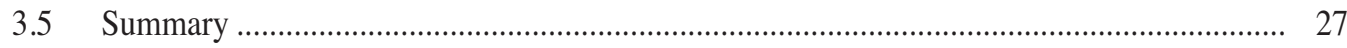

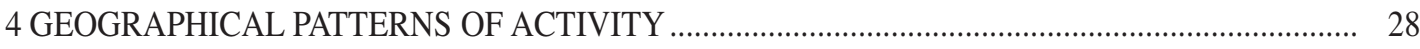

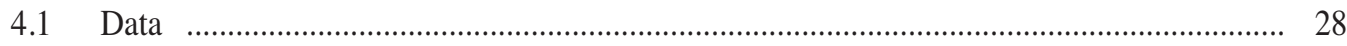

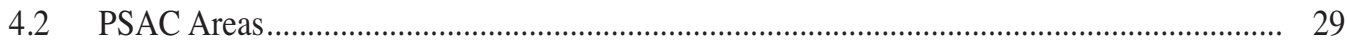

4.3 PSAC Area Characteristics ................................................................................... 30

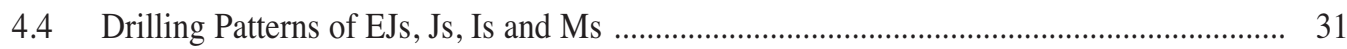

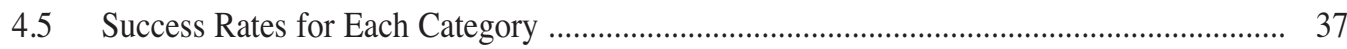

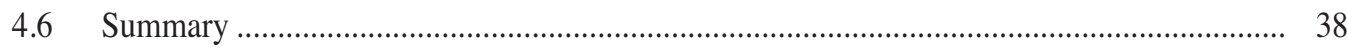

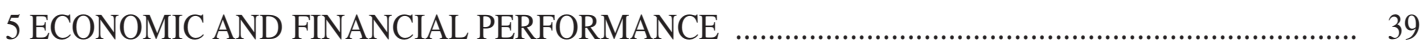

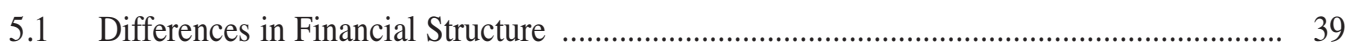

5.2 Differences in Revenue Generation .......................................................................... 41

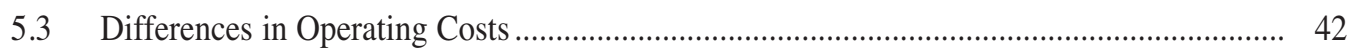

5.4 Differences in Royalties ..................................................................................... 43

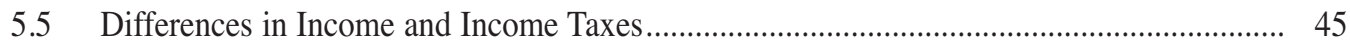

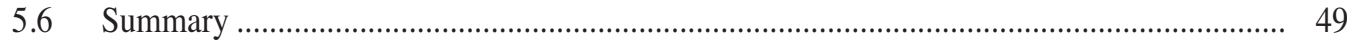

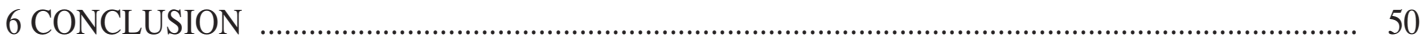


Appendix I ～- List of Firms in Sample ........................................................................................ 55

Appendix II - Aggregate Drilling Locations by PSAC Area and Firm Size, 2002 to 2008* ............ 61

Appendix III - Transitions and Firm Survival Rates ....................................................................... 66

Appendix IV - Percentages of Drilling Activity by Firm Size Category and PSAC Area .................. 67

Appendix V - Drilling Success Rates by PSAC Area and Size of Firm* ........................................ 70 


\section{INTRODUCTION}

\subsection{At Issue}

The oil and gas sector represents the primary engine of economic activity and prosperity in Alberta, and increasingly it has become an important driver of the Canadian economy. When the direct and indirect linkages are taken into account, this sector typically accounts for about onehalf of total value added (or Gross Domestic Product) in the province, about 40 percent of Alberta employment and around 50 percent of revenues for the provincial government. ${ }^{l}$ At the national level, the oil and gas sector now accounts for over one-half of all exports of goods and services; it is the dominant factor in the favourable trade balance; it accounts for about onequarter of all business profits and one-third of total business investment; and in 2007 paid almost $\$ 60$ billion to Canadian governments. ${ }^{2}$

In spite of the overall importance of this sector, relatively little quantitative information is available concerning the structure, behaviour and performance of the various components measured in terms of firm size. Commonly, the sector is portrayed simplistically as monolithic big oil and gas, when in fact there is huge variation in the size and roles of firms. Contrary to common perception, it is a highly complex and dynamic industry given the intricacies and sophistication associated with exploration, development and production. Generalities and folklore tend to grow up around oil and gas, and it is often difficult to separate myth from reality in terms of behaviour and performance.

This lack of information presents a major challenge in terms of forming appropriate and effective public policy for the oil and gas sector. For example, while it is commonly argued that small companies should be treated differently (typically preferentially) than large companies in areas such as tax and royalty policy, it is difficult to find well-grounded arguments as to why. Clearly, in order to achieve sector-specific and broader public policy goals such as optimizing wealth generation, good information on the roles, behaviour and performance of the various components is a prerequisite to effective policy formation.

There is a significant body of academic research for other sectors and especially for manufacturing. While this may provide some insights applicable to the oil and gas sector, there are substantial sectoral differences that may limit the usefulness of analogies. Compared to manufacturing, oil and gas activity generally has a higher capital and knowledge intensity, greater production, market/price and regulatory/policy risks and a greater requirement of high levels of ongoing investment in order to maintain production levels. The oil and gas sector is highly dynamic, embodying a strong element of continual change as new companies are formed, companies merge, companies exit, companies grow and some graduate to the next highest category. These dynamics underpin the Wild West caricature of the industry and give rise to many of the popular conceptions (and misconceptions) of roles and behaviour. Common examples of the disparate views include:

- The view that most employment growth and increase in industry activity is generated by small firms, and that to increase employment policy should be aimed at increasing incentives for those firms. However, one can often find counter claims that it is the large firms that are

\footnotetext{
1 See Section 2.1

2 See R. Mansell and L. Staples, Task Force on Resource Development and The Economy, Alberta Chamber of Resources, February 2011.
} 
the major job creators and are the key drivers of overall activity levels in the oil and gas sector. This in turn would mean quite a different set of policy levers if the objective is to affect growth and change in the sector.

- There is the view that growth in the oil and gas sector is mostly through a steady progression, as many small firms grow to become mid-sized and then large firms. A counter view is that any such expansion is primarily the result of large firms growing by exploiting economies of scale and scope, high drilling success rates and through the absorption of surviving small firms.

- One view is that small firms exhibit less variability in employment, investment and overall activity levels since they tend to be heavily committed to local or regional resource plays and, unlike the large firms, do not shift their focus among shifting international plays. The opposite view is also common. That is, it is the major firms that through their sheer size, financial strength and diversification exhibit the greatest stability.

- A common view is that the small firms are more agile, efficient and innovative and, consequently, provide dynamic and creative leadership that sets the tone for the entire industry. An equally common view is that, with the large economies of scale and scope, the very high capital requirements associated with the major innovations in the oil and gas sector and access to a much larger and deeper talent pool, it is the large firms that drive innovation in the oil and gas sector.

- A frequent claim is that entry of new investors into the small (Emerging Junior and Junior) categories is the primary source of renewal and expansion of exploration and production activity. However, there is also the view that this source lies mainly in the larger firms with their much higher levels of accumulated experience (learning by doing), and with their greater access to capital and talent in an industry where large and sophisticated projects are increasingly the norm.

- As a final example, there is the view that compared to the small firms the large companies tend to have a more concentrated geographical focus around a few big plays. However, there is also a competing view that it is the small firms that tend to be more concentrated, with a focus on the areas where less expensive shallow, conventional drilling is the norm.

A key goal in this study is to provide an information base to test these types of views to determine which are supported by the data, which are not and which require still more evaluation in order to make a determination of their validity.

\subsection{Study Objectives}

The primary objective in this study is to provide an information base for developing an understanding of the role, behaviour and performance of the various types of firms (measured by size) in the oil and gas sector. These main types are Emerging Juniors (EJs), Juniors (Js), Intermediates (Is) and Majors (Ms). These are defined as follows:

- Emerging Juniors (EJs) are companies that annually produce between 1 and 999 barrels of oil equivalent (BOE) per day.

- Juniors (Js) are companies annually producing between 1,000 and 9,999 BOE per day.

- Intermediates (Is) annually produce between 10,000 and 99,999 BOE per day.

- Majors (Ms) annually produce over 100,000 BOE per day. 
Given the lack of research on the roles, behaviour and performance of these firms in the oil and gas sector, this study is to a significant degree exploratory in nature. While considerable progress has been made in compiling a consistent database, there are nevertheless some gaps. For example, in some cases information is limited to that for public companies over the period 2002 to 2009. Data on private companies is not publicly available. Nevertheless, even here it can be noted that the companies covered represent about 80 percent of total investment and production for the sector and, as such, provide a fairly large sample. Further, while a longer time series would clearly be better, the period 2002-2009 does cover a fairly complete cycle for the sector embodying slow growth, rapid growth, retrenchment and the beginning of a recovery.

This study is focused on establishing a consistent base of information useful in understanding the roles played by the different sized firms (that is the EJs, Js, Is and Ms), the movements in and out of the sector and transitions from one size category to another, geographic patterns of activity for each component, and the relative behaviour and performance of firms in each category in terms of a variety of measures such as investment, production, unit costs, profitability and payments of royalties and taxes. While these measures are helpful in terms of supporting or rejecting many of the types of conceptions and misconceptions noted earlier, in some cases they are inconclusive and suggest the need for more detailed study.

\subsection{Study Outline}

Section 2 outlines the role of the oil and gas sector in the Alberta economy and examines patterns of change in activity in this sector. It also provides a review of the literature dealing with the general relationship between firm size, behaviour and performance and presents some aggregate results from a special survey of small and medium-size firms in the oil and gas industry.

Section 3 focuses on the shifts over the period 2002-2010 among firms in the Emerging Junior, Junior, Intermediate and Major size categories in the oil and gas sector. Using a large database, we examine the tendencies for entry, exit, absorption, consolidation and transitioning to the next size category over the period and in relation to the changing economic environment.

Geographical patterns of activity are examined in Section 4 by extending the database to include detailed well information. The objective here is to trace the exploration and development activity of firms in each of the four firm size categories to determine differences with respect to geographical concentration and dispersion, in the type of drilling and in geographical shifts as conditions change.

The last section (Section 5) focuses on the economic and financial performance of the different size categories for firms in the oil and gas sector. It examines differences and shifts in financial structure, revenue generation, operating costs, royalties paid and income earned.

A summary is provided at the end of each section. 


\section{BACKGROUND}

In this section we begin with a brief outline of the role of the oil and gas sector in the Alberta economy, and then proceed to describe the general patterns of change in factors such as oil and gas prices, costs and investment patterns. The latter are an important backdrop for understanding the shifts among the four groups of firms over time. Following this is a review of the literature on firm size, behaviour and performance. This provides a general assessment of the role of firm size, primarily in the context of other sectors, and is intended to shed some light on the general factors determining the role and performance of small vs. large firms. The final sub section gives a brief summary of the results from a Statistics Canada survey on small and medium enterprises (SMEs) applicable to the oil and gas sector.

\subsection{Role of the Oil and Gas Sector}

The oil and gas sector has been a dominant factor in Alberta's development and growth over the last six decades. The large capital investments and operating expenditures associated with finding and producing both conventional and unconventional oil and gas have directly provided a major stimulus to the economy. However, the indirect and induced impacts have been equally important. The development of many other industries supplying inputs to the energy sector, the generation of substantial export and government revenues, and the stimulus for considerable inflows of people to the province have resulted in large multiplier effects. In combination, these have played a major role in shaping Alberta's character, which is generally distinguished by its highly educated, adjustable and entrepreneurial labour force, low unemployment and high labour force participation rates, and a strong work ethic and sense of self-reliance.

Based on historical data for the various sectors of the provincial economy, and using the Statistics Canada Interprovincial Input Output model, the direct and indirect impacts associated with the oil and gas sector have been estimated over the period 1972 to 2009. These were then subtracted from aggregate value added (or GDP) to show what Alberta GDP would be in the absence of unconventional oil and gas production, then without the conventional oil and gas industry and finally (by the lower line), Alberta GDP in the total absence of the petroleum industry. Averaged over the period 2000-2009, this analysis of GDP, employment and government revenues indicates that, taking into account the direct and indirect impacts, the oil and gas sector accounted for 53 percent of total Alberta GDP, 44 percent of employment in the province and about 50 percent of all revenues collected by the Alberta government.

Alberta's economic future will be closely tied to the performance of the oil and gas sector. There is clearly huge potential associated with unconventional oil and gas and remaining conventional resources. However, translating this potential into reality will be daunting. Increasing constraints related to resource access, environmental impacts, infrastructure requirements, and the availability of highly qualified people need to be addressed. Equally challenging are the massive long-term investments in developing and implementing new technologies and making the right changes in the policy and regulatory framework. Effective and appropriate policy will, in turn, require a solid understanding of the various sizes and types of firms engaged in the oil and gas sector. 
FIGURE 2.1: IMPACT OF THE OIL AND GAS SECTOR ON ALBERTA REAL GDP

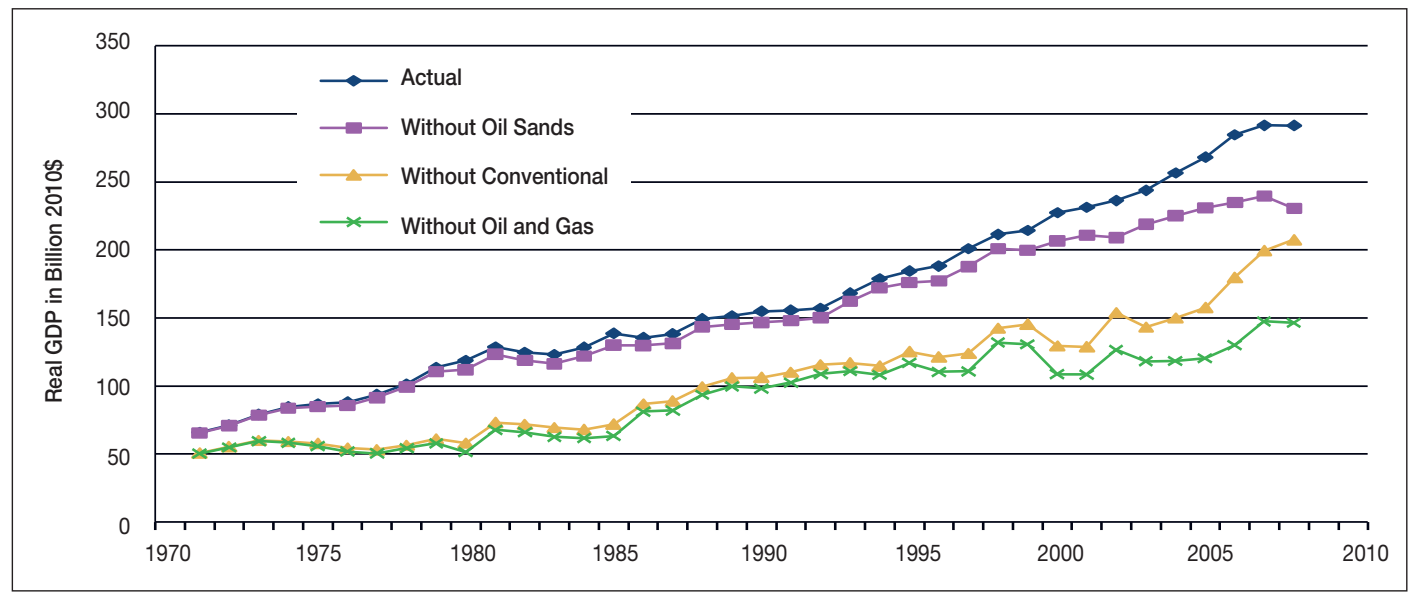

Source: Data from Statistics Canada and estimates by R. Mansell and R. Schlenker, The School of Public Policy and Department of Economics, University of Calgary.

\subsection{Patterns of Changes in Activity}

Investment in the form of expenditures on exploration and development activities is a sensitive measure of overall conditions (actual and expected) related to prices, costs, market access and policy/regulation facing the industry. Most firms, and particularly the Emerging Juniors (EJs), Juniors (Js) and Intermediates (Is), tend to be concentrated in the conventional side of the oil and gas industry. As shown in Figure 2.2, after a generally strong upward increase in investment activity from the early 1990s, investment in the conventional industry followed a general upward trend until 2006. The subsequent drop appears to be primarily related to the decline in gas prices and the decline in oil prices in $2008 .^{3}$

These oil and gas price patterns are shown in Figure 2.3 and the trends in oil and gas well completions are provided in Figure 2.4. Of particular note is the divergent trend in gas and oil well completions occurring after 2000, reflecting a divergence in natural gas and oil prices.

\section{FIGURE 2.2: INVESTMENT OF THE PETROLEUM INDUSTRY IN ALBERTA}

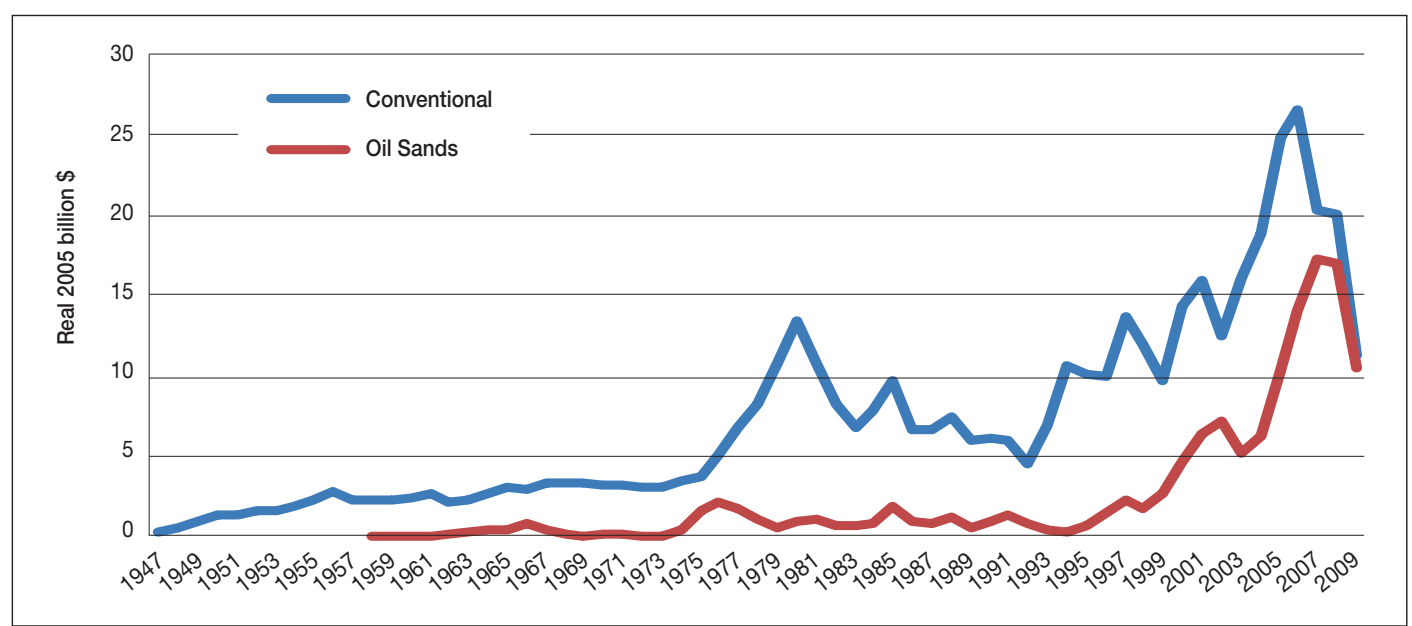

Source: Data from Canadian Association of Petroleum Producers, Statistical Handbook and from Statistics Canada (price deflators).

3 Other factors include the general financial and economic uncertainty related to the global recession in 2008, and the escalation of construction and other costs facing the industry over recent prior years. 


\section{FIGURE 2.3: REAL AVERAGE WESTERN CANADA WELLHEAD PRICES}

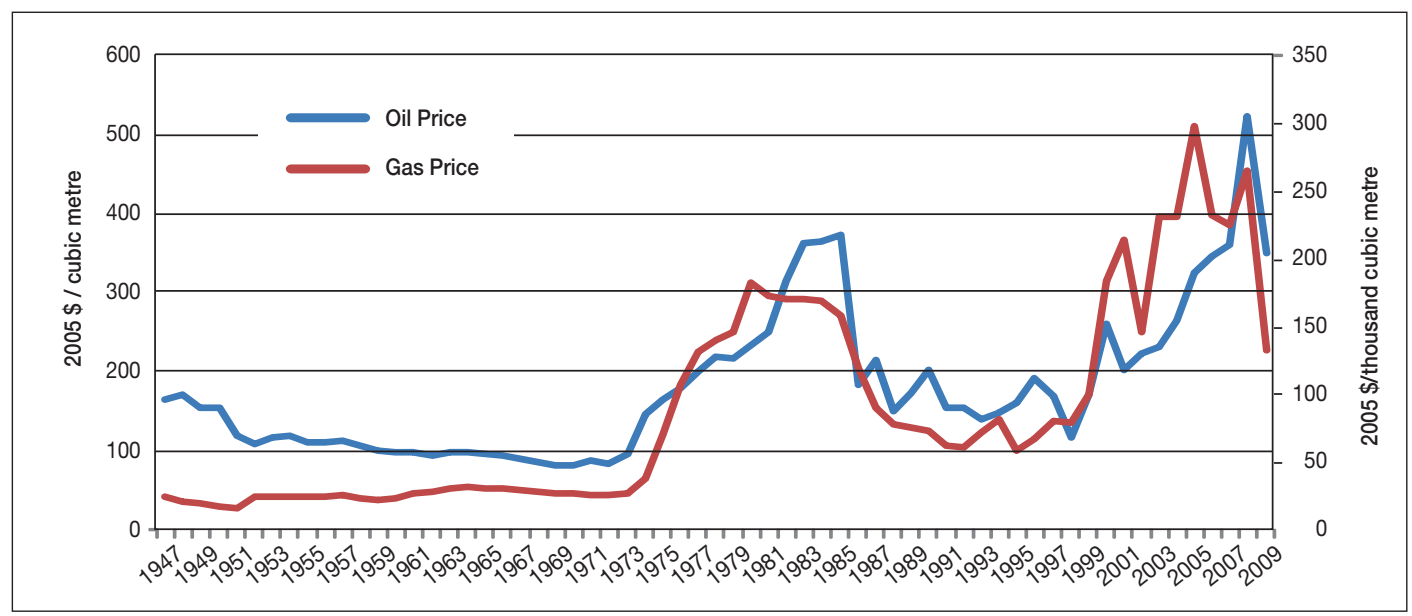

Source: Data from Canadian Association of Petroleum Producers, Statistical Handbook and from Statistics Canada (price deflators).

FIGURE 2.4: OIL AND GAS WELLS COMPLETED IN ALBERTA

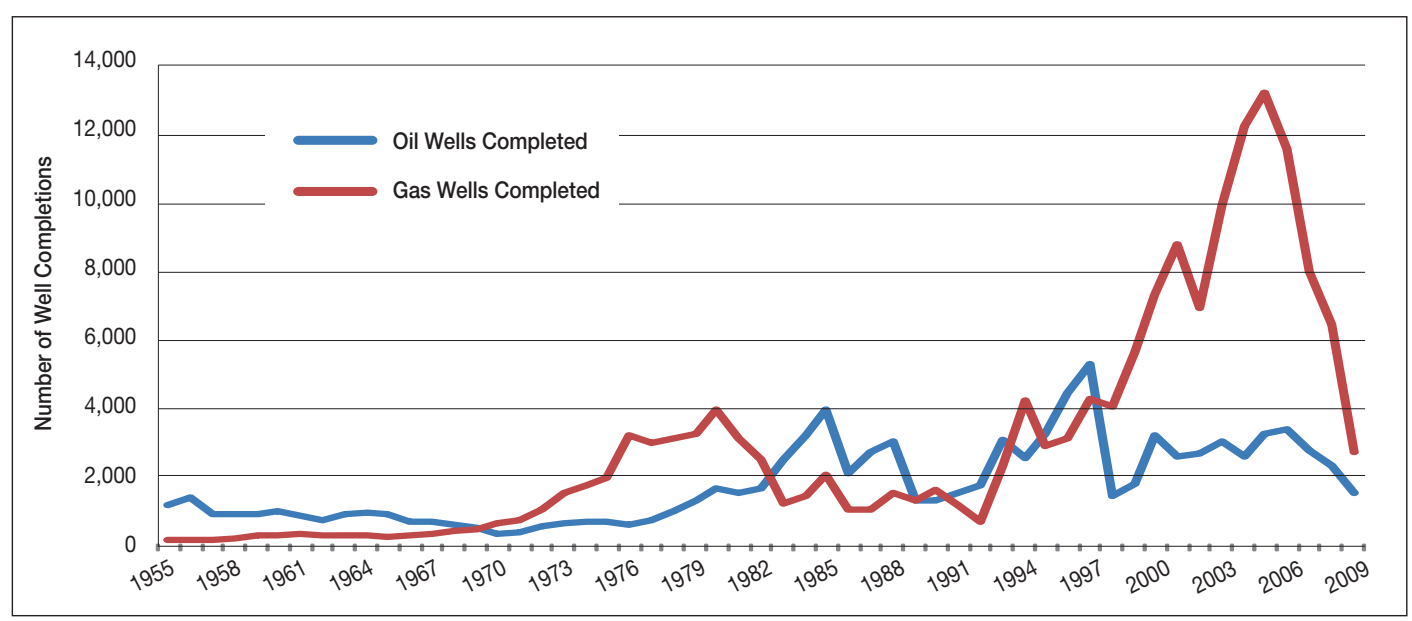

Source: Data from Canadian Association of Petroleum Producers, Statistical Handbook.

It is noteworthy that these shifts translate, not only into swings in the provincial economy, but into substantial variations in royalty revenues (and in other non-renewable resource revenues) for the government of Alberta (see Figure 2.5). 


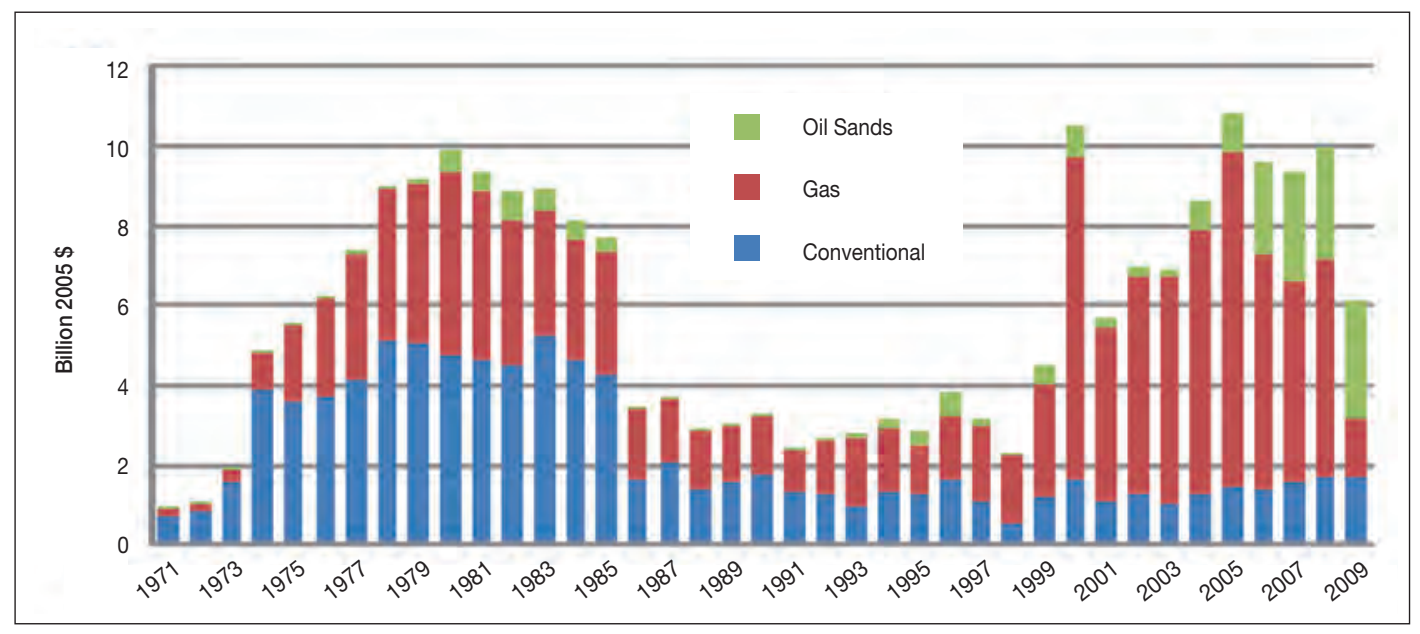

Source: Data from Alberta Finance and Enterprise, Government of Alberta Budgets.

\subsection{Literature Review on Firm Size, Behaviour and Performance}

There is extensive literature on the differences among small, medium and large firms in terms of behaviour and performance. This literature is generally focused on firms in the manufacturing sector. While recognizing the special characteristics of the oil and gas sector, such as high capital intensity and risk, it is nevertheless instructive to examine the results from this research for potential applicability to the issues at hand. This literature primarily studies the differences among firm sizes in terms of employment creation and wage levels, innovation, financing and financial constraints and the cost of regulatory and tax compliance.

\subsubsection{EMPLOYMENT AND WAGES}

There have been a number of surveys on the role of SMEs (small and medium enterprises) within the OECD (Organization for Economic Cooperation and Development) countries. These businesses form a substantial part of these economies, accounting for over 95 percent of all businesses and two-thirds of total private employment. ${ }^{4}$ There are still questions about the productivity of small firms and whether they generate employment when both entries and exits are taken into account. ${ }^{5}$

Broersma and Gautier ${ }^{6}$ find small firms are more adept at maintaining job creation during economic slumps than larger firms, perhaps due to their larger turnover rates. While entering and exiting, small firms are better able to continuously adjust their employment and take advantage of limited opportunities. Larger firms' employment patterns closely follow business cycles, as they choose to restructure during recessions.

4 OECD, 2005a, "A Qualitative Definition of SME," SBS Meeting on "Towards a More Systematic Statistical Measurement of SME Behavior," Background Report for the Second OECD Conference of Ministers responsible for SME (Paris: OECD).

5 International Tax Dialogue, 2007, “Taxation of Small and Medium Enterprises," Buenos Aires, Argentina

6 Broersma, Lourens and Gautier, Pieter, 1997, "Job Creation and Job Destruction by Small Firms: An Empirical Investigation for the Dutch Manufacturing Sector," Small Business Economics, 9, issue 3, p. 211-224 
The claim that small firms have higher net growth is largely anecdotal. For instance, in US manufacturing firms, smaller firms exhibit larger gross job creation rates, but have lower net job creation rates due to large numbers of failed small businesses. In absolute terms, large firms create and destroy the most jobs created each year due to the distribution of employment being more skewed towards large firms. ${ }^{7}$ Examining employment growth among surviving firms (therefore excluding births and exits), Baldwin et al. ${ }^{8}$ find employment rates are similar across firm sizes and industries.

Haltiwanger et al., using a large US database, explore the relationship between firm size and job growth. They find when statistical and measurement issues are properly interpreted, there is no relationship between firm size and job creation. When the age of firms (and not just size) is accounted for, there is no statistically significant relationship between net growth rates and firm size. Rather, it tended to be young or new firms that contributed substantially to both gross and net job creation; this can be missed because young firms tend to be classified in small size classes. The authors document a significant up-or-out dynamic associated with younger firms, where surviving young firms grow significantly faster than their mature counterparts, are more volatile and exhibit higher rates of gross job creation and job destruction. Longer job survival rates and tenure are also positively associated with firm size, ${ }^{10}$ which are important factors in overall job quality. ${ }^{11}$

Baldwin $^{12}$ finds jobs in smaller manufacturing plants tended to pay less, on average, than those in larger plants, either because they offered a lower hourly wage or did not supply as many weekly work hours. As early as 1973, plants that employed between five and 19 employees paid 84 percent of the Canadian national average, while those with more than 1000 employees paid 128 percent of the national average.

Other results suggest that, on average, large firms pay more than 50 percent higher wages than small firms. ${ }^{13}$ The wage differential is much higher for full-time jobs than for part-time jobs. Controlling for worker characteristics, the wage differential between large and small firms varies from 20 percent to 24 percent in full-time jobs, that is, roughly twice the wage differential found in part-time jobs, and this difference holds after controlling for benefits (pensions) and working conditions (hours) or the potential threat of unionization.

7 Davis, Steven, Haltiwanger, John and Schuh, Scott, 1996, "Small Business and Job Creation: Dissecting the Myth and Reassessing the Facts," Small Business Economics, 8, issue 4, p. 297-315

8 Baldwin, John Russel, Dupuy, Richard and Picot, Garnett, (1994), "Have Small Firms Created a Disproportionate Share of New Jobs in Canada? A Reassessment of the Facts," Analytical Studies Branch Research Paper Series, Statistics Canada, Analytical Studies Branch.

9 Haltiwanger, John C., Ron S. Jarmin and Javier Miranda. 2010, "Who Creates Jobs? Small Vs. Large Vs Young," NBER Working Paper 16300

10 Audretsch, David B., (1991), "New-Firm Survival and the Technological Regime," The Review of Economics and Statistics, 73, issue 3, p. 441-50

11 Davis, Steven, Haltiwanger, John and Schuh, Scott, (1998), Job Creation and Destruction, vol. 1, 1 ed., MIT Press

12 Baldwin, John Russel, (1996), "Were Small Producers the Engines of Growth in the Canadian Manufacturing Sector in the 1980s?" Analytical Studies Branch Research Paper Series, Statistics Canada, Analytical Studies Branch

13 Morissette, Rene, (1993), “Canadian Jobs and Firm Size: Do Smaller Firms Pay Less?” Canadian Journal of Economics, 26, issue 1, p. 159-74 
Wagner ${ }^{14}$ and Brown et al. ${ }^{15}$ also suggest non-wage benefits such as insurance or pension plans, job security, possibilities for worker decision-making, and opportunities for skill improvement are all lower in small firms compared to larger firms. Work organization is less rigid and institutionalized possibilities for workers' participation in decision-making are weaker.

Ultimately, basing judgments on size alone may be too simplistic and firm age may be just as important. Early studies established not only that the likelihood of new entrants surviving is quite low, but that the likelihood of survival is positively related to firm size and age in a diverse set of countries. ${ }^{16}$ Firm age has been shown to have a large effect on productivity and worker compensation, ${ }^{17}$ implying if these small firms are given time to develop, they may become large successful firms in the future.

\subsubsection{INNOVATION}

Based on survey data, Kumar and $\mathrm{Liu}^{18}$ characterise between 30-60 percent of OECD SMEs as being innovative firms. Though they are less likely to invest in research and development of new methods, they choose to innovate by creating or re-engineering products or services to develop new markets, undertake new organizational tactics, or improve on current techniques to increase sales. Some of the innovative SMEs are truly innovators, conducting advanced research and development in technology and displaying growth rates in the top 10 percent of all firms.

\subsubsection{FINANCING AND FINANCIAL CONSTRAINTS}

Special tax treatment for smaller firms is often argued on the basis that these firms may have trouble acquiring the necessary capital to fund their desired investments. Uncertainty and increased risk of these firms may cause capital market imperfections that impair financing of smaller firms. ${ }^{19}$ The easiest and perhaps the least expensive way to fund projects is through the use of retained earnings. Providing tax relief either by lowering the corporate tax rate or targeted tax incentives can increase the profits of firms and thus lower the cost of financing.

\footnotetext{
14 Wagner, J, 1997, "Firm Size and Job Quality: A Survey of the Evidence from Germany," Small Business Economics, vol. 9(5), pp 411-425

15 Brown, Charles, James Hamilton, and James Medoff, 1990, Employers Large and Small, Harvard University Press, Cambridge, Massachusetts

16 Audretsch, David. B., 1995, "Innovation, Growth and Survival," International Journal of Industrial Organization 13, $441-457$.

17 Audretsch, David B., 1999, "Small Firms and Efficiency," in Are Small Firms Important? Their Role and Impact, ed Zoltan J. Acs (Springer) pp. 241-272

18 Kumar, Sameer and Dan Liu, 2005. "Impact of globalisation on entrepreneurial enterprises in the world markets," International Journal of Management and Enterprise Development, Vol. 2(1), 46-64.

19 Storey, D. J. 1994. Understanding the small business sector. London: Routledge.
} 
Government policies can have different, and perhaps unintended, effects on addressing small business disadvantages. First, it has been found that lowering tax rates may increase total factor productivity of all firms, except those that are both small and young. ${ }^{20,21}$ This is likely because these firms already take advantage of different exemptions and tax credits in the tax system. For instance, junior oil and gas companies have a limited ability to use Successful Efforts as opposed to Full Cost Accounting, ${ }^{22}$ or they may not be profitable enough to take advantage of corporate tax reductions.

Johansson et al. ${ }^{23}$ emphasize previous findings by claiming that preferential tax treatment for small firms creates a significant disincentive for firms to grow to their optimal size and take advantage of potential returns to scale. They also claim that reducing the corporate income tax will produce more growth in larger firms than smaller firms, primarily because the limited profitability of small firms limits how much they are affected by corporate taxation. According to Coyne, ${ }^{24}$ small firms receive much more of a benefit from targeted tax incentives. Yet if market imperfections are the primary reason for complicating the tax structure, then it may be more effective to address these problems head-on by offering guaranteed loans, subsidised loans, or access to more venture capital. ${ }^{25}$

\subsubsection{REGULATORY AND TAX COMPLIANCE COSTS}

Smaller firms may have to bear higher proportional costs associated with compliance costs of different government regulations and taxes. Many of these costs are generally unrelated to firm size, and thus smaller firms will face a larger burden of these fees. The European Commission $^{26}$ found larger firms paid 0.02 percent of total revenue to comply with the EU VAT and corporate taxes, while the costs for small firms were 2.6 percent of total revenue. In a Canadian study, Vaillancourt ${ }^{27}$ also found that compliance costs (as a percentage of revenue) decreased with firm size. An increase in firm size by one percent was associated with an absolute increase in cost of only 0.3 percent.

20 Schwellnus, Cyrille and Arnold, Jens Matthias, 2008, "Do Corporate Taxes Reduce Productivity and Investment at the Firm Level?: Cross-Country Evidence from the Amadeus Dataset," No 641, OECD Economics Department Working Papers, OECD Publishing

21 Vartia, Laura, 2008, "How do Taxes Affect Investment and Productivity?: An Industry-Level Analysis of OECD Countries,” No 656, OECD Economics Department Working Papers, OECD Publishing

22 Harris, Trevor and Ohlson, James, 1987, “Accounting Disclosures and the Market's Valuation of Oil and Gas Properties," Accounting Review 62, 651-670.

23 Johansson, Åsa, Heady, Christopher, Arnold, Jens Matthias, Brys, Bert and Vartia, Laura, 2008, "Taxation and Economic Growth,” No 620, OECD Economics Department Working Papers, OECD Publishing

24 Coyne, E. J. 1995, Proposed Analytical Model for FDI Attraction Into Developing Countries, Essays in International Business 1, The International Business Center, College of Professional Studies, University of the District of Columbia, Washington D.C.

25 International Tax Dialogue, 2007, “Taxation of Small and Medium Enterprises," Buenos Aires, Argentina

26 European Commisstion, 2004, “European Tax Survey”, Commission Staff Working Paper, SEC(2004) 1128/2.

27 Vaillancourt, François, 1987, “The Compliance Costs of Taxes on Business and Individuals: A Review of the Evidence," Public Finance 42, 3: 395-414. 
Crain and Hopkins ${ }^{28}$ examine the cost of regulation per employee in the US. They find that the average cost of tax and regulation compliance for firms with fewer than 20 employees is $\$ 7,647$ per employee, while for larger firms it is only $\$ 5,282$ per employee. These differences are largely driven by compliance with environmental regulations, where costs are 364 percent higher for small firms, and tax compliance, which are 67 percent higher for small firms.

\subsection{Statistics Canada Survey}

Some indications of the differences between small, medium and large firms in the oil and gas sector in Alberta can be gleaned from data covering 2000 to 2008 collected by Statistics Canada. ${ }^{29}$ While the data used in this section is for firms in the mining, quarrying and oil and gas-extraction business, the vast majority of these firms in this sector operating in Alberta are in the oil and gas industry.

\subsubsection{EMPLOYMENT AND GROWTH BY SIZE CATEGORY}

As shown in Figure 2.6, in 2008, 63 percent of these firms had fewer than five employees and 85 percent has less than 20 employees. For the same year, the firms with less than five employees accounted for six percent of employment in this sector and those with less than 20 employees accounted for 15 percent of employment (See Figure 2.7).

Expressed differently, the firms with more than 100 employees represented only three percent of the total number of firms but accounted for 71 percent of employment in the sector. Firms with more than 20 employees represented 15 percent of the total number of firms but accounted for 85 percent of total employment. It is clear that the larger firms dominate in terms of employment in the sector and, consequently, one would expect any significant positive or negative shifts in this employment to be determined by activity levels of the larger firms.

FIGURE 2.6: FIRM DISTRIBUTION BY FIRM SIZE (NUMBER OF EMPLOYEES)

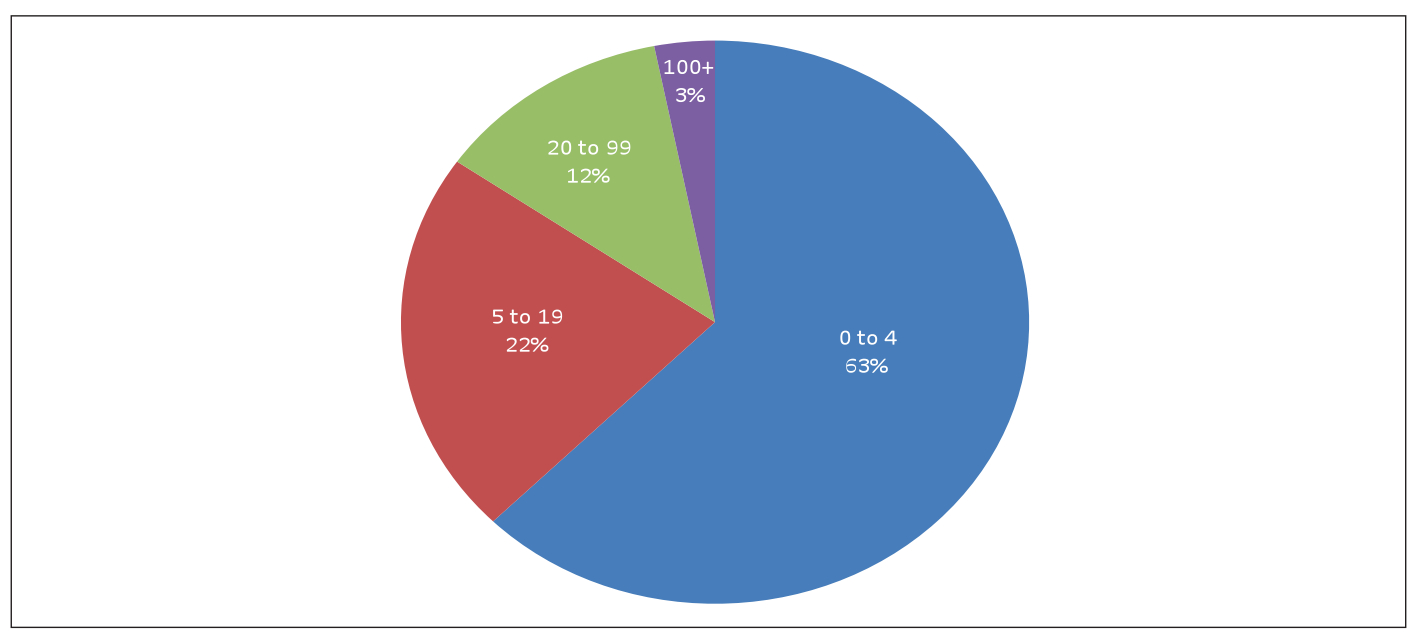

Source: Statistics Canada, Canadian Business Patterns Database, June 2011

${ }^{28}$ Crain, M., and Hopkins, D. 2001, "The Impact of Regulatory Costs on Small Firms,” Office of Advocacy, U.S. Small Business Administration: Washington D.C. EC (2004).

29 Statistics Canada, Canadian Business Patterns Database, June 2011 


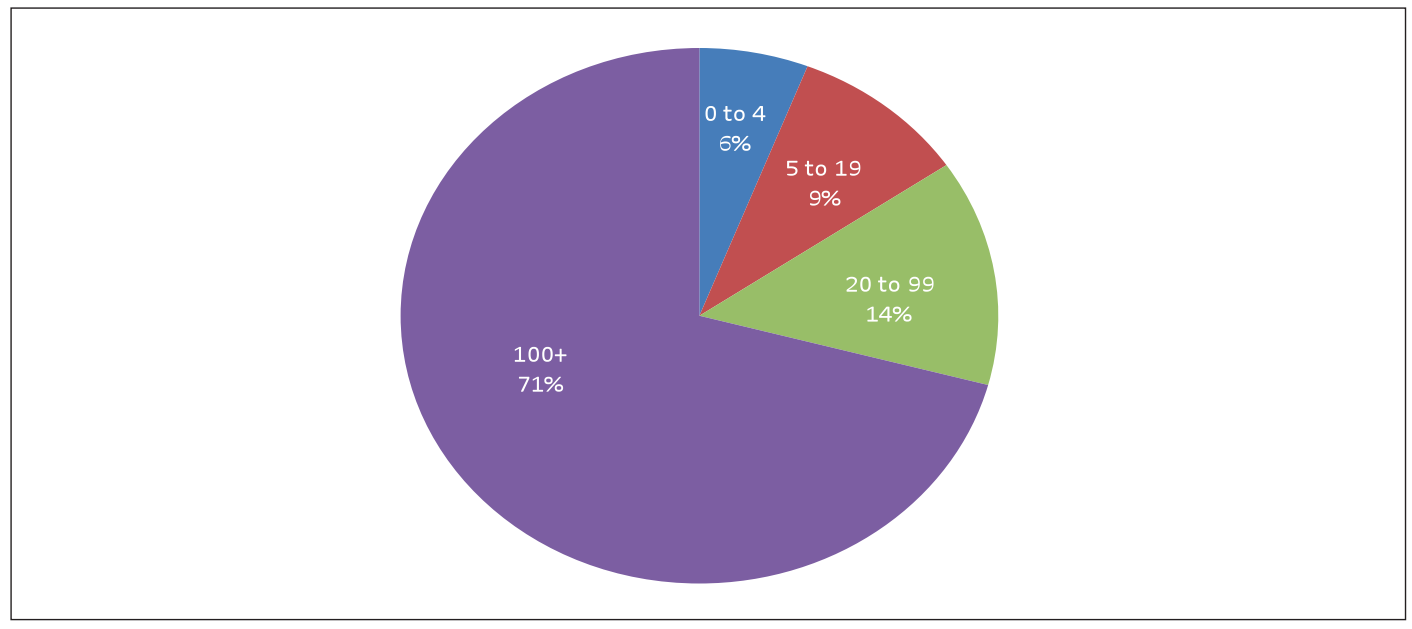

Source: Statistics Canada, Canadian Business Patterns Database, June 2011

These data can also be used to show the growth rates over the period 2000 to 2008. Of course, it is important to note that growth rates can be misleading, in that it is mathematically much easier to achieve a very high growth rate from a small base than from a large base. This factor alone would suggest that the small firms in the oil and gas sector should show a much higher rate of growth in employment than the large firms. As indicated in Figure 2.8, however, this is not the case. Over the period to 2008, employment by firms with more than 100 employees increased by 77 percent (or a total of 36,368 employees), compared to an increase of 66 percent (or a total of 2,461 employees) for the firms with less than five employees. The rates of growth for the firms with 5-19 employees and 20-29 employees were, respectively, 31 percent (or an increase of 1,966 employees) and 37 percent (or an increase of 2,934 employees).

FIGURE 2.8: PERCENTAGE GROWTH IN EMPLOYEES AND FIRMS BY FIRM SIZE

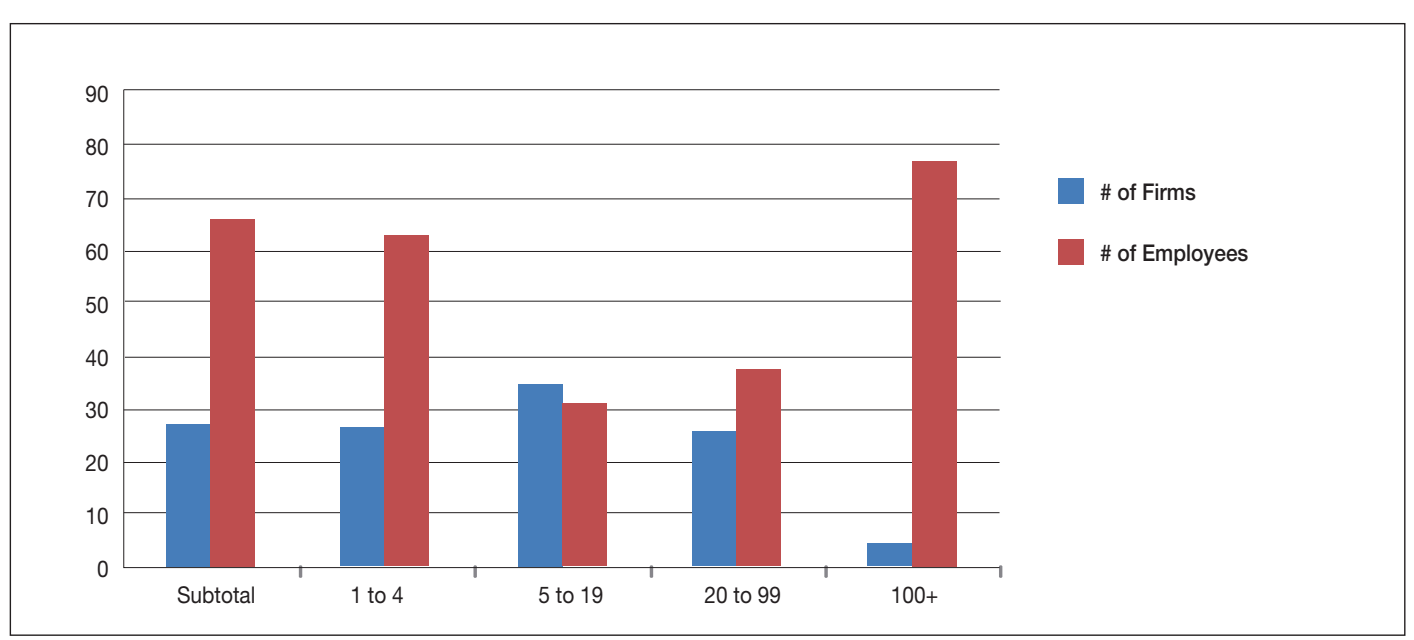

Source: Statistics Canada, Canadian Business Patterns Database, June 2011 


\subsubsection{HOURS WORKED AND EARNINGS}

Statistics Canada data from the same survey also sheds some light on the differences among firm size categories in terms of average hours worked and average wages and salaries. As shown in Figure 2.9, average weekly hours are generally increasing in firm size, up to firms with less than 500 employees. There is a similar pattern in average weekly earnings (see Figure 2.10). However, as shown in Figure 2.11, there is much less variation in terms of average earnings per hour worked.

FIGURE 2.9: AVERAGE HOURS WORKED BY FIRM SIZE (2008)

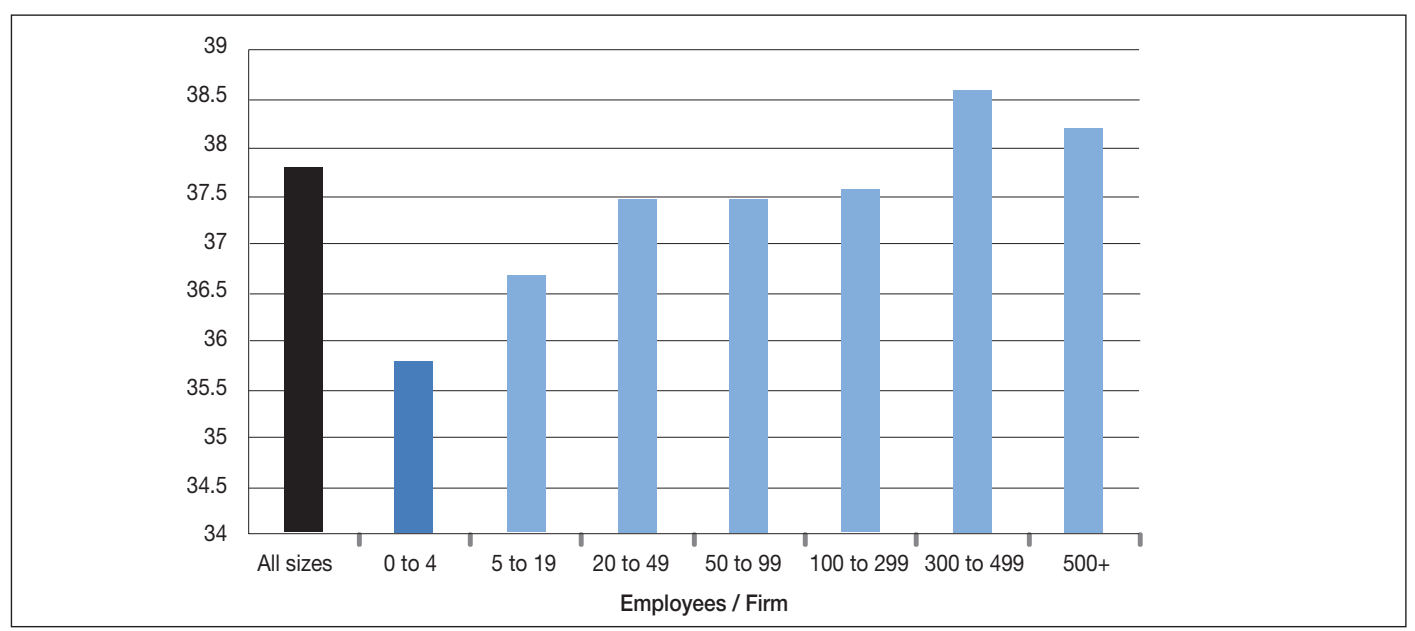

Source: Statistics Canada, CANSIM Table 2810046

FIGURE 2.10: AVERAGE NOMINAL WEEKLY EARNINGS BY FIRM SIZE, 2000 AND 2008

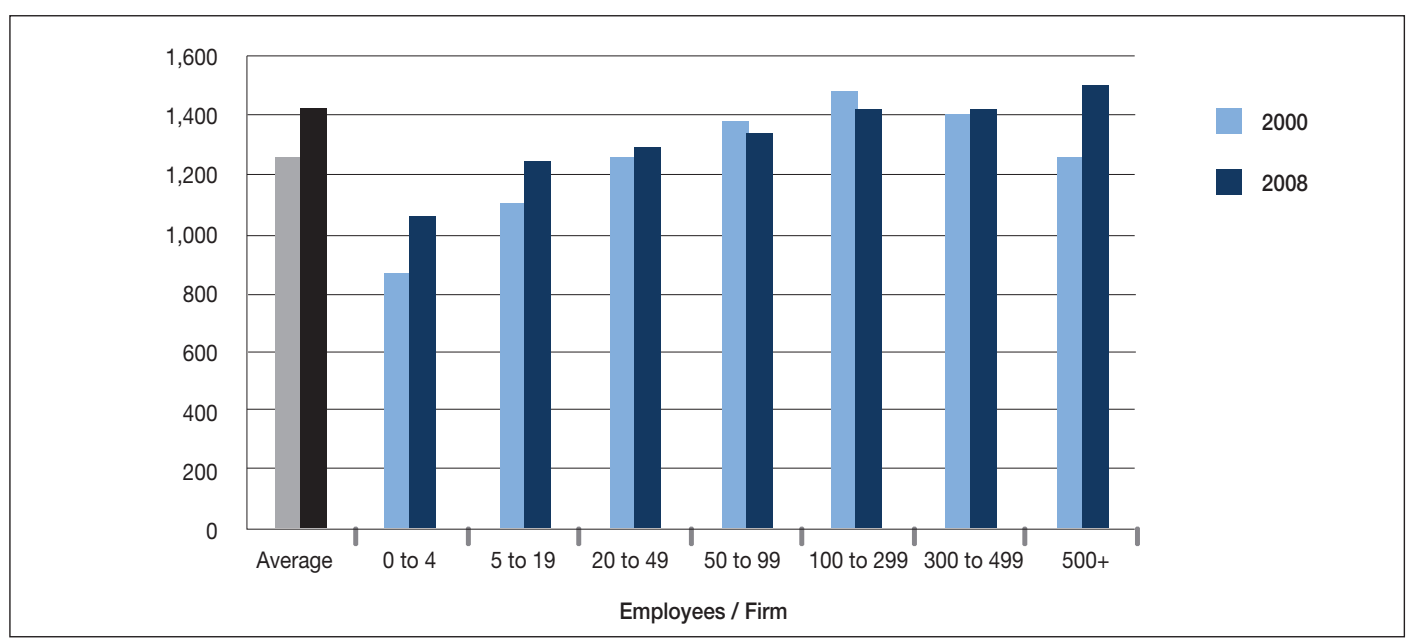

Source: Statistics Canada, CANSIM Table 2810044 
FIGURE 2.11: AVERAGE NOMINAL HOURLY WAGE BY FIRM SIZE, 2000 AND 2008

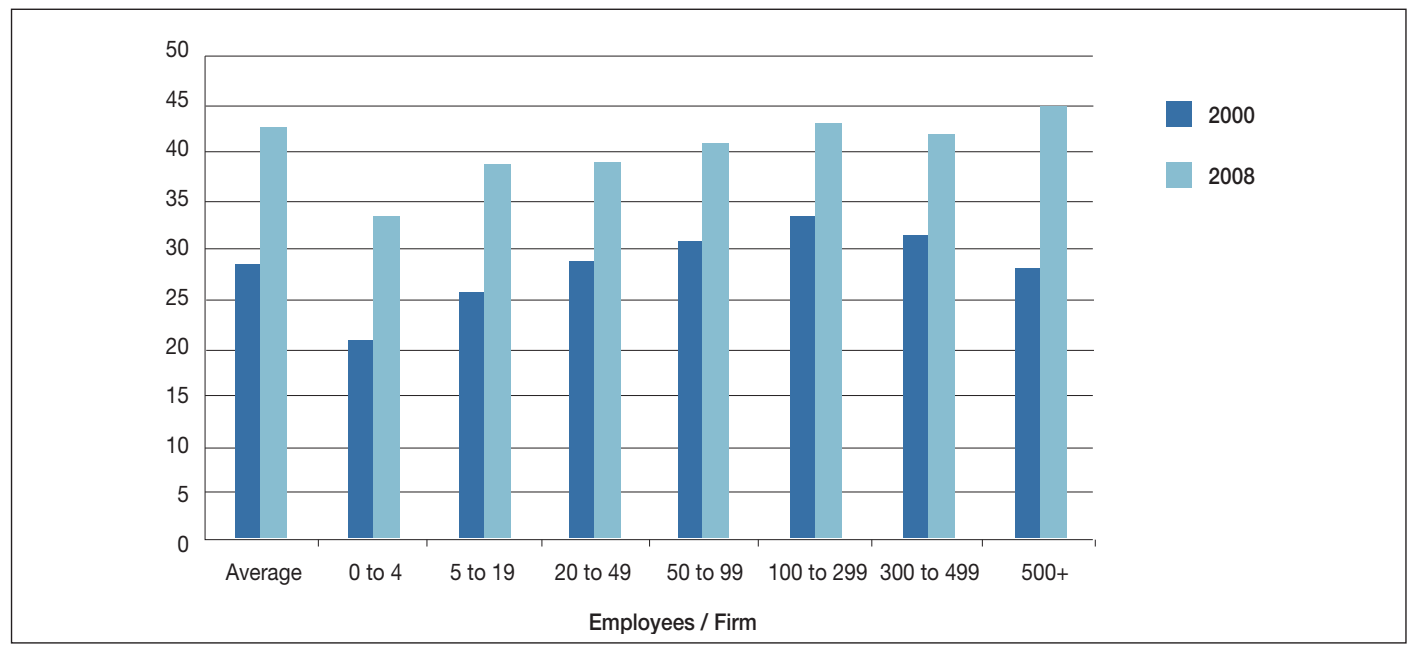

Source: Statistics Canada, CANSIM Tables 2810044 and 2810046

\subsection{Summary}

While there are always some exceptions, the general results found in the literature on the implications of firm size and the results from the Statistics Canada survey of firms tend to paint a similar picture. The summary provided focuses on the relationship between firm size, employment growth and innovation, and it reviews the issues concerning the common justification for special treatment of small firms due to financial constraints and regulatory and tax compliance costs. We summarize these below as stylized facts; that is, they are generally well-supported, but not definitive.

- A common view from a policy perspective is that most jobs are created by small firms and that they account for most employment growth. The academic literature is inconclusive regarding a relationship. However, it appears the larger firms account for most of the direct employment, and it is changes in their level of activity that would primarily determine employment changes in the sector.

- While there is a common perception that small firms grow faster than large firms, this is not supported by the data and, in the case of the oil and gas sector, it would appear that it is the large firms that, more often than not, demonstrate the highest growth rates. Small firms can sometimes have higher job creation rates, but they also have higher job destruction rates. It is also noteworthy that, mathematically, it is more difficult to achieve high growth rates starting from a large base than a small base.

- New firms do create significant amounts of new employment, but the probability of their survival is low, and so they also account for a substantial number of job losses. Rather than a clear relationship between firm size and employment growth, there is a strong relationship between firm age and growth. This has obscured the true relationship between size and growth since new firms are, in general, small.

- Larger firms have much higher survival rates and exhibit greater stability. They have better credit ratings, better access to capital markets, are much less dependent on retained earnings to finance growth, and are much more sensitive to fiscal changes (for example, lowering corporate tax rates will have a greater expansionary effect for larger firms compared to small firms). 
- In general, larger firms have greater stability, they are more likely to reallocate jobs in a recession (compared to small firms where this is more likely to be ongoing through all phases), they pay higher wages, offer higher job satisfaction, greater job security and higher non-wage income (fringe benefits), but demand more hours of work per week.

- Small firms are less likely to conduct R\&D but may be more innovative in other ways, through creating or re-engineering products or services to meet new market demand, introducing new organizational approaches to enhance productivity, or developing new techniques to expand sales.

- A common justification for lower taxes for small enterprises is that they face greater challenges in obtaining financing; due to imperfect capital markets, there is higher risk, lower retained earnings, and limited access to debt financing, which is more attractive under common corporate tax structures. Changes in tax rates have a greater impact on larger firms than on smaller firms and are likely distortionary. A better approach is to engineer policy aimed at fixing capital market imperfections, rather than treating the symptoms through potentially distortionary preferential tax policy aimed at small firms.

- An additional argument for preferential tax treatment of small firms is the higher unit compliance and administration costs for small firms. One study suggests they are 40 percent higher, on average, for firms with fewer than 20 employees compared to costs in large firms, and these are primarily related to compliance with environmental regulations and taxrelated paperwork. However, a possible offset is the benefits from compliance and more complete accounting - such as easier access to financing and insurance.

- One indicator of the contribution to employment by the various components of the oil and gas sector is provided by data for various firm sizes in the Statistics Canada category of mining, quarrying and oil and gas extraction. For Alberta this category is dominated by oil and gas firms. Employment by size category over the period 2000-2008 is shown below.

TABLE 2.1: EMPLOYMENT BY FIRM SIZE: MINING, QUARRYING AND OIL AND GAS EXTRACTION, 2000-2008

\begin{tabular}{|l|r|r|r|r|r|}
\hline \multirow{2}{*}{ Year } & \multicolumn{6}{|c|}{ Number of Employees } \\
\cline { 2 - 6 } 2000 & $\mathbf{0 - 4}$ & $\mathbf{5 - 1 9}$ & $\mathbf{2 0 - 9 9}$ & $\mathbf{1 0 0 - 4 9 9}$ & $\mathbf{5 0 0 +}$ \\
2001 & 3,948 & 6,422 & 9,156 & 10,360 & 37,075 \\
2002 & 4,476 & 6,633 & 9,643 & 11,538 & 42,213 \\
2003 & 4,820 & 7,187 & 10,730 & 9,936 & 47,393 \\
2004 & 4,926 & 7,176 & 11,431 & 11,388 & 51,354 \\
2005 & 5,114 & 7,548 & 12,167 & 12,449 & 52,262 \\
2006 & 5,246 & 7,916 & 11,734 & 13,706 & 56,698 \\
2007 & 5,701 & 8,288 & 12,073 & 15,337 & 66,139 \\
2008 & 5,944 & 8,879 & 12,808 & 16,782 & 66,642 \\
\hline Average Annual Compound Growth Rate & 6,409 & 8,388 & 12,577 & 16,816 & 66,987 \\
\hline Increase in Employment, 2000 over 2008 & $3.5 \%$ & $3.3 \%$ & $4.0 \%$ & $6.1 \%$ & $7.4 \%$ \\
\hline
\end{tabular}


- Over this period the share of employment accounted for by the largest firms (500+ employees) increased from 55 percent in 2000 to 60 percent in 2008 and, over this period, accounted for 68 percent of the total increase in employment in this category. This is significant in that, in general, an inverse relationship has tended to be observed in most industries between growth and size. Clearly, from a purely mathematical viewpoint it is much easier for a small firm to grow by a large percentage than it is for a large firm. The higher growth rates observed for the large firms (500+ employees) would seem to suggest that, at least over this period, larger firms had a competitive advantage in this sector.

- There is a positive relationship between firm size in the Alberta oil and gas sector and average weekly earnings. In 2008, average weekly earnings for employees in small firms (0-4 employees) were about 20 percent less than in firms with 5-19 employees, which were in turn about 20 percent less than in firms with 500+ employees.

\section{DYNAMICS OF FIRM BEHAVIOUR}

This section begins with an outline of the data used to measure the various movements of firms in the four size categories over the period 2002 to 2010. As noted earlier, the focus is on the shifts among and between the Emerging Junior, Junior, Intermediate and Major categories. These movements are placed against the backdrop of changes in overall conditions facing the oil and gas sector. They portray a very dynamic structure, particularly with respect to the smaller firms, with some firms growing to the next size category, some remaining in the category they started in, some exiting through bankruptcy or becoming dormant or inactive, and some being absorbed by a larger firm or through a multi-firm consolidation.

\subsection{Data and Methodology}

The data used reflect the designations of Emerging Junior (EJ), Junior (J), Intermediate (I) and Major (M) and encompass firms in both oil and natural gas operations. The companies reporting publicly and included in the database are listed in Appendix 1. These companies represent most of the total industry in Alberta; missing firms are private companies and public companies with activities primarily outside Canada and without a significant presence in Alberta or Canada.

The majority of the data used for the analysis in this section of this report is from the CanOils database produced by Evaluate Energy. Access was provided by the Alberta Department of Energy. The CanOils database contains data on firm finances and operations, merger and acquisition deals, financings, oil sands projects and broker forecasts for firms active in the Canadian oil and gas market. The database covers all firms listed on the Toronto Stock Exchange (TSX) and Toronto Venture Exchange (TSX-V). In some cases where data for a firm was not in the CanOils database, they were obtained from annual reports for the individual companies. $^{30}$

\footnotetext{
30 Information from other databases compiled by the Canadian Association of Petroleum Producers (CAPP), the National Energy Board, the Alberta Energy Resources Conservation Board and Statistics Canada were used to check the aggregates for various measures of activity obtained using the CanOils database.
} 
For the analysis here, firms were selected from the database if they were categorized as an exploration and production firm, or listed as a Canadian firm in the period 2002 to 2010. This yielded 506 firms. Firms were removed from the sample if: (i) they did not produce in Canada; and, (ii) they did not report production over the entire sample period. The final sample is 340 firms.

Firms were classified as inactive, Emerging Junior, Junior, Intermediate or Major in each year based on their total Canadian and outside-Canada production of oil and natural gas. As noted earlier, these different firm categories are defined as follows:

- Emerging Juniors (EJs) are companies that annually produce between 1 and 999 barrels of oil equivalent (BOE) per day.

- Juniors (Js) are companies annually producing between 1,000 and 9,999 BOE per day.

- Intermediates (Is) annually produce between 10,000 and 99,999 BOE per day.

- Majors (Ms) annually produce over 100,000 BOE per day.

An inactive firm did not have reported production in a given year for any one of the following reasons: temporary cessation of production; production is not reported even though the firm is active; it does not exist as an entity; or it exists but has not begun to produce. For our purposes, a firm that does not produce in a given year is considered to be inactive, regardless of the reason.

The number of firms in the various categories in each year, along with a measure of relative production and revenue levels, is indicated in Tables 3.1 and 3.2.

TABLE 3.1: FIRMS BY CATEGORY AND YEAR

\begin{tabular}{|l|r|r|r|r|r|r|r|r|r|}
\hline Category & $\mathbf{2 0 0 2}$ & $\mathbf{2 0 0 3}$ & $\mathbf{2 0 0 4}$ & $\mathbf{2 0 0 5}$ & $\mathbf{2 0 0 6}$ & $\mathbf{2 0 0 7}$ & $\mathbf{2 0 0 8}$ & $\mathbf{2 0 0 9}$ & $\mathbf{2 0 1 0}$ \\
\hline Emerging Junior (E) & 37 & 71 & 108 & 134 & 155 & 134 & 118 & 102 & 34 \\
Junior (J) & 28 & 33 & 49 & 68 & 69 & 67 & 58 & 53 & 44 \\
Intermediate (I) & 15 & 19 & 23 & 30 & 36 & 29 & 34 & 29 & 32 \\
Major (M) & 13 & 15 & 15 & 14 & 13 & 14 & 13 & 13 & 13 \\
Inactive & 247 & 202 & 145 & 94 & 67 & 96 & 117 & 143 & 217 \\
Sample Size & 93 & 138 & 195 & 246 & 273 & 244 & 223 & 197 & 123 \\
\hline
\end{tabular}

Source: Database compiled by authors from CanOils data

TABLE 3.2: AVERAGE PRODUCTION AND REVENUES BY CATEGORY (2002 - 2010)

\begin{tabular}{|l|c|c|c|}
\hline Category & $\begin{array}{c}\text { Avg Daily Production } \\
\text { by Firm (BOE/d) }\end{array}$ & $\begin{array}{c}\text { Avg Total Daily Production } \\
\text { by Category (BOE/d) }\end{array}$ & $\begin{array}{c}\text { Avg Annual Revenue } \\
\text { by Category (millions \$Cdn) }\end{array}$ \\
\hline EJ & 251 & 23,364 & 278 \\
J & 3,468 & 177,786 & 2,032 \\
I & 29,614 & 800,471 & 11,680 \\
M & 213,126 & $2,907,495$ & 76,786 \\
\hline
\end{tabular}


As noted, the sample size (excluding inactive firms) used for the analysis varies over time, from a low of 93 firms in 2002 to a high of 273 in 2006. Most of this variation is related to the initial growth and later fall in the number of EJs.

Large variation in average size of the firms across categories can also be observed. For example, on average over the period 2002-2010, the production of EJs (in barrels of oil equivalent per day) was less than one percent of that for the Ms (majors), while the production of Js was about six percent of that for the Ms. On average, production for the Is (intermediates) represented about 28 percent of that of the Ms. Put differently, the production by the Ms and Is accounted for just over 94 percent of total production. The relative production levels by year are illustrated in Figure 3.1.

\section{FIGURE 3.1: TOTAL DAILY CANADIAN PRODUCTION (BOE/D)}

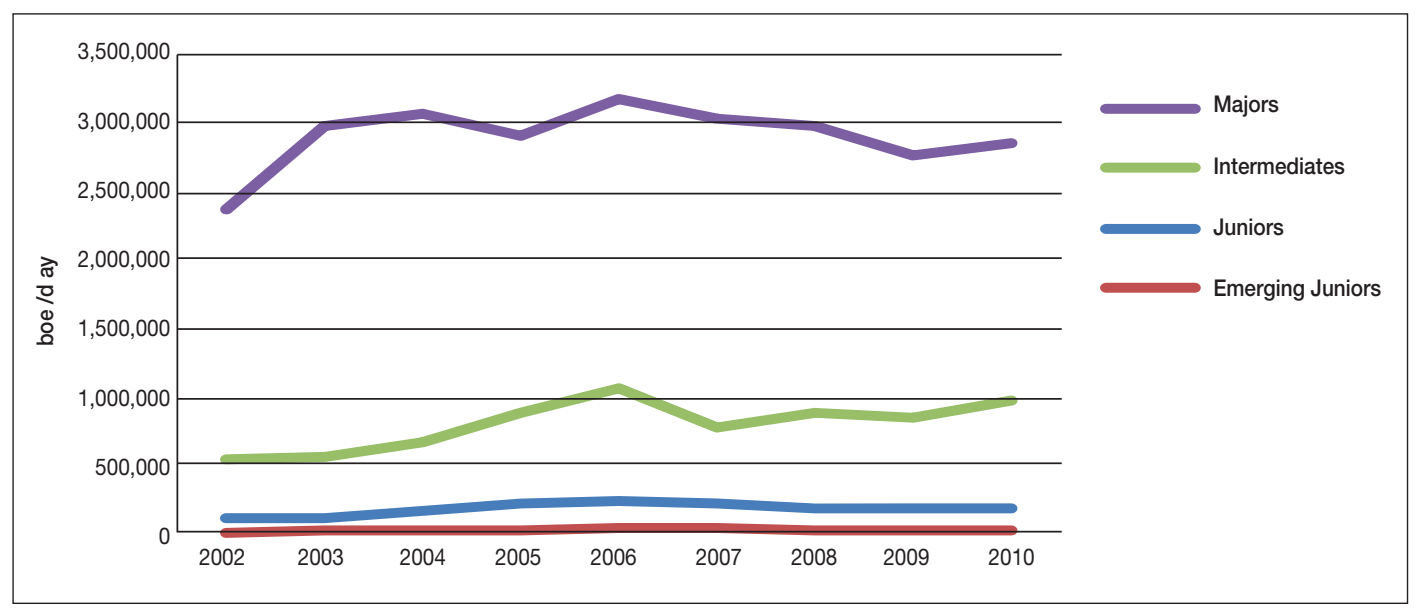

Source: Database compiled by authors from CanOils data.

Although considerable effort has gone into the assembly of the database used in this study, there remain some deficiencies. First, the period covered is relatively short, with a maximum length of 2002 to 2010. In some cases 2002 and 2010 are omitted from the sample because of missing observations. The year 2010 is particularly susceptible to data issues as, in many cases, while production data was available, financial and other operating data was not. The main problem with 2002 is that many firms were active, but have not been recorded in the database.

Second, in a few instances, some interpolation was required. This was necessitated by gaps due to incomplete recordkeeping or changes in definitions or standards used. These gaps were often for years where a firm exits the industry (via bankruptcy or acquisition or other), in which case recorded data is often minimal or confusing. For instance, as long as a firm reports once in the CanOils database, it has a record for each year of the CanOils database. This creates some confusion, as firms will have "No data" for years before and after they exist as producing entities.

Third, again in a few instances, the data for a firm appeared unreliable and consequently that firm had to be deleted from the sample. 


\subsection{Economic Conditions Backdrop}

Activity levels and performance of the oil and gas sector as a whole depends on a variety of both current and expected conditions that are highly variable. These conditions primarily relate to wellhead oil and gas price levels, market access, drilling and construction costs, surface and mineral rights acquisition costs, tax and royalty rates and costs of financial capital. Clearly these will have differential impacts on the relative activity and performance levels of firms in the various size categories. Given that the focus of this study is on differences in behaviour and performance between small and large firms, it is important to keep the variations in overall conditions firmly in mind when examining the various measures for each size category.

Part of this backdrop has already been presented in Section 2 (see Figures $2.2-2.5$ ). In general, there was a significant increase in real (i.e., inflation-adjusted) oil and gas prices over the period to 2005, followed by significant declines in, first, gas prices and, then, in oil prices. Overall oil and gas sector investment followed a similar pattern.

Other indicators of general conditions facing the sector are indicated in Figures 3.1 - 3.5 below, which provide data for Alberta and comparative values for BC, Saskatchewan and Western Canada.

\section{FIGURE 3.2: REAL AVERAGE PRICE PER HECTARE FOR MINERAL RIGHTS}

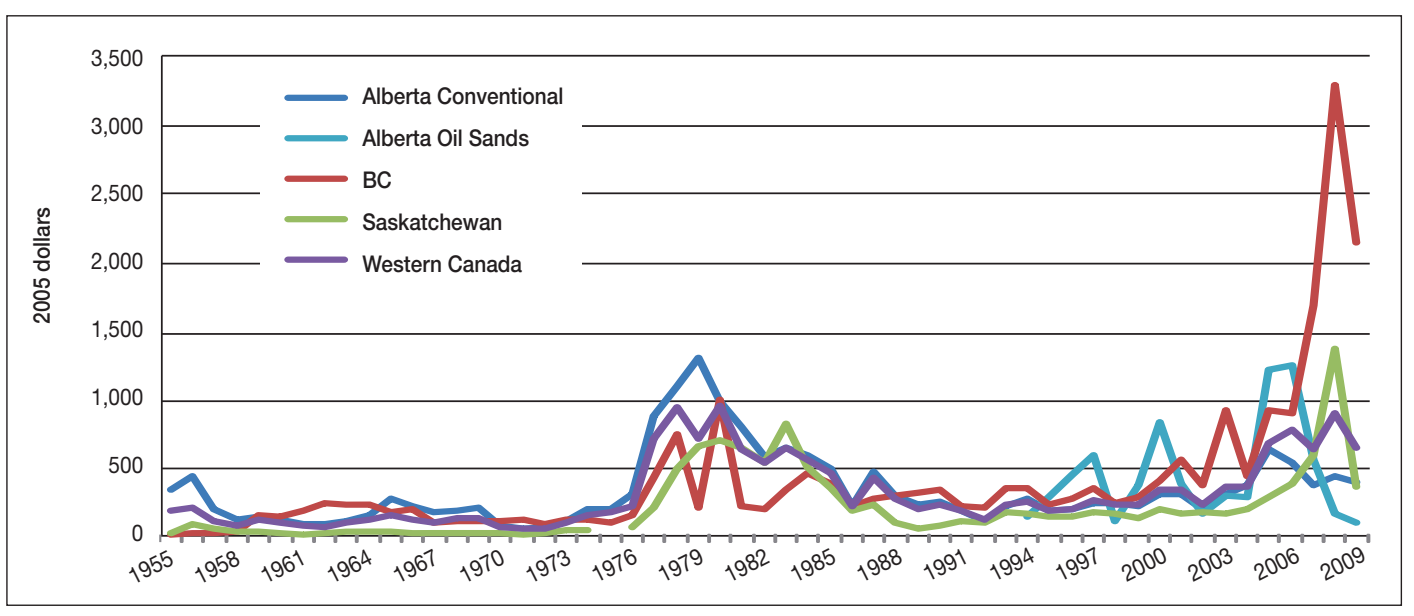

Source: Canadian Association of Petroleum Producers, Statistical Handbook and Statistics Canada (price deflators)

\section{FIGURE 3.3: AVERAGE YEARLY DRILLING RIG ACTIVITY AND RIG UTILIZATION}

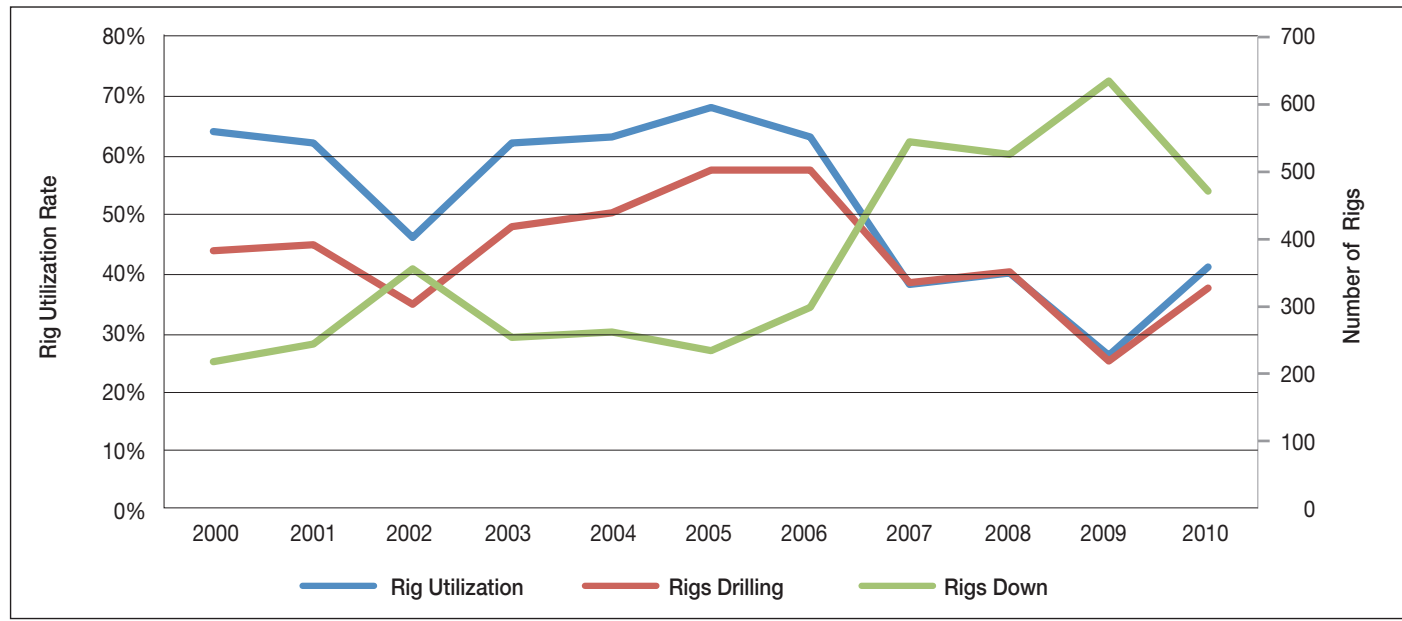

Source: Canadian Association of Oil Well Drilling Contractors, Annual Drilling Rig Operating Days/Depth Summary 
FIGURE 3.4: TOTAL WELLS DRILLED

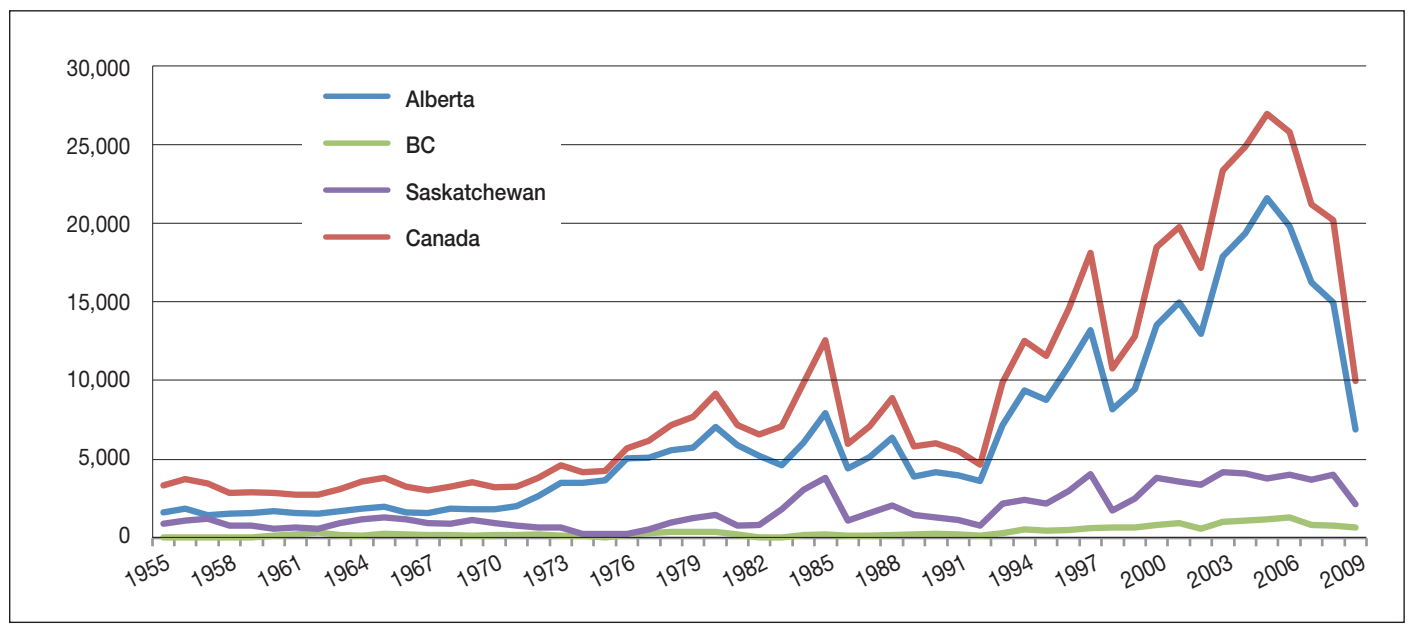

Source: Canadian Association of Petroleum Producers, Statistical Handbook

\section{FIGURE 3.5: REAL AVERAGE DRILLING COST PER METRE}

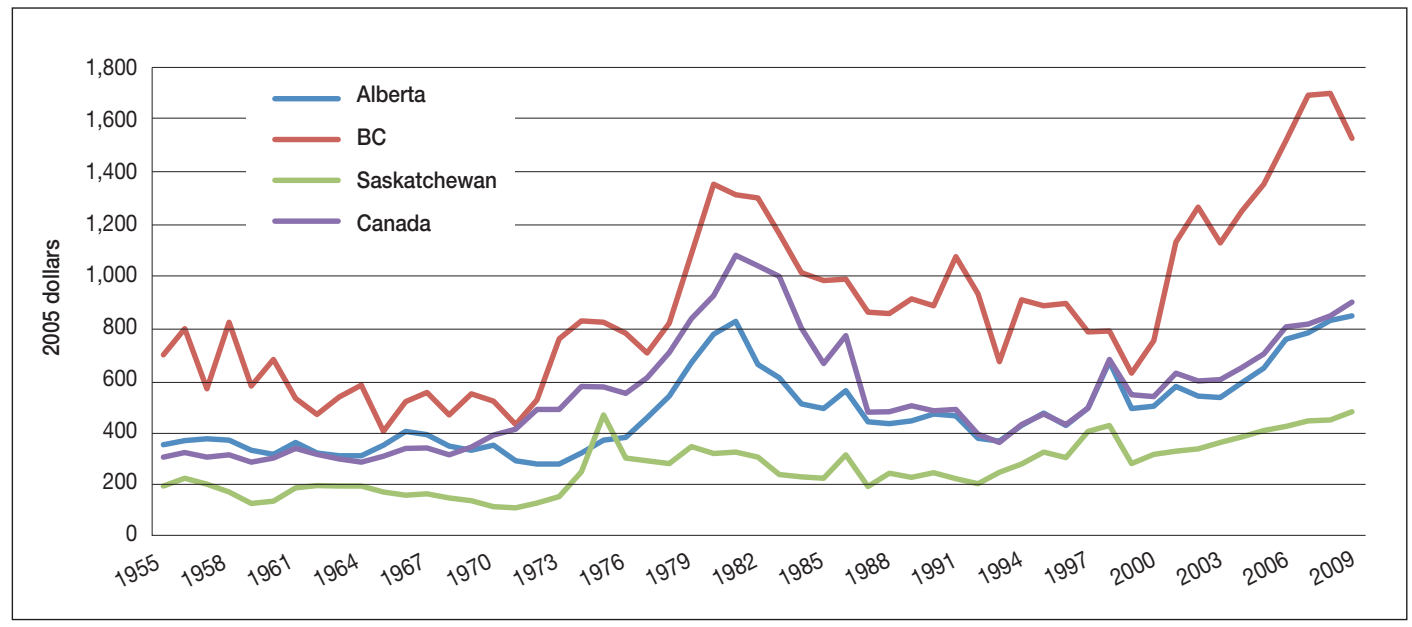

Source: Canadian Association of Petroleum Producers, Statistical Handbook

In general, for the period 2002 to 2010 these figures show:

- A significant run-up in land costs in Alberta for the conventional industry until 2005 and then a substantial decline. This was in contrast to the continued increases in the other Western provinces. Although a detailed evaluation of the disparate trends in Alberta and the other provinces has not been conducted, it would appear that the land rushes in British Columbia for acreage in the Horn River and Montney plays, and in Saskatchewan for acreage in the Bakken play, are likely major factors. An additional factor may have been the drop in natural gas prices that had a particularly large impact in Alberta, given the large size of the natural gas component in that province. Estimates for 2010 show significant gains in land values in Alberta, which appear to be related to the growing interest in the Cardium and Duvernay formations. Land values are an important measure of the expected profitability of drilling. 
- High levels of rig utilization until 2006, combined with an escalation in the number of wells drilled in Alberta to that same year, followed by a sharp decline.

- A significant increase in real (inflation-adjusted) drilling costs per metre drilled and per well in Alberta, followed by a slight drop after 2006 in the rate of increase.

The changes in production by the various firm size components of the oil and gas sector are indicated in Figures 3.6 and 3.7. As shown in the former, the changes in production by the Ms (Majors) and Is (Intermediates) dominate in most years. Measured in percentage terms (Figure 3.7), the EJs (Emerging Juniors) and Js (Juniors) show the greatest volatility and declines in production over most of the period.

\section{FIGURE 3.6: CHANGE IN GROUP TOTAL DAILY CANADIAN PRODUCTION OVER PREVIOUS YEAR}

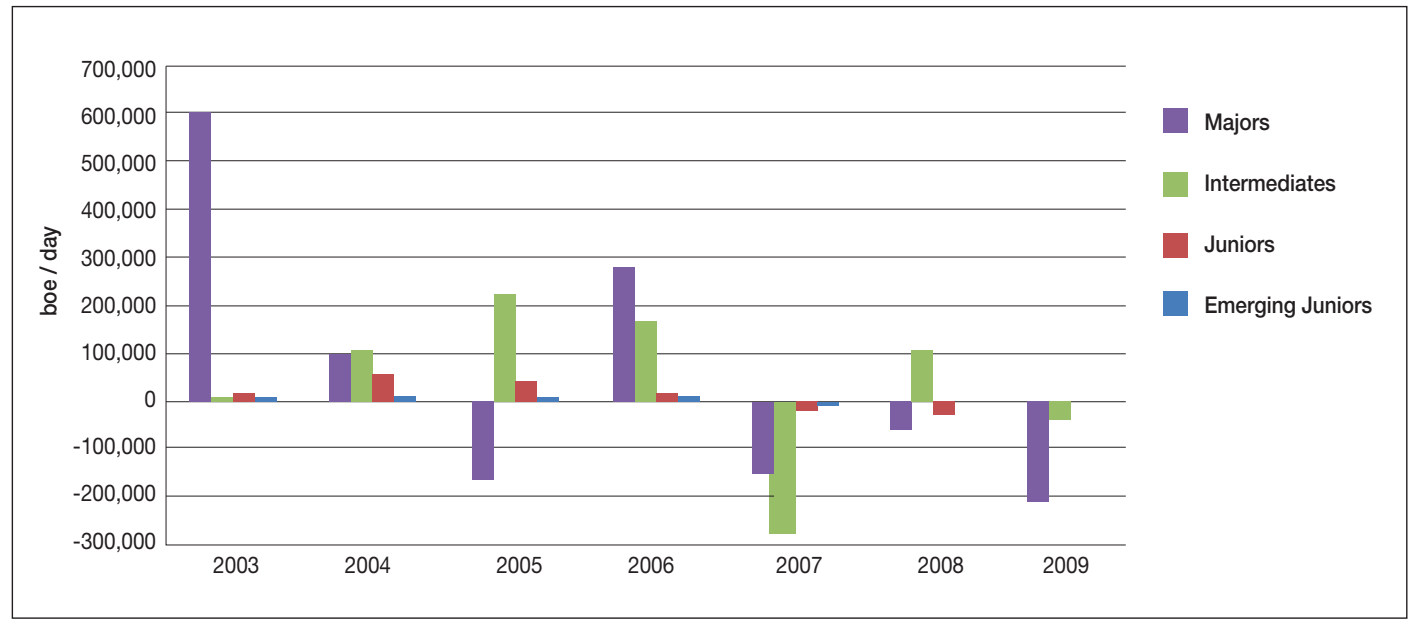

Source: Database compiled by authors from CanOils data.

FIGURE 3.7: PERCENTAGE CHANGE IN GROUP TOTAL DAILY CANADIAN PRODUCTION OVER PREVIOUS YEAR

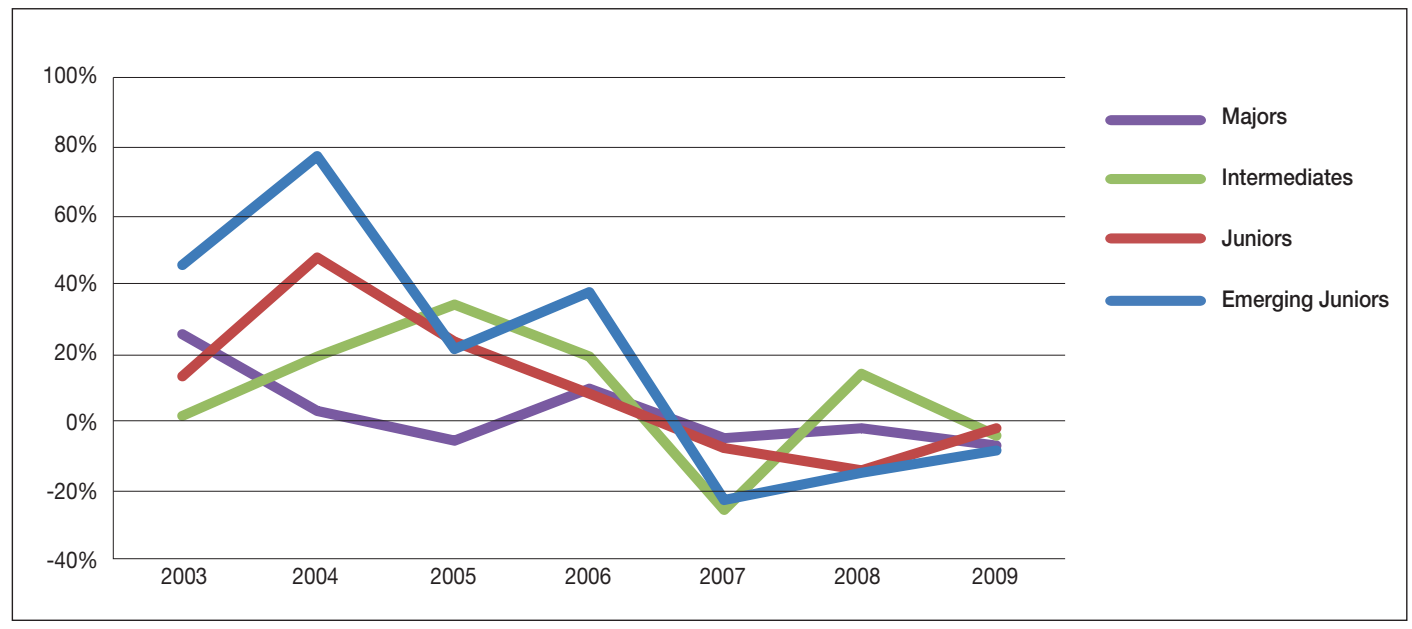




\subsection{Entry and Exit Dynamics}

The purpose here is to map the changes in the structure of the oil and gas sector within the context described in the previous section. This structure, particularly with respect to the smaller firms, is very dynamic, with some firms growing to the next size category, some remaining in the category they started in, some exiting through bankruptcy or becoming dormant or inactive and some being absorbed by a larger firm or through a multi-firm consolidation.

There are significant transitions between size categories from year to year. This trend is illustrated by examining entries and exits to/from each size category by year. We refer to this as transitional activity.

We have screened for double counting in these examples; consequently the data show clear movement of firms by type and year. As shown in Figure 3.8, the number of firms grew substantially until 2005 and then began a period of slow decline, more or less following the trends in overall conditions noted earlier. The largest contributors to these changes were the EJs and Js, with the Ms and Is showing much greater stability.

\section{FIGURE 3.8: NUMBER OF FIRMS CONTINUING TO NEXT CALENDAR YEAR}

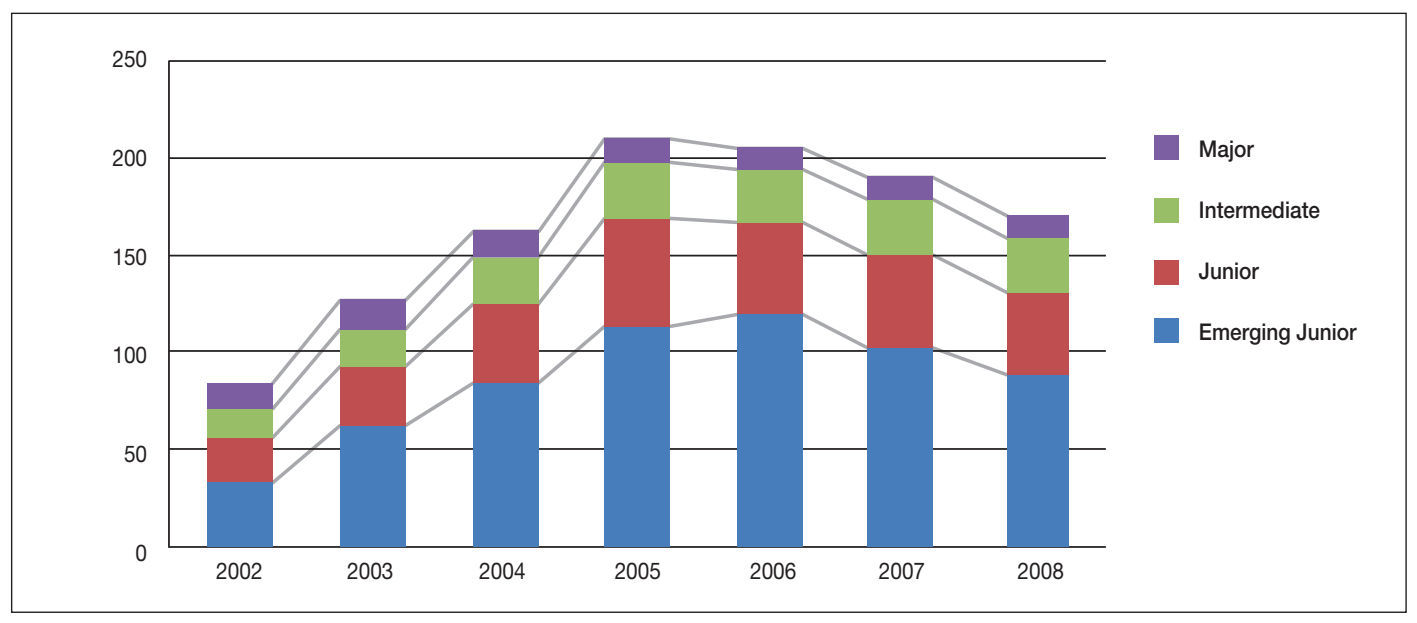

Source: Database compiled by authors from CanOils data

An examination of the movements between years provides some illumination of the role of each category in supporting and diversifying the overall oil and gas industry in Alberta. From Table 3.3 below it is evident that the overall changes in the number of firms are primarily driven by: (i) until recent years, the decline in the number of inactive firms; (ii) the large number of entries in the early part of the period; and, (iii) the significant increase in exits in recent years. Exits from the industry in any given year seem to average under 15 percent, except when there is a significant downturn in profitability in the industry. In general, it would appear that there is a positive relationship between the number of firms and overall economic conditions in the oil and gas sector. In the earlier part of the period, with significant increases in oil and gas prices and a stable fiscal environment and drilling costs, entries increased and there were few exits. However, after 2006, with the combination of rising costs and a less attractive fiscal environment, entries dropped and exits increased significantly. ${ }^{31}$

31 The decline in inactive firms is due to new entries; inactive firms are those that exist in the database but do not exist as corporate entities in a given year. 
TABLE 3.3: ANNUAL STATUS OF ALL FIRMS

\begin{tabular}{|l|r|r|r|r|r|r|r|}
\hline Movement & $\mathbf{2 0 0 2 -}$ & $\mathbf{2 0 0 3 -}$ & $\mathbf{2 0 0 4}-$ & $\mathbf{2 0 0 5 -}$ & $\mathbf{2 0 0 6}-$ & $\mathbf{2 0 0 7 -}$ & $\mathbf{2 0 0 8}-$ \\
& $\mathbf{2 0 0 3}$ & $\mathbf{2 0 0 4}$ & $\mathbf{2 0 0 5}$ & $\mathbf{2 0 0 6}$ & $\mathbf{2 0 0 7}$ & $\mathbf{2 0 0 8}$ & $\mathbf{2 0 0 9}$ \\
\hline Continued & 90 & 135 & 187 & 230 & 228 & 208 & 183 \\
Inactive & 200 & 144 & 87 & 51 & 51 & 81 & 103 \\
Enter & 47 & 59 & 59 & 43 & 16 & 15 & 14 \\
Exit & 3 & 2 & 7 & 16 & 45 & 36 & 40 \\
\hline
\end{tabular}

Source: Database compiled by authors from CanOils data

When looking at the reasons for exit during the entire study period, we find acquisition by other firms is the dominant strategy for growth and change as indicated in Table 3.4.

TABLE 3.4: EXIT RATIONALE

\begin{tabular}{|l|c|}
\hline Exit Type & Number of Firms \\
\hline Bought out & 104 \\
Bankruptcy & 16 \\
Exit Canadian operations & 10 \\
Merger or takeover & 3 \\
Non-reporting & 8 \\
Stop producing & 1 \\
\hline
\end{tabular}

Source: Database compiled by authors from CanOils data

This is reflected in the total values of asset deals in Alberta as illustrated in Figure 3.9. It is interesting that the average value of these deals (see Figure 3.10) has tended to follow the overall economic conditions facing the oil and gas sector as outlined earlier in this Section.

FIGURE 3.9: ASSET DEALS IN ALBERTA

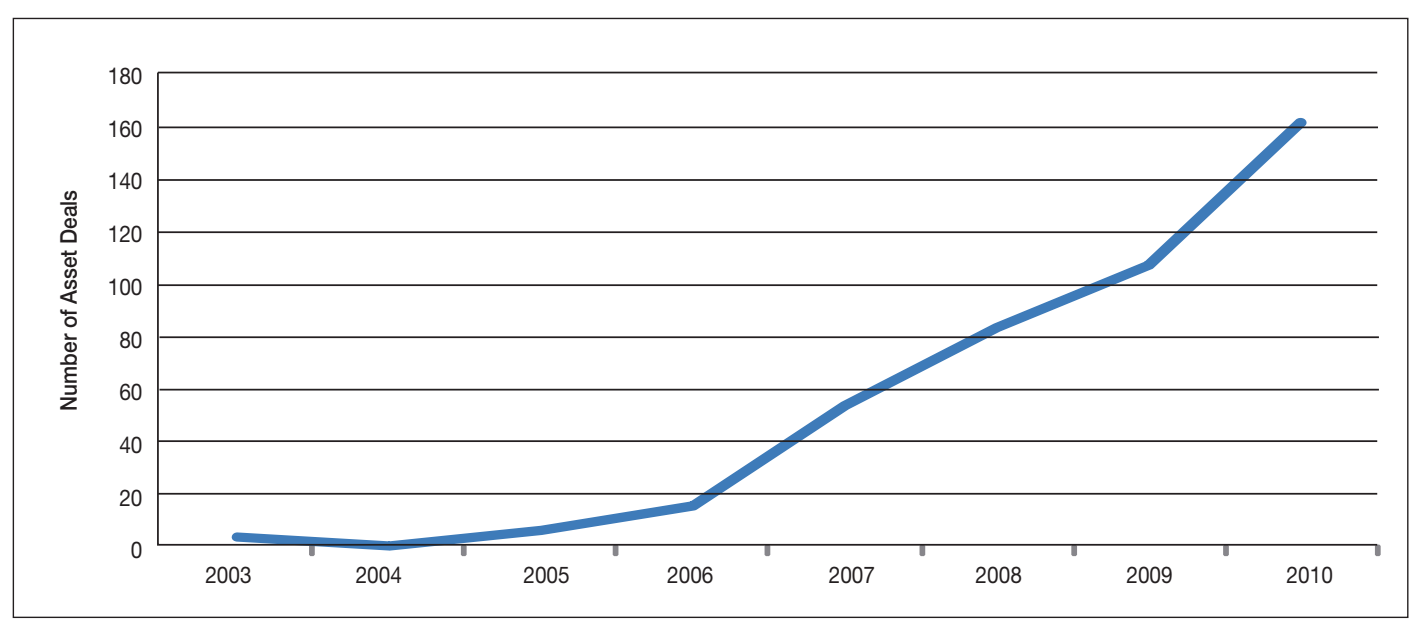


FIGURE 3.10: AVERAGE VALUE OF ASSET DEALS IN ALBERTA

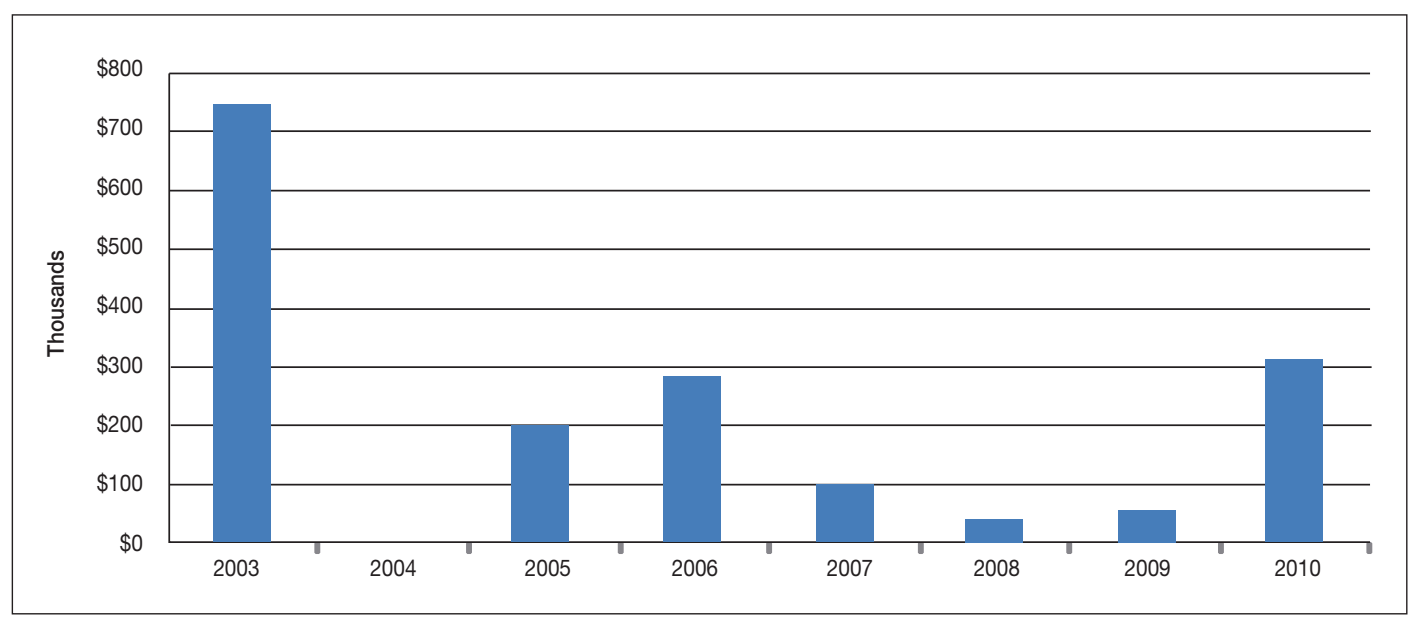

Source: Database compiled by authors from CanOils data

When viewed from the vantage of entry rationale, we find the dominant group is that reporting an existing business (delayed reporting but not entry, which distorts the record) or that which actually starts producing from a dormant/new property or lease. Often emerging juniors are incorporated but production is delayed for up to two years after incorporation. Other significant reasons for entry include the categories of new capital funds for investment, plus reorganization of existing firms, takeovers and mergers and the spinoff of existing firms into this area of investment.

\section{TABLE 3.5: ENTRY CHARACTERISTICS}

\begin{tabular}{|l|c|}
\hline Entry Type & Number of Firms \\
\hline Start reporting+ & 73 \\
Enter+ & 55 \\
Merger & 9 \\
Start producing+ & 32 \\
Capital firm conversionf & 18 \\
Takeover & 29 \\
Spun out & 9 \\
Corporate reorganization & 17 \\
Qualifying transaction* & 4 \\
\hline
\end{tabular}

Source: Database compiled by authors from CanOils data

+ Firms classified as 'Start reporting' exist and produce but do not yet have a record in CanOils prior to the reporting year. Firms that 'Enter' begin to produce and/or have income statements for that year. Firms that 'Start producing' entered but did not produce until the entry year.

‡ A capital firm converts to an oil and gas exploration and production company.

* A financial transaction where a firm without exploration properties acquires an existing exploration and production firm and assumes the name of the acquired firm.

Movement between categories is the most dominant path for changes in the industry. After removing those firms staying in the same size category, the most volatile changes occur in the entry to EJ status and the movement path from EJ to J, effectively establishing these categories as the stock for overall growth of the industry as shown in Table 3.6 below. 
TABLE 3.6: TRANSITIONS BETWEEN CATEGORIES BY YEAR

\begin{tabular}{|c|c|c|c|c|c|c|c|}
\hline Movement & $\begin{array}{c}2002- \\
2003\end{array}$ & $\begin{array}{c}2003- \\
2004\end{array}$ & $\begin{array}{c}2004- \\
2005\end{array}$ & $\begin{array}{r}2005- \\
2006\end{array}$ & $\begin{array}{r}2006- \\
2007\end{array}$ & $\begin{array}{r}2007- \\
2008\end{array}$ & $\begin{array}{r}2008 \\
2009\end{array}$ \\
\hline Same & 84 & 127 & 163 & 210 & 206 & 190 & 171 \\
\hline Up to $M$ & 1 & 0 & 0 & 1 & 2 & 0 & 0 \\
\hline Up to I & 3 & 1 & 4 & 5 & 2 & 7 & 0 \\
\hline Up to J & 2 & 7 & 18 & 11 & 16 & 10 & 7 \\
\hline Down to I & 0 & 0 & 1 & 1 & 0 & 0 & 0 \\
\hline Down to J & 0 & 0 & 0 & 0 & 0 & 0 & 2 \\
\hline Down to EJ & 0 & 0 & 1 & 2 & 2 & 1 & 3 \\
\hline Enter to EJ & 38 & 45 & 49 & 40 & 12 & 14 & 10 \\
\hline Enter to J & 6 & 11 & 8 & 2 & 4 & 1 & 2 \\
\hline Enter to I & 2 & 3 & 2 & 1 & 0 & 0 & 1 \\
\hline Enter to M & 1 & 0 & 0 & 0 & 0 & 0 & 1 \\
\hline Exit from $\mathrm{E}$ & 2 & 2 & 5 & 10 & 19 & 21 & 22 \\
\hline Exit from J & 1 & 0 & 2 & 5 & 18 & 12 & 13 \\
\hline Exit from I & 0 & 0 & 0 & 0 & 7 & 2 & 4 \\
\hline Exit from $M$ & 0 & 0 & 0 & 1 & 1 & 1 & 1 \\
\hline
\end{tabular}

Source: Database compiled by authors from CanOils data

The stability of these transitions is illustrated clearly in Figure 3.8 above, which graphically portrays the volatile nature of the EJ and $\mathrm{J}$ categories, viewed in contrast to the smaller changes in I and $\mathrm{M}$ over the sample period. This is even clearer when viewing the transitions and survival rates by category shown in Table 3.7. Fuller detail is available in Appendix III.

TABLE 3.7: PROBABILITY OF FIRMS SURVIVING TO NEXT YEAR

\begin{tabular}{|l|r|r|r|r|r|r|l|}
\hline & $\mathbf{2 0 0 2}$ & $\mathbf{2 0 0 3}$ & $\mathbf{2 0 0 4}$ & $\mathbf{2 0 0 5}$ & $\mathbf{2 0 0 6}$ & $\mathbf{2 0 0 7}$ & $\mathbf{2 0 0 8}$ \\
\hline Emerging Juniors & 89.1 & 87.3 & 78.5 & 84.3 & 77.4 & 76.8 & 75.4 \\
Juniors & 85.7 & 96.8 & 85.0 & 82.2 & 68.1 & 70.1 & 72.4 \\
Intermediates & 93.3 & 100 & 100 & 96.6 & 75.0 & 93.1 & 82.3 \\
Majors & 100 & 100 & 93.3 & 85.7 & 92.3 & 92.8 & 92.3 \\
\hline
\end{tabular}

Source: Database compiled by authors from CanOils data

These data show high rates of entry for EJ firms through 2007 when they decline, a reflection of changing fiscal structures as well as the cumulative effects of rising costs, and an increase in borrowing costs for smaller firms. Residual EJ firms appear to be acquired by $\mathrm{J}$ firms, matching exits from those firms to Intermediate firms. Intermediate firms seem to be the most stable, with limited transition to Major firms. However, the only exits of Majors are because the firms in question sold their Canadian properties. The difficulty of transition from a smaller to a larger firm becomes greater as the firms increase in size, either in terms of total employment or total output. This difficulty is also tied to the substantial increase in production necessary to reach the next size category.

The stock of entrant firms appears to be driven primarily by new entries in the category of Emerging Junior (EJ) and Junior (J) firms during the study period. 


\subsection{Longer Term Survival Rates}

The year-to-year survival rates (see Table 3.7 above) are much higher for the Is (Intermediates) and Ms (Majors) than for the EJs and Js. Indeed, survival in the oil and gas sector is clearly positively influenced by size and this continuity has important regulatory and policy implications.

In this context it is useful to focus on the longer-term survival rates for the smaller firms. Table 3.8 shows the survival rates for the EJs by year of entry. For example, of the 38 new entries in 2002, over 76 percent still existed in Year Five. Overall, while there are significant differences in survival rates related to the year of entry, the 50-75 percent survival rate appears to be better than that for most small non-oil and gas businesses.

\section{TABLE 3.8: SURVIVAL RATES OF EMERGING JUNIORS BY YEAR OF ENTRY}

\begin{tabular}{|l|c|c|c|c|c|c|}
\hline \multirow{2}{*}{ Year } & \multirow{2}{*}{ Initial Number } & \multicolumn{5}{|c|}{ Number of firms that remain at: } \\
\cline { 3 - 6 } & 37 & Year 5 & Year 4 & Year 3 & Year 2 & Year 1 \\
\hline 2002 & 38 & $55 \%$ & $78 \%$ & $86 \%$ & $95 \%$ & $97 \%$ \\
2003 & 44 & $52 \%$ & $70 \%$ & $84 \%$ & $100 \%$ & $100 \%$ \\
2004 & 48 & $50 \%$ & $51 \%$ & $61 \%$ & $76 \%$ & $94 \%$ \\
2005 & 37 & & $58 \%$ & $68 \%$ & $89 \%$ & $95 \%$ \\
2006 & 10 & & & $36 \%$ & $64 \%$ & $91 \%$ \\
2007 & 12 & & & & $85 \%$ & $85 \%$ \\
2008 & 9 & & & & & $100 \%$ \\
2009 & & & & & & \\
\hline
\end{tabular}

Source: Database compiled by authors from CanOils data

An important dimension of this survival is the ability of EJs to graduate to Js. Table 3.9 shows the percentage of EJs in each year that moved up to the J category. While there is substantial variation over the period, it would appear that on average, about ten percent of the EJs moved up to the $\mathrm{J}$ category, with only minor movement in the opposite direction.

TABLE 3.9: MOVEMENT OF EMERGING JUNIORS TO JUNIORS

\begin{tabular}{|c|c|c|c|}
\hline Year & Initial Number & Move from EJ to J & \% Moving Up \\
\hline 2002 & 37 & 2 & $5.4 \%$ \\
2003 & 71 & 7 & $9.9 \%$ \\
2004 & 108 & 18 & $16.7 \%$ \\
2005 & 136 & 11 & $8.1 \%$ \\
2006 & 156 & 16 & $10.3 \%$ \\
2007 & 135 & 10 & $7.4 \%$ \\
2008 & 118 & 7 & $5.9 \%$ \\
2009 & 102 & & \\
\hline
\end{tabular}




\subsection{Summary}

A total of 340 public firms were tracked over the period 2002-2010 to evaluate the dynamics of the structure of the oil and gas sector in Alberta. These were categorized as EJs (emerging juniors), Js (Juniors), Is (Intermediates) and Ms (Majors). Averaged over the period, the Ms accounted for 74 percent of total oil and gas production (measured in boe/d), with the Is contributing 20.5 percent, the Js 4.5 percent and the EJs 0.6 percent.

Activity levels and performance of the oil and gas sector as a whole depend on a variety of both current and expected conditions that are highly variable. These conditions primarily relate to wellhead oil and gas price levels, market access, drilling and construction costs, surface and mineral rights acquisition costs, tax and royalty rates and costs of financial capital. These have differential impacts on the various size categories. In general:

- Along with rising oil and gas prices, there was a significant increase in land costs in Alberta for the conventional industry until 2005 , followed by a substantial drop off. This was in contrast to the continued increases until 2008 in BC and Saskatchewan that appear largely associated with the Horn River, Montney and Bakken plays, combined with the drop in natural gas prices that had a particularly significant negative impact on Alberta, given the large size of the natural gas component of the sector in that province. More recently there has been an increase in land values in Alberta with the growing interest in the Cardium and Duvernay formations. Land values are an important measure of the expected profitability of drilling.

- Over these varying conditions, changes in production by the Ms (Majors) and Is (Intermediates) dominated in most years. Measured in percentage terms, the EJs (Emerging Juniors) and Js (Juniors) showed the greatest volatility and declines in production over most of the period.

- It would appear there is a positive relationship between the number of firms and overall economic conditions in the oil and gas sector. In the earlier part of the period, with significant increases in oil and gas prices and a stable fiscal environment and drilling costs, entries increased and there were few exits. However, after 2006, with the combination of rising costs and a less attractive fiscal environment, entries dropped and exits increased significantly.

- When looking at the cause of exits, it appears that the acquisition by other firms is the dominant strategy for growth and change.

- Significant reasons for entry include new capital funds for investment, reorganization of existing firms, takeovers and mergers and the spinoff of existing firms into this area of investment.

- Movement between the lower categories is the most dominant path for changes in the industry. After removing those firms staying in the same size category, the most volatile changes occur in the entry to EJ status and the movement path from EJ to J, effectively establishing these categories as the stock for overall growth of the industry.

- There are high rates of entry for EJ firms through 2006. At that point the significant decline appears to be a reflection of changing fiscal structures, as well as the cumulative effects of rising costs and an increase in borrowing costs for smaller firms. Residual EJ firms appear to be acquired by $\mathrm{J}$ firms, matching exits from those firms to Intermediate firms. Major firms seem to be the most stable, with limited transitions from Intermediates to Majors. 
- The stock of entrant firms appears to be driven primarily by new entries in the category of Emerging Junior and Junior firms during the study period. Given the role of oil and gas in overall economic transactions within the economy, the entries are, not surprisingly, tied to overall economic health of the industry.

- While there are significant differences in survival rates related to the year of entry, the 50-75 percent survival rate for EJs appears to be better than for most small businesses.

- Although there are substantial variations over the period, it would appear that on average, about one-third of the EJs moved up to the J category over the study period, with only minor movement in the opposite direction.

\section{GEOGRAPHICAL PATTERNS OF ACTIVITY}

In this section we combine the data outlined in Section 3 with detailed well data from IHS Inc. and the Alberta Department of Energy to track the well activity associated with firms in each of the four size categories. The focus is on establishing geographical patterns of exploration and development activity within the province by EJs, Js, Is and Ms to determine such things as differences across size categories in the concentration and dispersion of activity, in propensities for drilling in deep vs. shallow formations, and in geographical shifts in activity as conditions change.

\subsection{Data}

The data used in this section are a combination of well information provided by the Alberta Department of Energy (ADOE) and a dataset available from the University of Calgary Library through an agreement with IHS Inc.

The data from IHS Inc. include the universal well identifier, the well name,${ }^{32}$ current operator and current licensee, location of the surface hole by township and range, latitude and longitude of the surface hole, bottom hole latitude and longitude, total well depth, license date, spud date, final drill date, on-production date, status and date status was updated, lahee, field, pool, oldest formation downhole, depth of the oldest formation, producing formation, whether the well is deviated, and whether the well is horizontal. ${ }^{33}$

The data from ADOE include wells and the agreements they are tied to. The well data is similar to dataset from IHS Inc., with the addition of the following information: original operator, current operator, cumulative gas production, cumulative oil production, cumulative condensate production, cumulative water production, status history, and whether the well is tied to a lease agreement. The agreement data includes status of the agreement, the designated representative, the relevant mineral rights, expiry date, continuation date, cancellation date, termination date, area, and payment for the lease.

Wells were assigned a PSAC area by linking the well data file to a file with PSAC areas using the program ArcGIS.

32 Wells are always named after the original licensee, pursuant to the Energy Resources Conservation Board Directive 007

33 For details, see IHS, Canadian Energy Critical Information Update, 2009/2010. 
Wells for each firm category in each year were extracted from the full dataset using ArcGIS and Quantum GIS. Wells were extracted based on the well name, which includes the name of the original licensee. The list of companies was based on information from CanOils as outlined in Section 3.1 above.

\subsection{PSAC Areas}

Land (mineral) leases and well location are important indicators of current and future activity levels and production success. For organizing this information, a map created by the Petroleum Services Association of Canada (PSAC) is used to assign relative geographic status for collected well data. The PSAC areas outlined in the map shown in Figure 4.1 generally correspond to areas that are either geologically distinct or have unique resource characteristics.

\section{FIGURE 4.1: PSAC AREAS FOR ALBERTA}

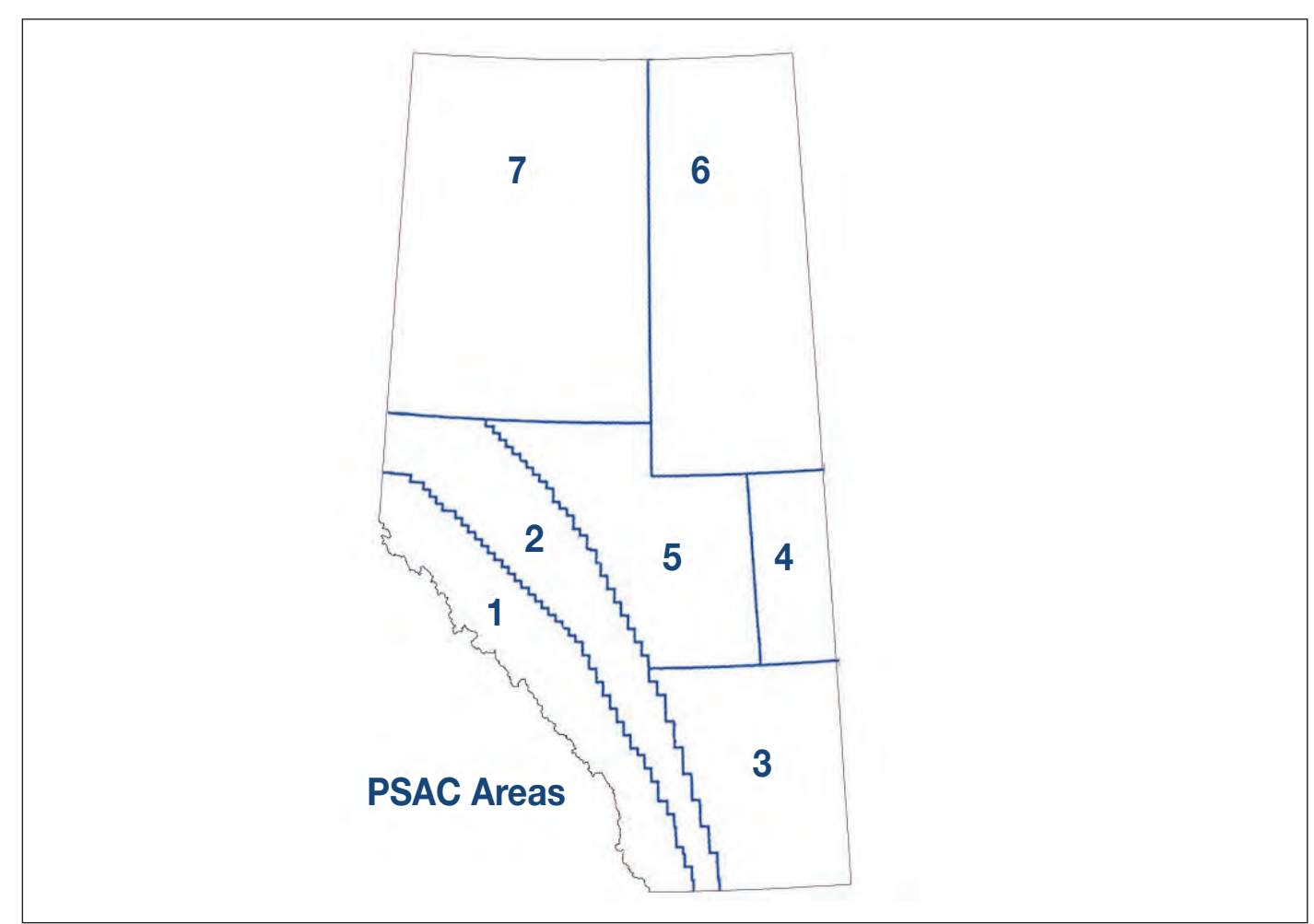

The map is drawn to follow Range and Township lines in defining each region, with consequent irregular-appearing boundaries. The areas covered are included in Table 4.1 below. Time series data for PSAC areas over the study period, are aggregated by area and category and are included in Appendix II. 
TABLE 4.1: PSAC AREA SIZES (SQUARE KILOMETRES)

\begin{tabular}{|l|c|c|}
\hline PSAC Area & Area & Areas as \% of Total \\
\hline 1 & 62,227 & 9 \\
2 & 81,791 & 12 \\
3 & 88,070 & 13 \\
4 & 37,190 & 6 \\
5 & 89,374 & 14 \\
6 & 104,450 & 16 \\
7 & 198,697 & 30 \\
Total & $\mathbf{6 6 1 , 8 4 8}$ & $\mathbf{1 0 0}$ \\
\hline
\end{tabular}

\subsection{PSAC Area Characteristics}

The PSAC areas are generalized in terms of geographic location and potential. When taken on an individual area basis, however, they are illustrative of not only the underlying formations, but also the requirements that firms must meet in order to operate within the zone. For instance, EJ and J producers will tend not to operate in very deep well zones, such as those in the deepest portion of the sedimentary basin, nor will they be capitalized sufficiently to operate within the oil sands areas.

In general, sedimentary deposits increase in depth in going from east to west. As indicated in Figure 4.2, the average depth is much greater in PSAC areas 1 and 2 (the mountain and foothills regions) than in other areas. Costs per well in these two areas are also much higher on average. PSAC areas 3-7 generally support moderate, consistent drilling depths per well. The greatest concentrations of EJ (Emerging Junior) and $\mathrm{J}$ (Junior) companies occur in areas 3 and 5.

The highest volume of drilling occurs in PSAC Area 3; the balance of the areas sees fairly consistent rates of drilling over time (See Figure 4.3). Area 3 has the largest concentration of freehold land with attendant secure tenure and known resources. While it has seen by far the largest decline in drilling in recent years, this is likely related to low natural gas prices (since Area 3 is gas-prone), combined with the fact that, with freehold status and the absence of a need to drill to prove productivity, gas production is being deferred until gas prices improve.

FIGURE 4.2: AVERAGE WELL DEPTH BY PSAC AREA

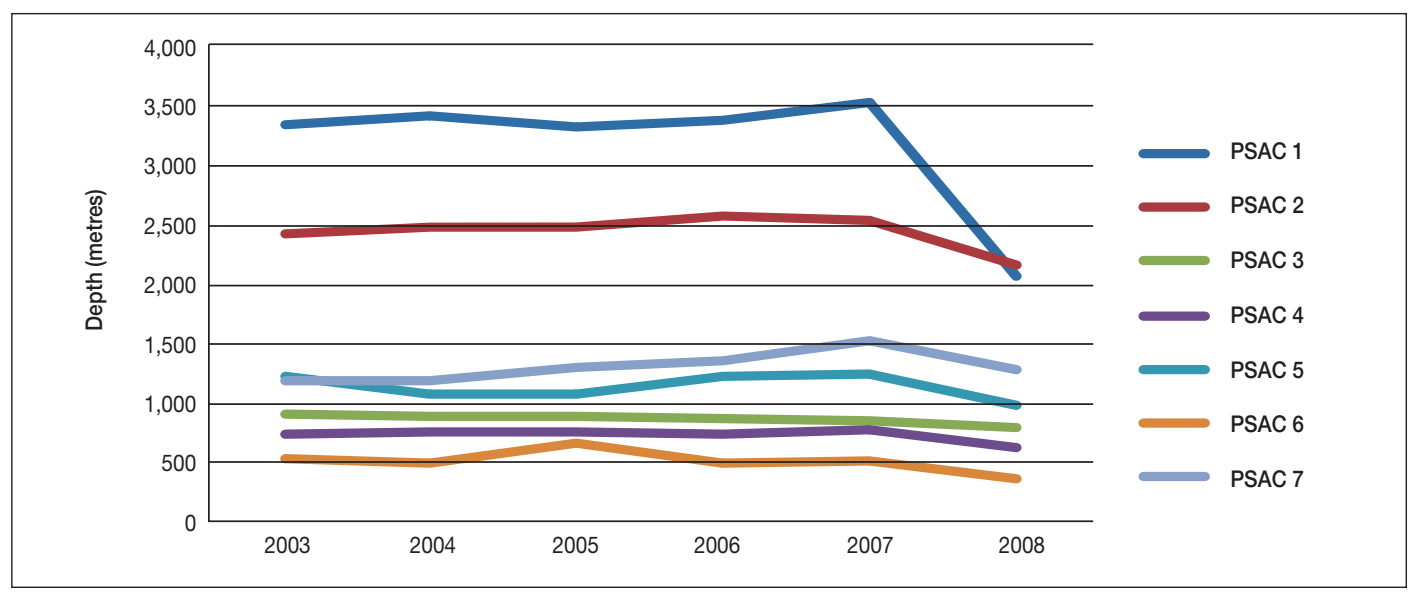


FIGURE 4.3: TOTAL WELLS DRILLED BY PSAC AREA

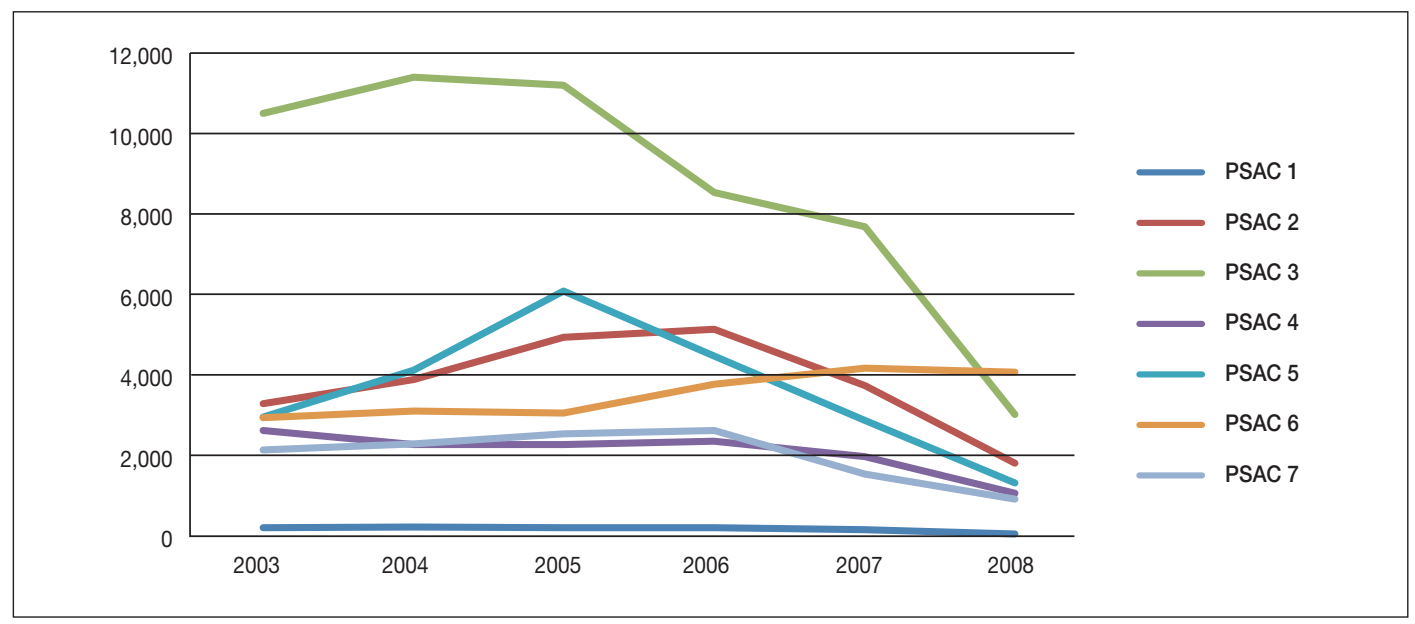

Source: Derived from database compiled by authors from IHS Inc. and ADOE data.

As shown in Figure 4.4, historical success rates vary by PSAC area, but the differences are fairly consistent over time, with the exception of Area 6, which exhibits signs of decline. In general, success rates are highest in PSAC areas 2, 3, and 4, and lowest in areas 1 and 6.

\section{FIGURE 4.4: DRILLING SUCCESS RATES BY PSAC AREA}

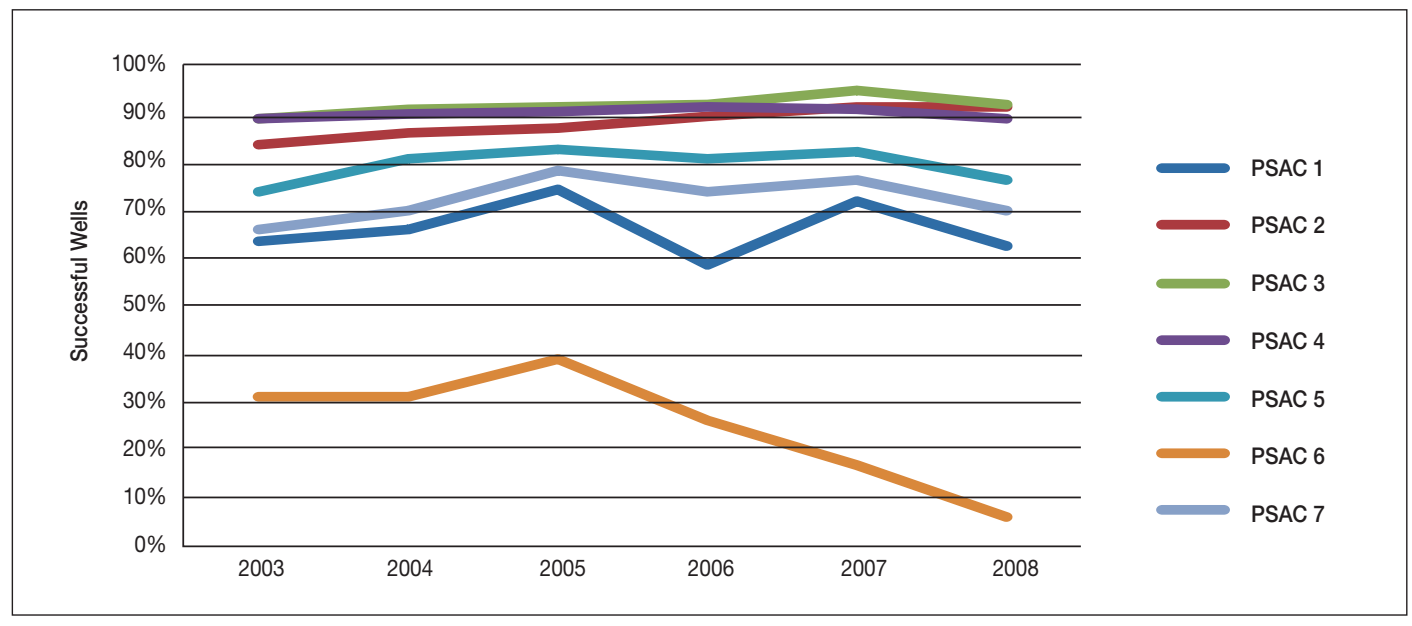

Source: Derived from database compiled by authors from IHS Inc. and ADOE data.

\subsection{Drilling Patterns of EJs, Js, Is and Ms}

The distribution of drilling across firm size categories and average depth of wells drilled by firms in each size category is indicated in Figures 4.5 and 4.6. Over the period, there is no discernible increasing or decreasing trend in the percentage of drilling accounted for by the EJs, Js and Is. 
FIGURE 4.5: PERCENTAGE OF WELLS DRILLED BY FIRM TYPE

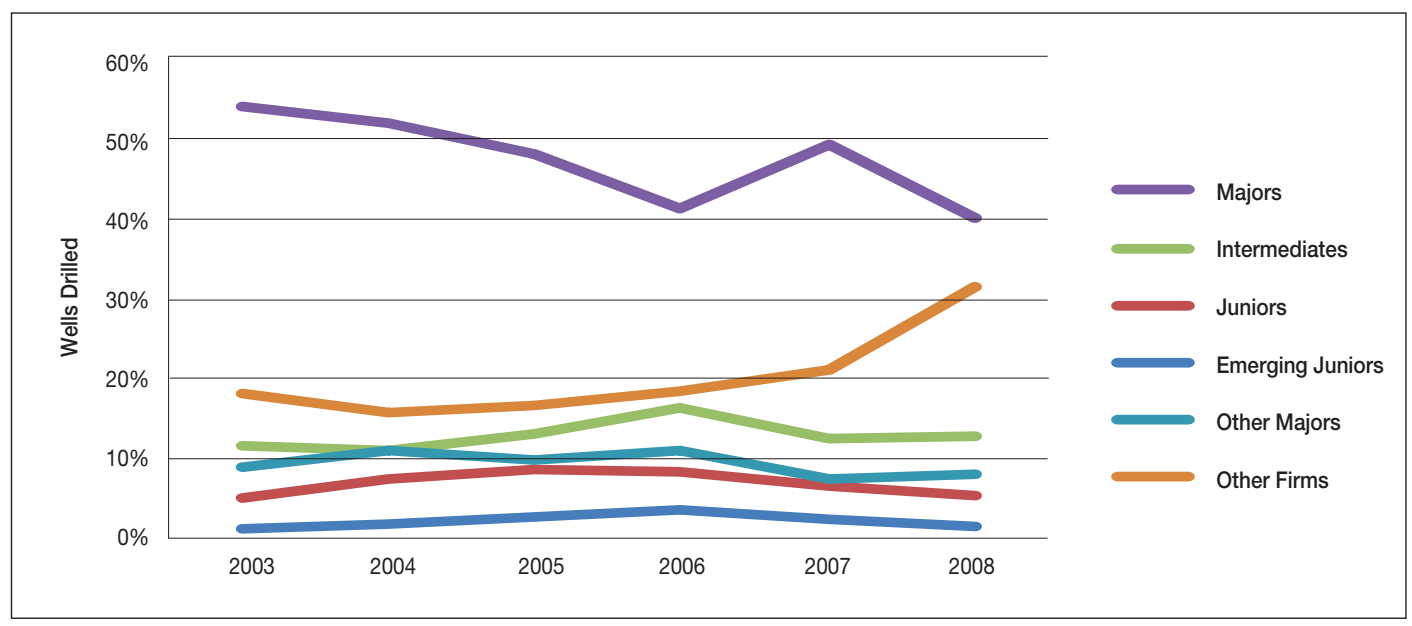

Source: Derived from database compiled by authors from CanOils, IHS Inc. and ADOE data.

\section{FIGURE 4.6: AVERAGE DEPTH OF WELLS BY FIRM TYPE}

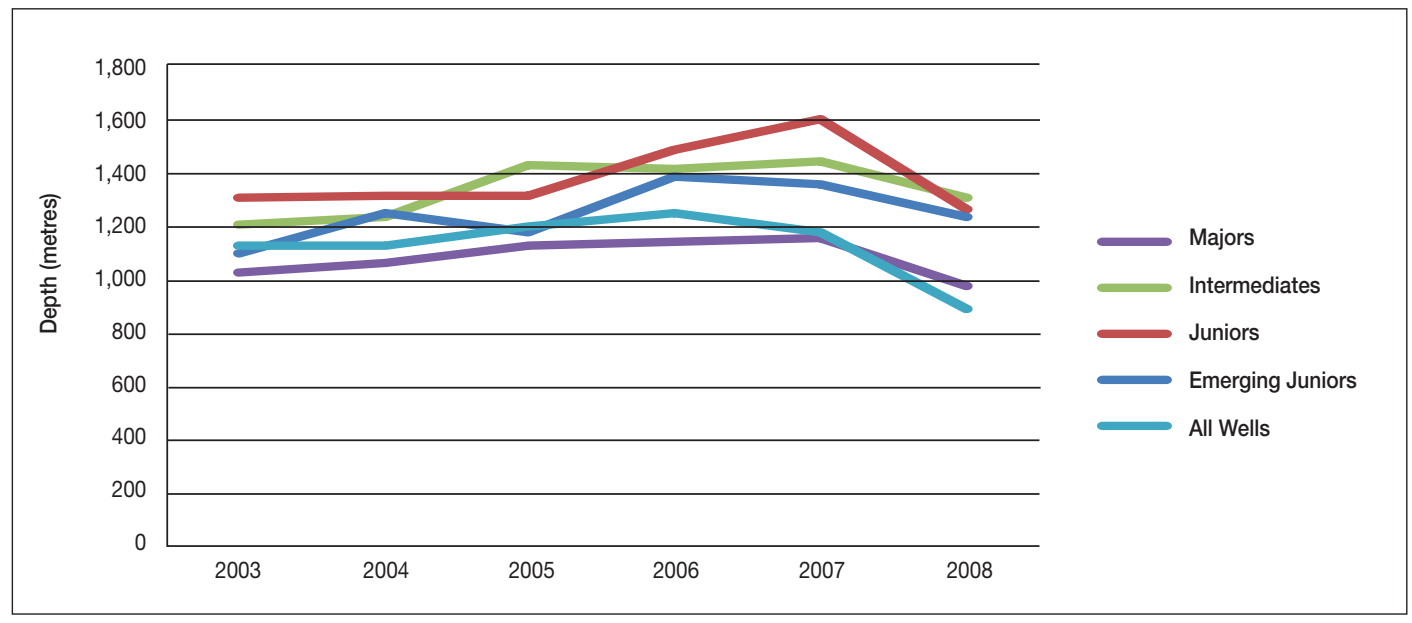

Source: Derived from database compiled by authors from CanOils, IHS Inc. and ADOE data.

The decline in the Ms' share appears to be an anomaly reflecting the rapid growth in drilling by companies not included in the CanOils data. It is somewhat surprising that the average well depth for Ms was below that for the other three categories. This average disguises the fact that, while the Ms tend to dominate drilling in the deeper formations (such as PSAC areas 1 and 2), they also dominate drilling in the shallower formations to an extent that pulls the average depth down to levels below that for EJs, Js and Is. As shown in Figure 4.7, the Ms tend to have the lowest average cost per well drilled. Costs over the study period have been generally increasing, faster for smaller firms than larger firms. For the smaller firms, the fact that costs generally exceed those of the majors might be expected, given economies of scale combined with larger and longer-term contracts with drilling companies. 
Figures 4.8 and 4.9 show the number of horizontal and deviated ${ }^{34}$ wells as a percentage of the total wells drilled by each size category. We see an interesting upward trend in both types of wells. The sharpest upward trend for horizontal wells occurs in the Intermediate, Junior and Emerging Junior categories. In contrast, Majors and Intermediates show the strongest increase in the deviated well category. This indicates all size categories are benefiting from advances in drilling technology.

An overview of the geographical drilling patterns for two representative years, 2003 and 2007, is provided in Figures 4.10 and 4.11 (see Appendix IV for the maps for other years). In general, drilling activity of firms in all four size categories is fairly widely distributed, with the addition of significant clustering in certain parts of the PSAC areas. The locations of these clusters appear fairly stable over the period analyzed. Further, it would appear that the smaller firms (EJs and Js) tend to follow major investments and commitments of larger firms in areas that are relatively well characterized and discovered, although with gaps in terms of actual leases secured.

The PSAC areas have geologic, as well as geographic, characteristics that help define economic and drilling activity and participation by firms in the four categories. We have created descriptors that generally portray these characteristics in order to further define the activities and behaviour of these firms. Generally, most activity is concentrated in a band from the SW corner of zone 7, through zones 2, 3, 4 and 5. Most EJ and $\mathrm{J}$ interest is predominantly located in the southern portions of zones 2 and 3. A summary is provided in Table 4.2.

FIGURE 4.7: AVERAGE COST PER WELL DRILLED

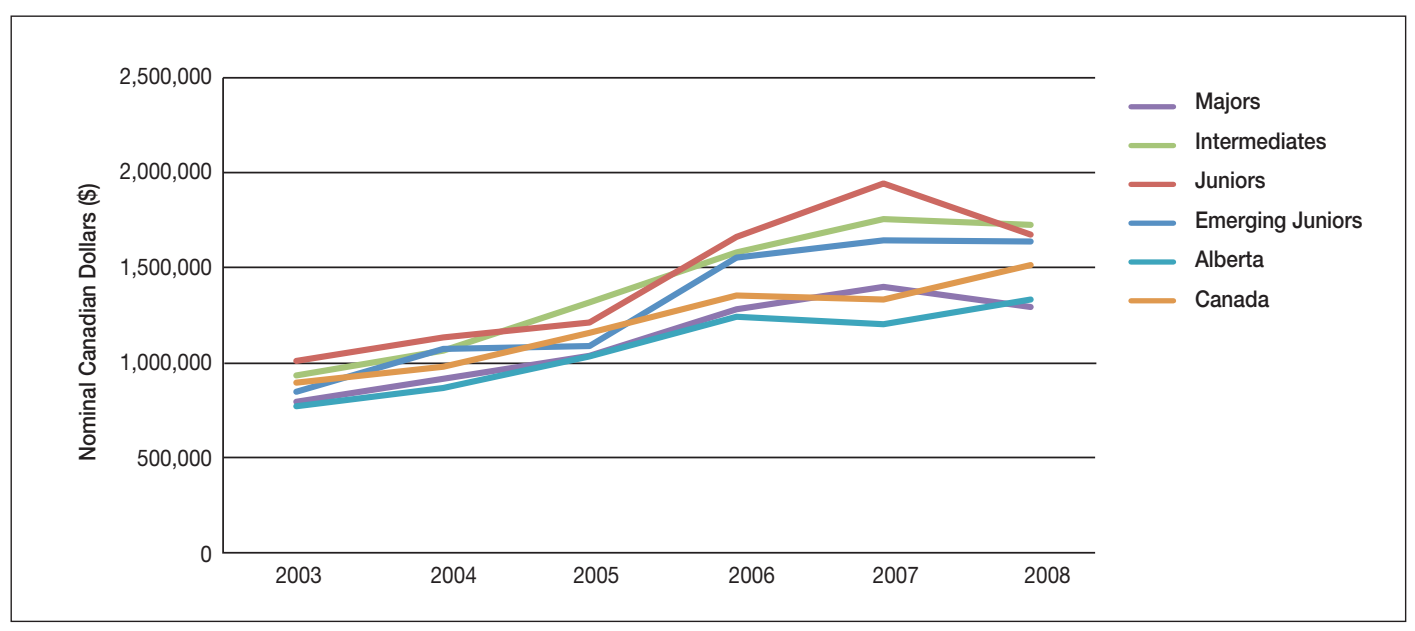

Source: The Canadian Association of Petroleum Producers, Statistical Handbook and data derived from database compiled by authors from CanOils, IHS Inc. and ADOE data

\footnotetext{
${ }^{34}$ Wells that are drilled at angles to reach a vertical formation not directly under the well pad due to surface access restrictions.
} 
FIGURE 4.8: HORIZONTAL WELLS AS PERCENTAGE OF TOTAL

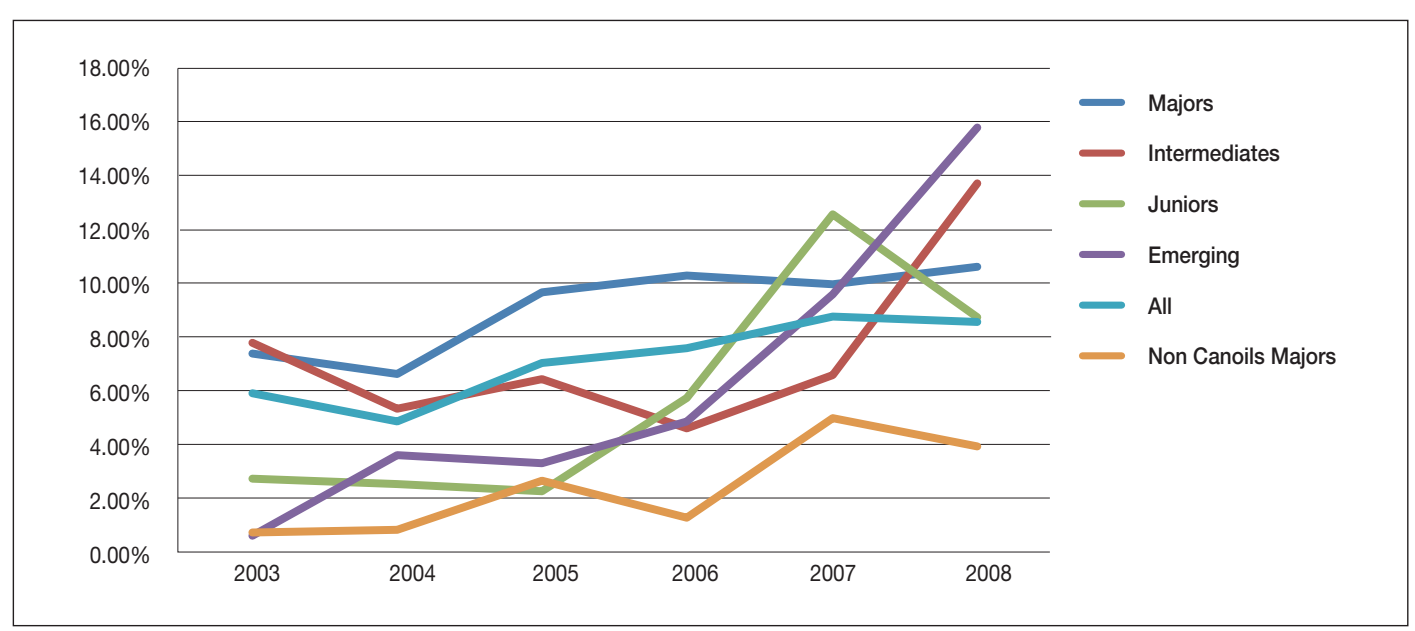

Source: Derived from database compiled by authors from CanOils, IHS Inc. and ADOE data

FIGURE 4.9: DEVIATED WELLS AS A PERCENTAGE OF TOTAL

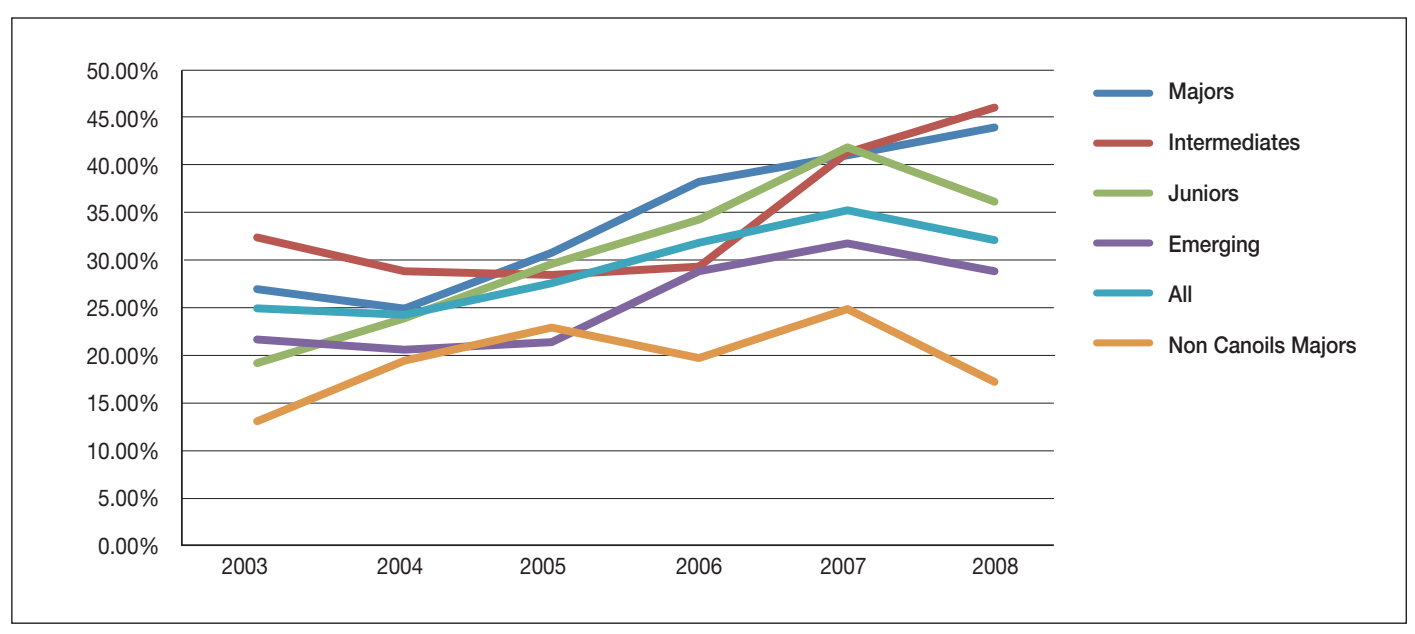

Source: Derived from database compiled by authors from CanOils, IHS Inc. and ADOE data 
FIGURE 4.10: AGGREGATE DRILLING LOCATIONS BY PSAC AREA AND FIRM SIZE, 2003

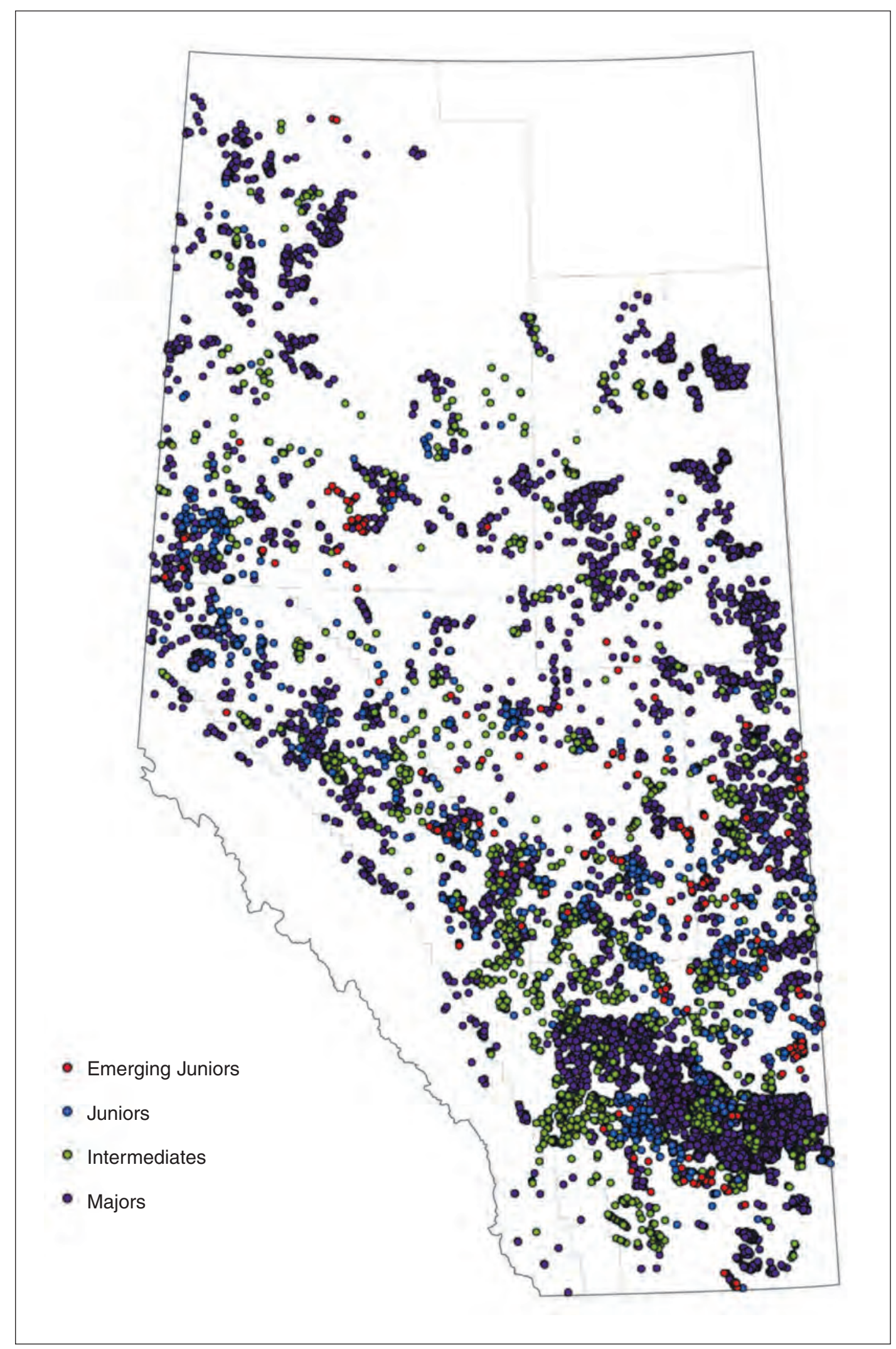


FIGURE 4.11: AGGREGATE DRILLING LOCATIONS BY PSAC AREA AND FIRM SIZE, 2007

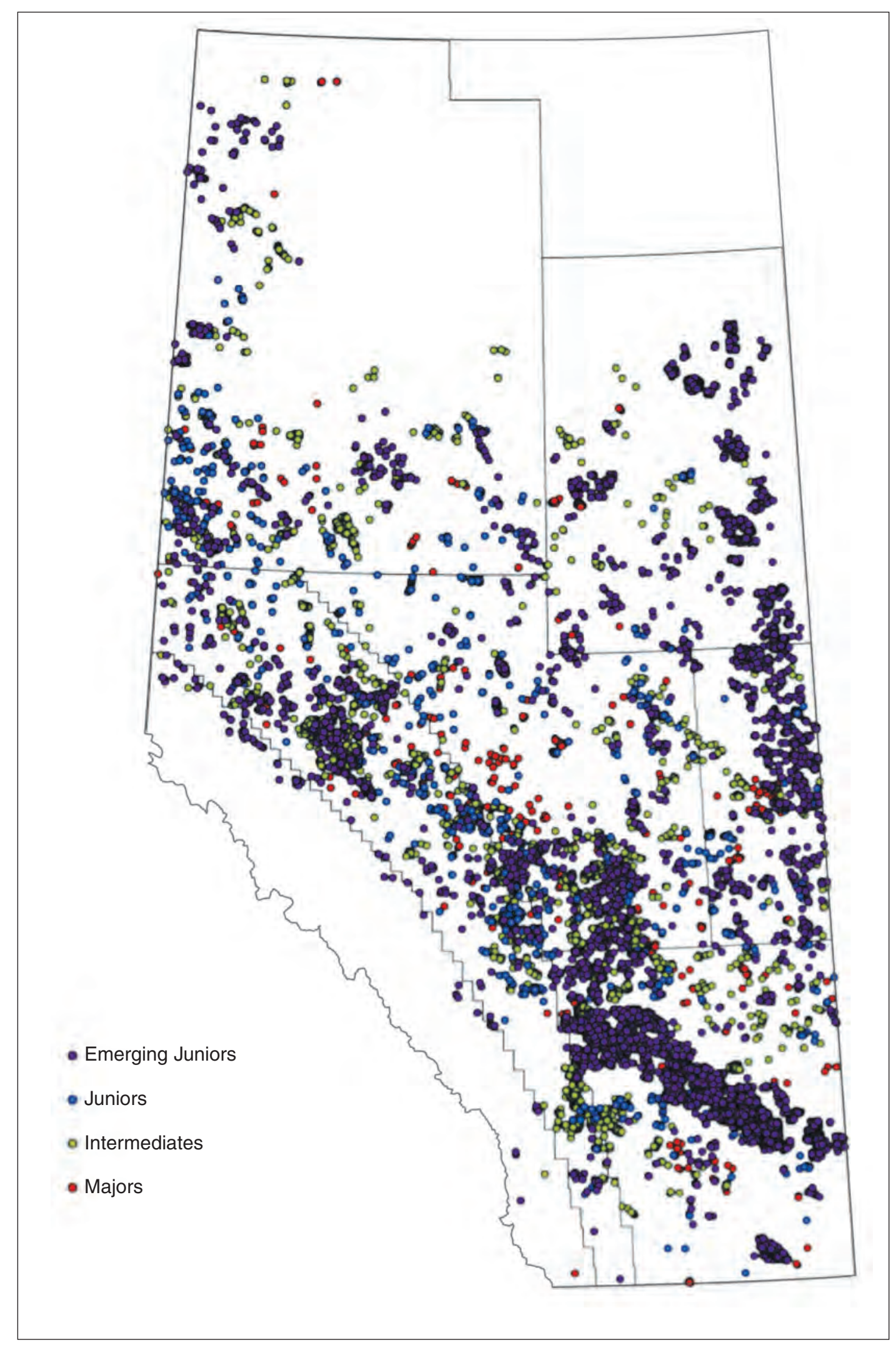


TABLE 4.2: GENERAL CHARACTERISTICS BY PSAC ZONE

\begin{tabular}{|c|c|c|}
\hline $\begin{array}{l}\text { PSAC } \\
\text { Area }\end{array}$ & General Characteristics & Wells Drilled $2002-08$ by Category \\
\hline 1 & $\begin{array}{l}\text { Deepest area of the Sedimentary Basin; capital- } \\
\text { intensive; lowest intensity of operations; success } \\
\text { rates generally } 50 \text { percent for total wells drilled; } \\
\text { conventional oil dominates production. }\end{array}$ & $\begin{array}{l}\text { EJ - little activity except in SW corner of area } \\
\text { J - little activity, widely dispersed in S part of area } \\
\text { I - moderate interest in SW } \\
\text { M - some clusters of activity in SW and NW }\end{array}$ \\
\hline 2 & $\begin{array}{l}\text { Deep area of sedimentary basin; highest } \\
\text { concentration of activity for conventional oil; } \\
\text { success rates } 70 \text { percent; dominated by Major } \\
\text { firms. }\end{array}$ & $\begin{array}{l}\text { EJ - little activity except in centre of area } \\
\text { J - small clusters evenly distributed } \\
\text { I - most active in this zone } \\
\text { M - most active of all in this zone, high cluster activity in SW }\end{array}$ \\
\hline 3 & $\begin{array}{l}\text { SW corner of province; high concentration of gas } \\
\text { wells and highest success rates of approximately } \\
85 \text { percent. }\end{array}$ & $\begin{array}{l}\text { EJ - clusters of activity in NE corner } \\
J \text { - clusters of activity in NE corner } \\
\text { I - moderate activity, clusters in N of zone } \\
M \text { - clusters of activity mostly in centre of zone }\end{array}$ \\
\hline 4 & $\begin{array}{l}\text { Eastern centre of province; encompasses southern } \\
\text { portion of oil sands region; dominated by } \\
\text { unconventional oil activity; overall success rates of } \\
\text { approximately } 80 \text { percent. }\end{array}$ & $\begin{array}{l}\text { EJ - concentrated clusters in E centre } \\
J \text { - widely scattered line from W boundary through centre } \\
\text { I - widely scattered in zone } \\
M \text { - dense concentrations in E half of zone }\end{array}$ \\
\hline 5 & $\begin{array}{l}\text { Centre of the province; midpoint of sedimentary } \\
\text { basin; moderate depths; western edge of oil sands } \\
\text { activity; success rates approximately } 65 \text { percent } \\
\text { for new wells. }\end{array}$ & $\begin{array}{l}\text { E - highest concentrations of activity, centre \& S centre } \\
\text { J - concentrated in } S \text { centre of zone } \\
\text { I - clusters in E centre } \\
M \text { - wide dispersed clusters in N \& concentration in S centre }\end{array}$ \\
\hline 6 & $\begin{array}{l}\text { Northeast corner of province, with oil sands } \\
\text { production in S and national park lands restricting } \\
\text { activity in N; success rates low overall of } \sim 30 \\
\text { percent. }\end{array}$ & $\begin{array}{l}\text { EJ - widely scattered individual wells } \\
J \text { - widely scattered individual wells } \\
\text { I - clusters and concentration in S } \\
M \text { - clusters and concentration in S }\end{array}$ \\
\hline 7 & $\begin{array}{l}\text { NW corner of province, with some oil sands } \\
\text { activity in SE corner of zone and shale gas activity } \\
\text { in NW corner of zone; success rates } \sim 55 \text { percent. }\end{array}$ & $\begin{array}{l}\text { EJ - clusters in SW corner } \\
J \text { - clusters in S of zone } \\
\text { I - clusters in SW corner } \\
\text { M - clusters in SW and NW of zone }\end{array}$ \\
\hline
\end{tabular}

Additional details can be found in Appendix IV, from the graphs showing the percentage of drilling activity in each year in each PSAC area that is accounted for by firms in each size category.

\subsection{Success Rates for Each Category}

On one hand, one would expect the larger firms to have higher drilling success rates, given the much greater experience arising from significantly larger drilling programs over many years and across highly diverse prospects. Further, it would seem likely that these firms have better access to talent and sophisticated tools. However, on the other hand, as indicated earlier, they are more active in the areas characterized by deeper formations and more complex geology where success rates tend to be lower.

As indicated in Figure 4.12, the Majors (Ms) and Intermediates (Is) have similar average success rates; these tend to be about 10 percentage points above the average success rates for Juniors (Js) and roughly 20 percentage points above average success rates for Emerging Juniors (EJs). However, as shown in Appendix V, these differences vary widely across PSAC areas, with both EJs and Js achieving average success rates close to or comparable to those for the Ms and Is in the shallower, more heavily explored areas. 
FIGURE 4.12: WELL SUCCESS RATIOS

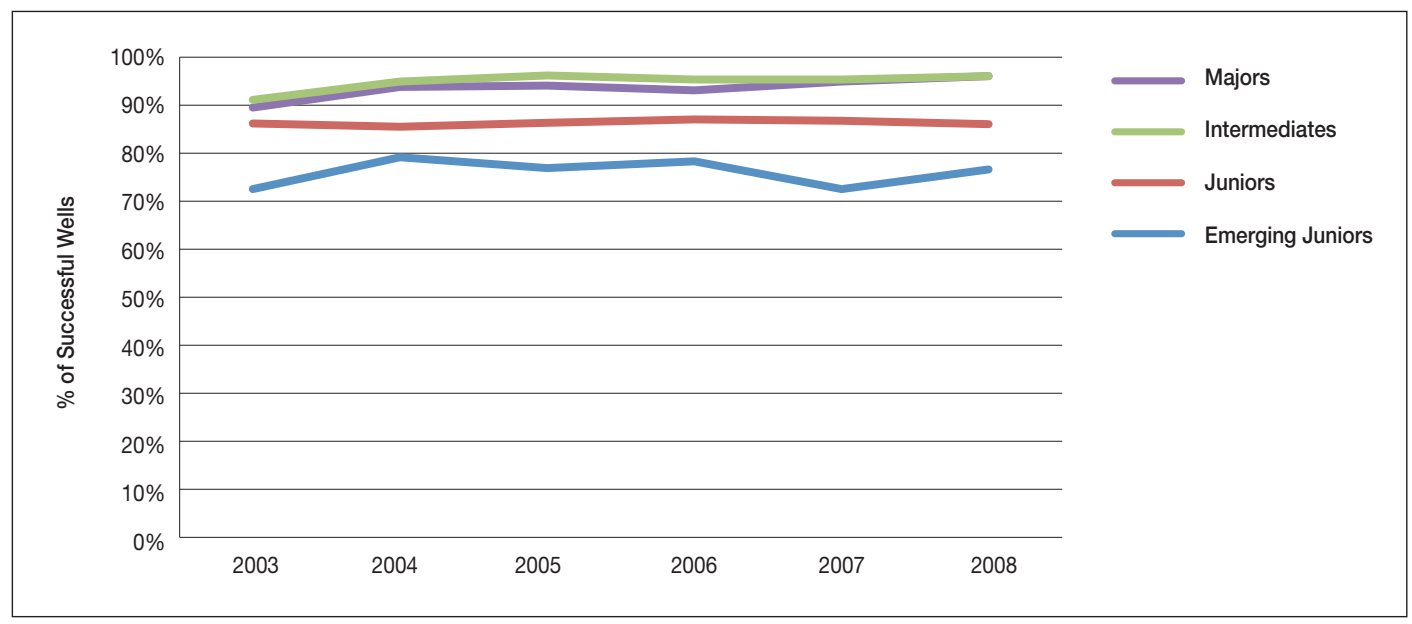

Source: Derived from database compiled by authors from CanOils, IHS Inc. and ADOE data.

\subsection{Summary}

This section was focused on establishing geographical patterns of exploration and development activity within the province by EJs, Js, Is and Ms. The purpose was to identify differences across firm size categories in the concentration and dispersion of activity, in propensities for drilling in deep vs. shallow formations, in geographical shifts in activity as conditions change and in costs and success rates. The analysis was based on detailed Alberta drilling and well data for 340 companies in each of the seven PSAC areas over the period 2002 to 2008, integrated with the dataset outlined in Section 3.1 The main points are as follows:

- Average depth is much greater in PSAC areas 1 and 2 (the mountain and foothills regions) than in other areas. Costs per well in these two areas are also much higher on average. PSAC regions 3-7 generally support moderate, consistent drilling depths per well. The greatest concentrations of EJ (emerging junior) and $\mathbf{J}$ (junior) companies occur in areas 3 and 5. The Ms (majors) and intermediates (Is) tend to dominate in areas 1 and 2.

- The highest volume of drilling occurs in PSAC area 3 (generally the south and south eastern corner of the province); the balance of the areas sees fairly consistent rates of drilling over time. Area 3 has seen by far the largest decline in drilling in recent years.

- Over the period 2003 to 2008, EJs accounted for about two percent of the drilling, Js roughly eight percent, Is about 15 percent and Ms (and others) approximately 75 percent.

- The average well depth for Ms was below that for the other three categories. This average disguises the fact that, while the Ms tend to dominate drilling in the deeper formations (such as PSAC areas 1 and 2), they also dominate drilling in the shallower formations to an extent that pulls the average depth down to levels below that for EJs, Js and Is.

- Ms tend to have the lowest average cost per well drilled. Costs over the study period have been generally increasing, faster for smaller firms than larger firms. For the smaller firms, the fact that costs generally exceed those of the majors might be expected, given economies of scale combined with larger and longer- term contracts with drilling companies. 
- There is a significant increase in the frequency of horizontal and deviated drilling by firms in all size categories, suggesting that the use of advanced drilling technology (also the most expensive) is not limited to the larger firms.

- Drilling activity of firms in all four size categories is fairly widely distributed, with the addition of significant clustering around key plays in certain parts of the PSAC areas. The locations of these clusters appear fairly stable over the period analyzed. It would appear that the smaller firms (EJs and Js) tend to follow major investments and commitments of larger firms in areas that are relatively well characterized and discovered, although with gaps in terms of actual leases secured.

- The Majors (Ms) and Intermediates (Is) have similar average success rates, and these tend to be about 10 percentage points above the average success rates for Juniors (Js) and roughly 20 percentage points above average success rates for Emerging Juniors (EJs). However, these differences vary widely across PSAC areas, with both EJs and Js achieving average success rates close to or comparable to those for the Ms and Is in the shallower, more heavily explored areas.

\section{ECONOMIC AND FINANCIAL PERFORMANCE}

This section examines the differences across size categories in economic and financial performance based on firm size. The focus is on various measures indicative of how activity is financed, debt levels, earnings, productivity of assets in generating revenues, operating costs, royalties paid and net income.

\subsection{Differences in Financial Structure}

The debt-to-equity ratio compares total liabilities to total shareholder equity. One would expect the larger firms to have better access to financial capital than smaller firms. However, given their larger capacity to generate retained earnings and possibly less willingness to be highly leveraged, it is not clear, a priori, that they would tend to have higher debt-to-equity ratios.

As indicated in Figure 5.1, it is the Intermediates (Is) that, over the period, tended to be the most highly leveraged. In most years the Emerging Juniors (EJs) and Juniors (Js) had the lowest debt-to-equity percent, averaging between approximately 30 and 40 percent. 
FIGURE 5.1: AVERAGE DEBT AS A PERCENTAGE OF EQUITY

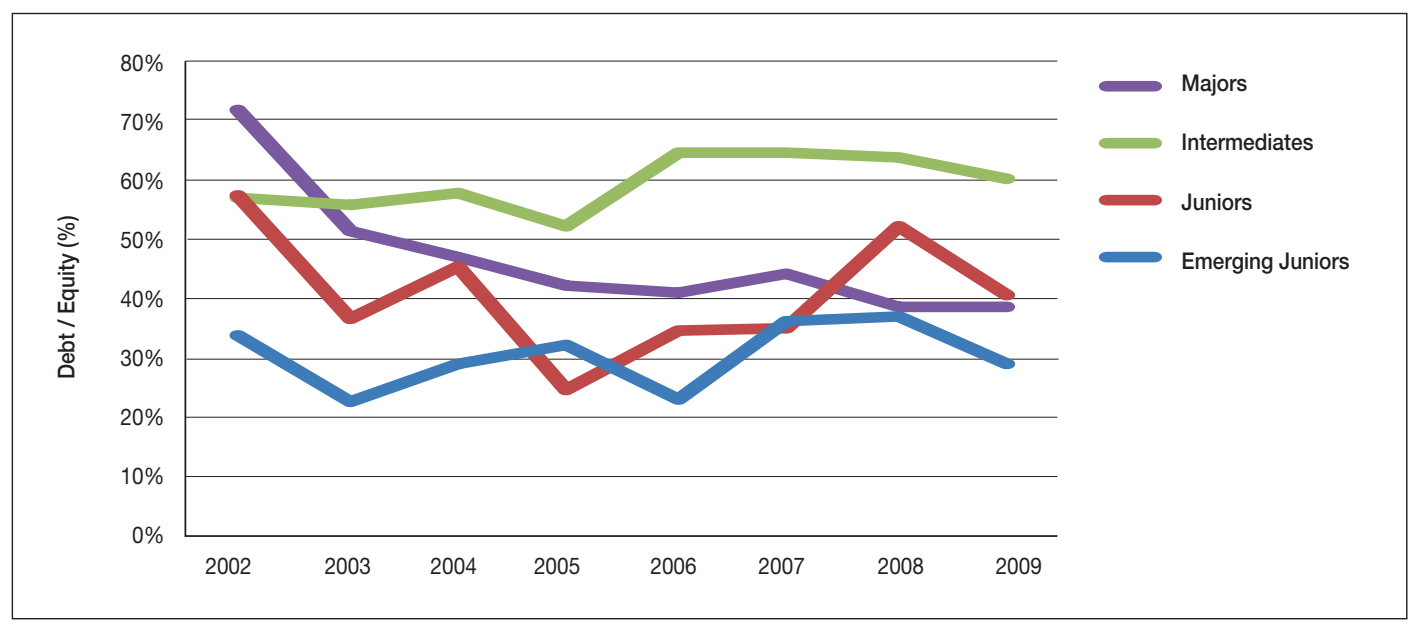

Source: Derived from database assembled by authors using CanOils data

Similarly, it is the Is that tend to have the highest debt-to-capital ratio (see Figure 5.2), while the EJs have typically had the lowest ratio.

\section{FIGURE 5.2: AVERAGE DEBT TO CAPITAL RATIO}

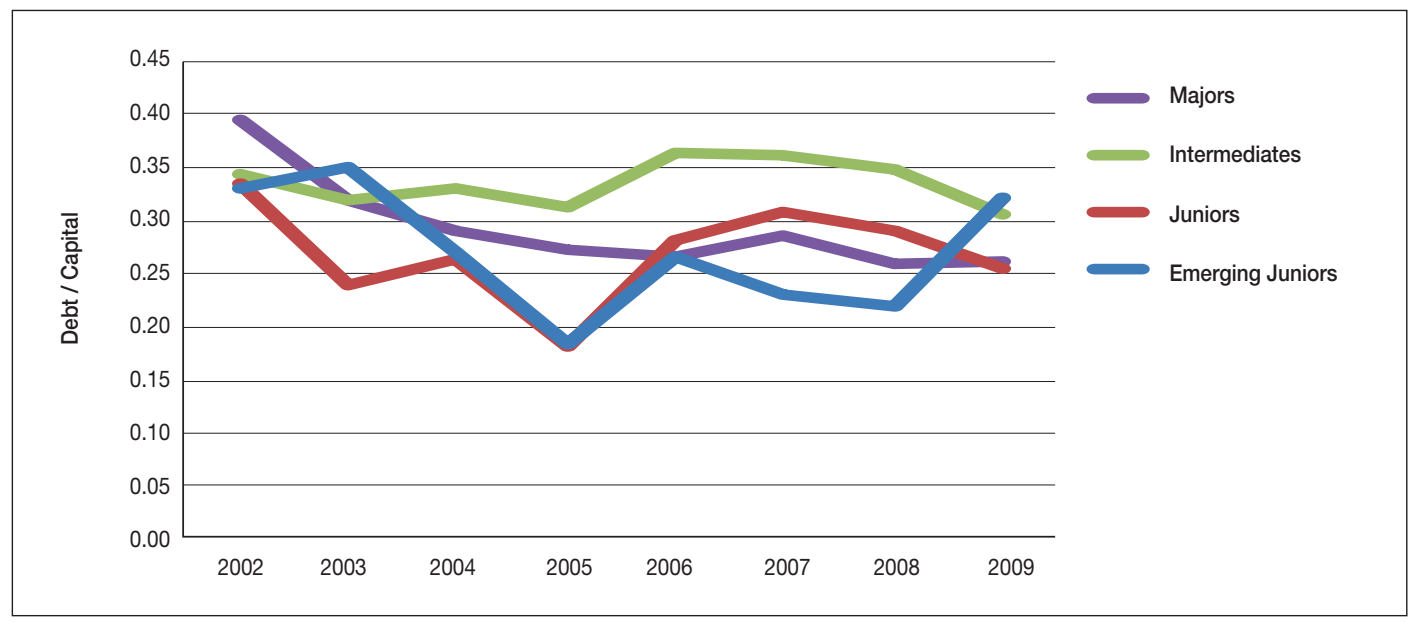

Source: Derived from database assembled by authors using CanOils data

Generally, being able to finance investments all, or in part, out of retained earnings represents an important advantage for a firm. As indicated in Figure 5.3, only the Ms have maintained substantial retained earnings relative to total equity. For the Js and Is, this percentage has tended to be close to zero and for the EJs, it is apparent that they were operating with large and growing losses. This would suggest that the key objective for EJs is, on average, to survive long enough to be acquired by larger firms. That is, the expectation is that the capital gain through such acquisitions would be more than the accumulated operating losses.

Liabilities as a percentage of assets is often used as an important measure of the financial strength of a firm, particularly in relation to the ability of the firm to prosper in a period of interest rate volatility. As shown in Figure 5.4, the EJs and Js tend to have the lowest ratio of 
liabilities to assets, reflecting in part that these small firms are typically less reliant on debt for financing than is the case for the larger companies. However, it can be noted that the differences in liabilities as a percent of total assets among the four size categories are not large.

\section{FIGURE 5.3: AVERAGE RETAINED EARNINGS AS A PERCENTAGE OF EQUITY}

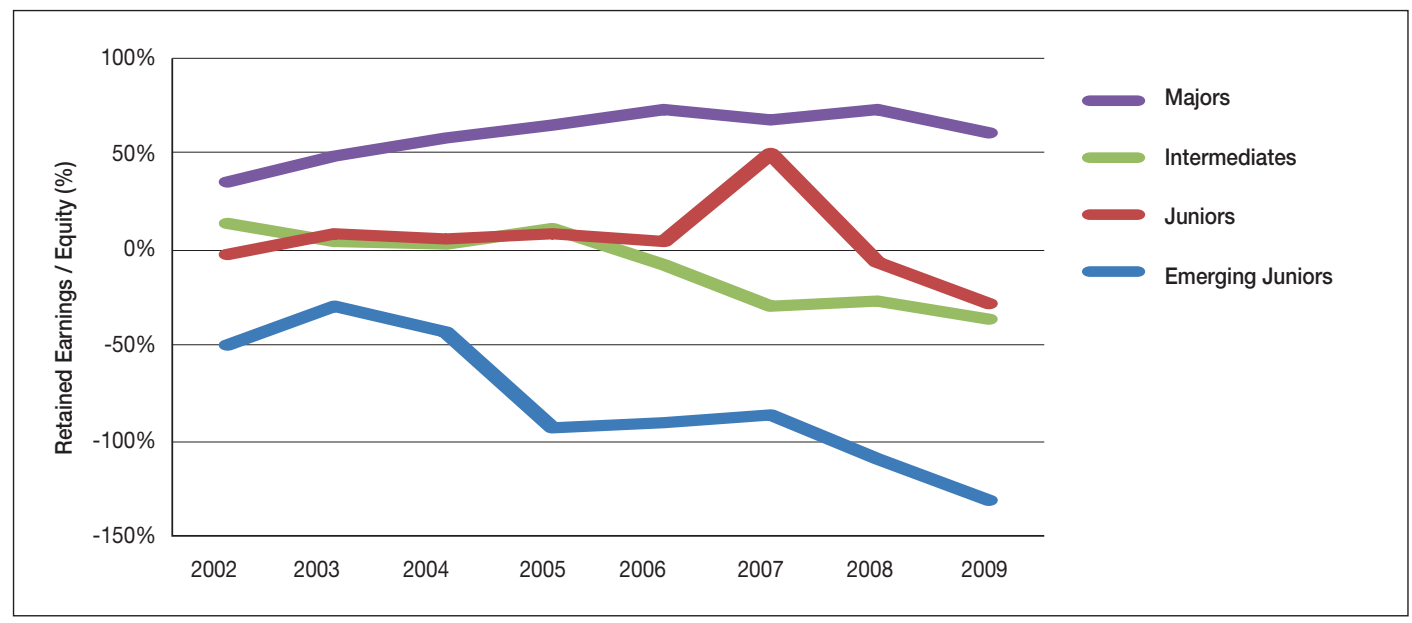

Source: Derived from database assembled by authors using CanOils data

FIGURE 5.4: AVERAGE TOTAL LIABILITIES AS A PERCENTAGE OF TOTAL ASSETS

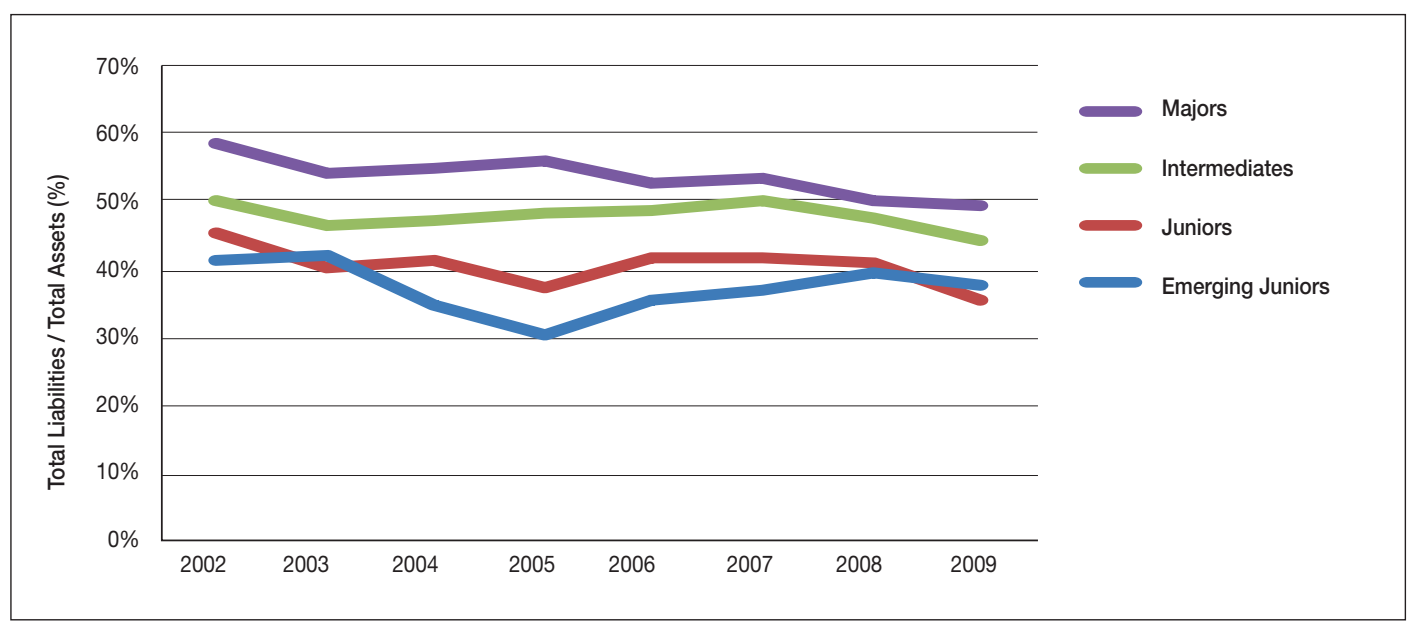

Source: Derived from database assembled by authors using CanOils data

\subsection{Differences in Revenue Generation}

There appear to be large differences between small and large firms in the oil and gas sector in the productivity (measured in terms of revenue) of their assets. On average over the period, the Ms have total revenues equal to about 60 percent of assets, compared to 30 percent for Is and Js, and about 20 percent for EJs. (See Figure 5.5). 
FIGURE 5.5: AVERAGE TOTAL REVENUE AS A PERCENTAGE OF TOTAL ASSETS

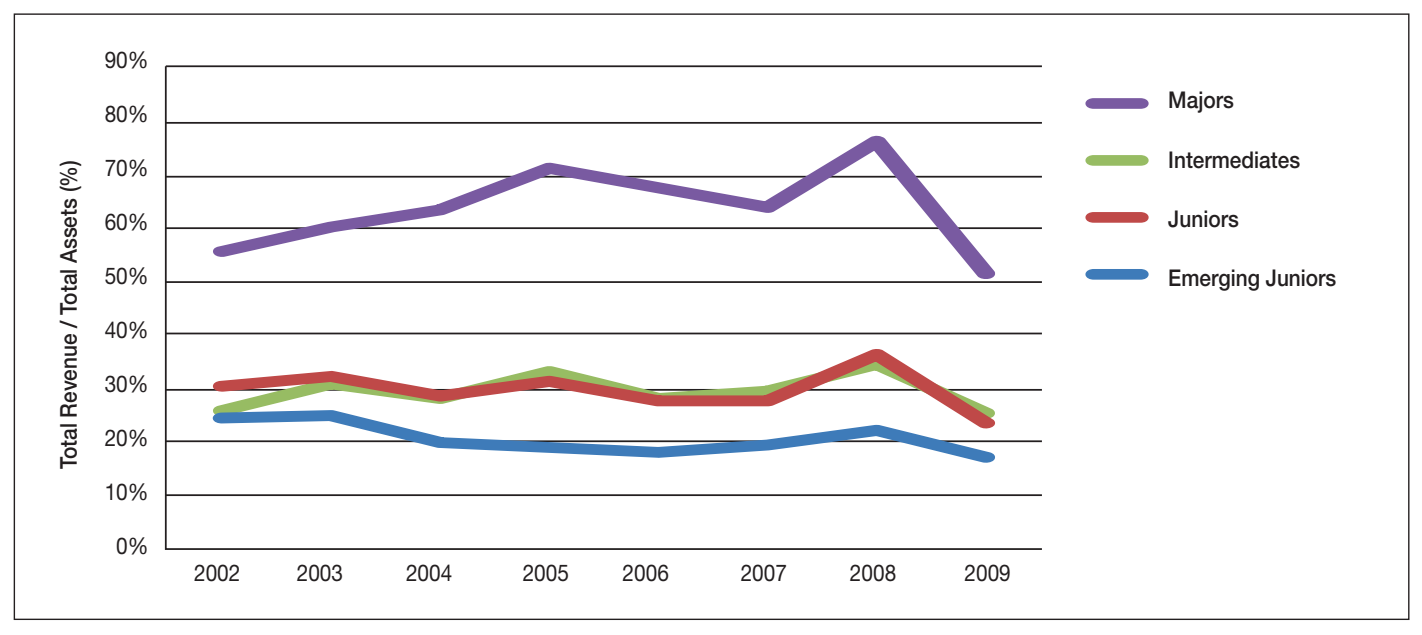

Source: Derived from database assembled by authors using CanOils data

However, when gross revenue is calculated on a per-BOE (barrel of oil equivalent) basis, the differences across size categories is surprisingly small, at least until 2006 when the Ms began showing a significant revenue advantage over firms in the smaller size categories. (See Figure 5.6).

\subsection{Differences in Operating Costs}

Data on operating costs may be less reliable than that for most of the other categories in this section. Nevertheless, as indicated in Figure 5.7, they do show fairly consistent differences across size categories, with the Js and Is having the lowest operating costs per BOE, and EJs and Ms having the highest.

FIGURE 5.6: AVERAGE NOMINAL GROSS REVENUE PER BOE

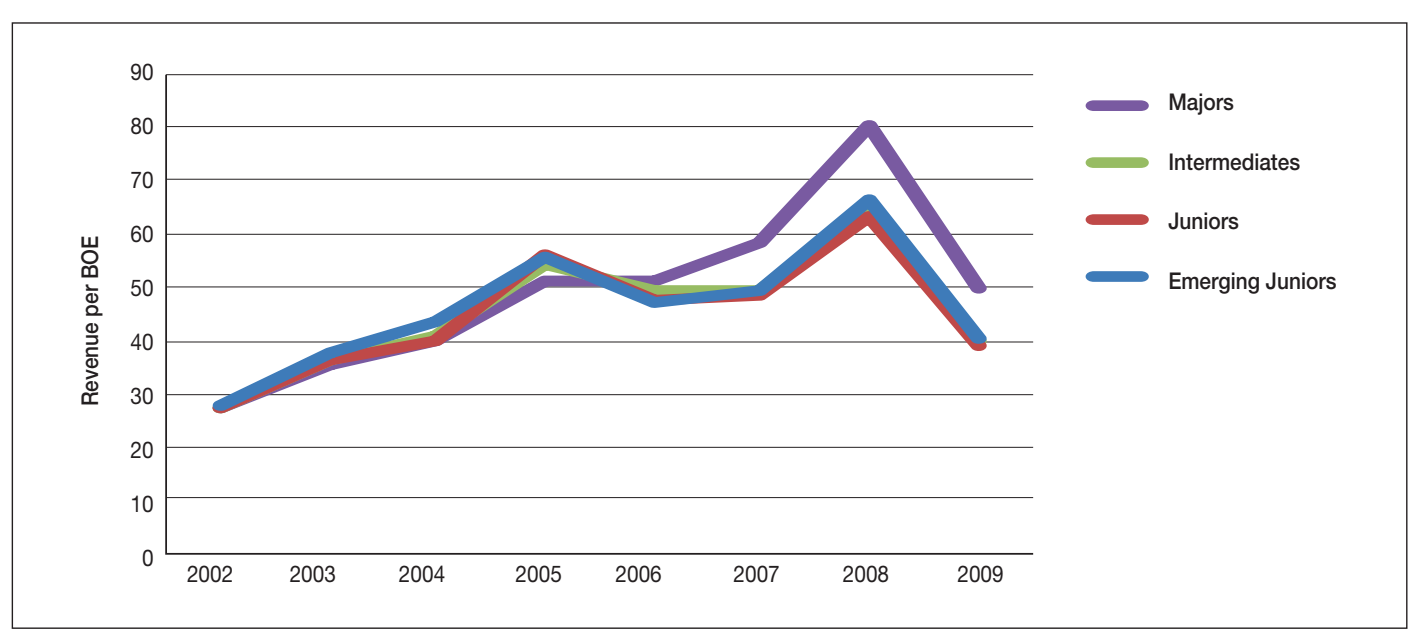


FIGURE 5.7: AVERAGE NOMINAL OPERATING COSTS PER BOE

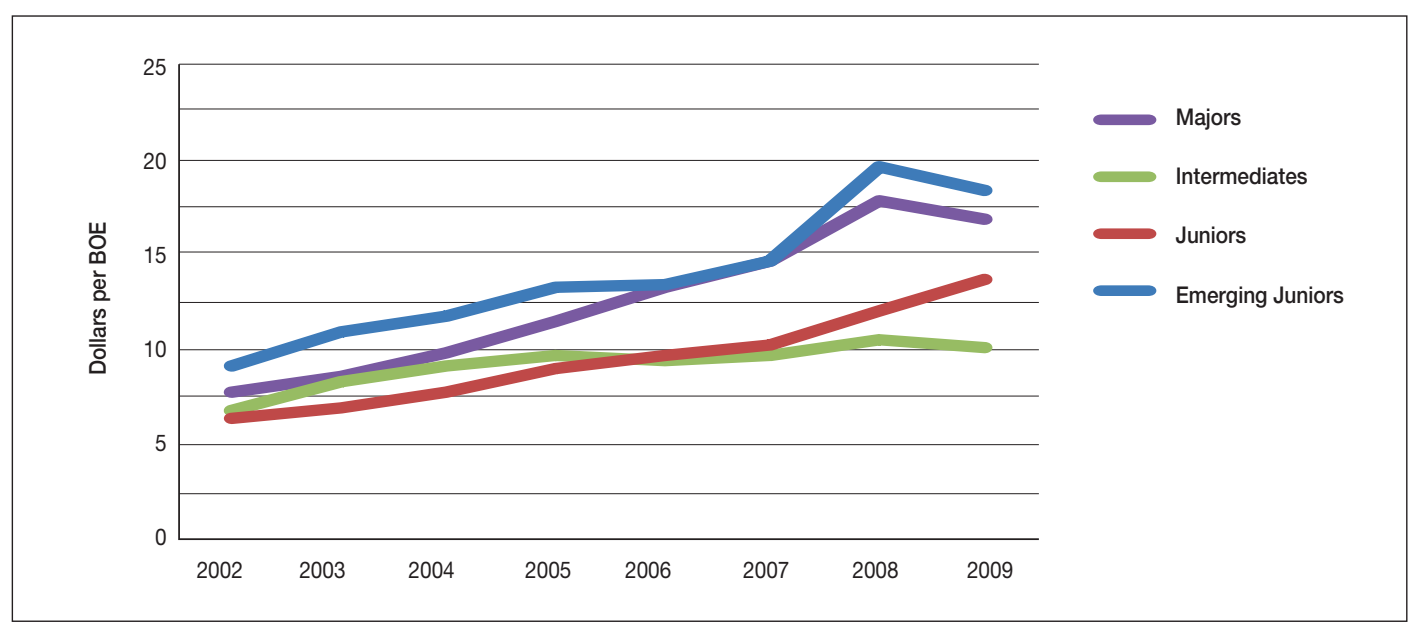

Source: Derived from database assembled by authors using CanOils data

\subsection{Differences in Royalties}

Figure 5.8 shows average royalties paid (net of Alberta Royalty Tax Credit or ARTC) per BOE for each of the size categories. In general there are significant differences for limited periods, followed by a convergence in 2009. It would appear that the differences among size categories in terms of the production mix of natural gas, conventional oil and unconventional oil (production from the oil sands) are an important factor in the differences in net royalties per BOE. For example, over the historical period, natural gas and production from the oil sands have tended to have the lowest royalties per BOE. Consequently, for example, large firms focused on oil sands and/or natural gas production would be seen as paying lower royalties per BOE.

\section{FIGURE 5.8: AVERAGE NOMINAL ROYALTIES (NET OF ARTC) PAID PER BOE}

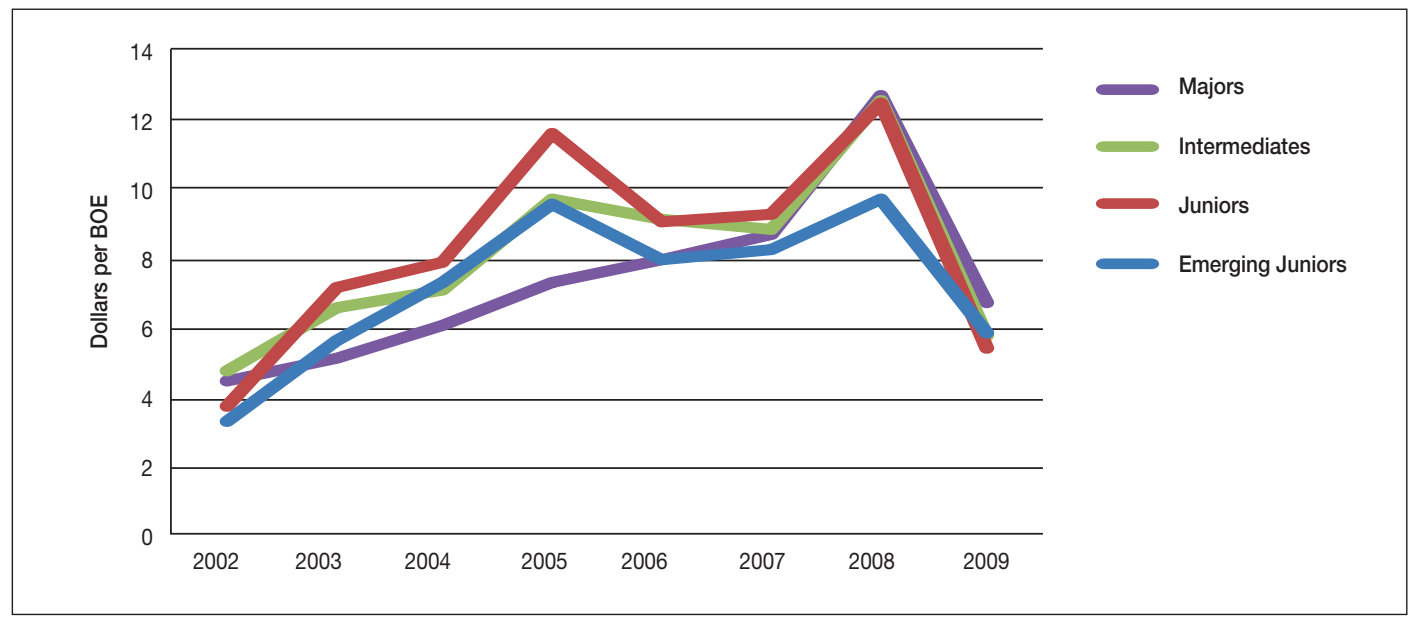


Total gross royalties paid by the different size categories are shown in Figure 5.9. The average paid per firm in each size category is shown in Figure 5.10. Due to scale issues, Figure 5.11 omits the Major category, and therefore allows one to more easily see the numerical values for the EJs, Js and Is.

Net royalties paid take into account the Alberta Royalty Tax Credit, which was eliminated effective January 1, 2007. Figure 5.12 shows the annual amounts for the ARTC received by each size category. The major beneficiaries were the EJs and Js.

FIGURE 5.9: YEARLY GROSS ROYALTIES PAID

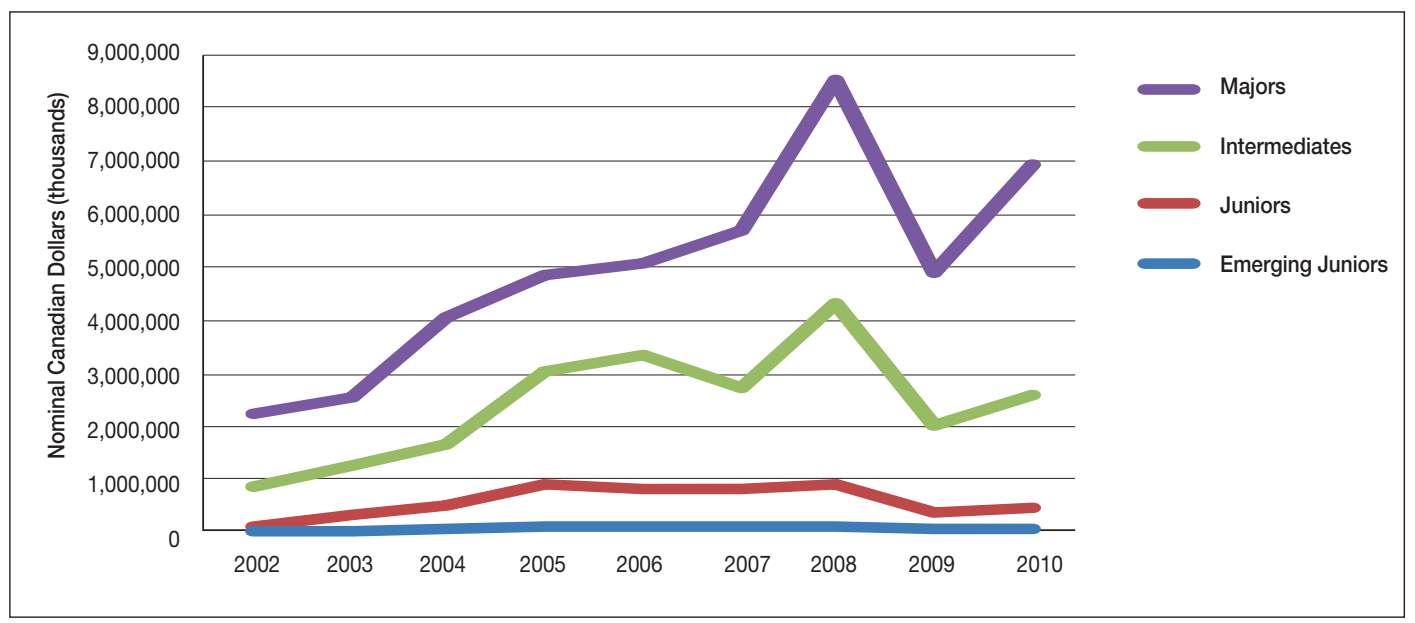

Source: Derived from database assembled by authors using CanOils data

FIGURE 5.10: AVERAGE GROSS ROYALTIES PAID

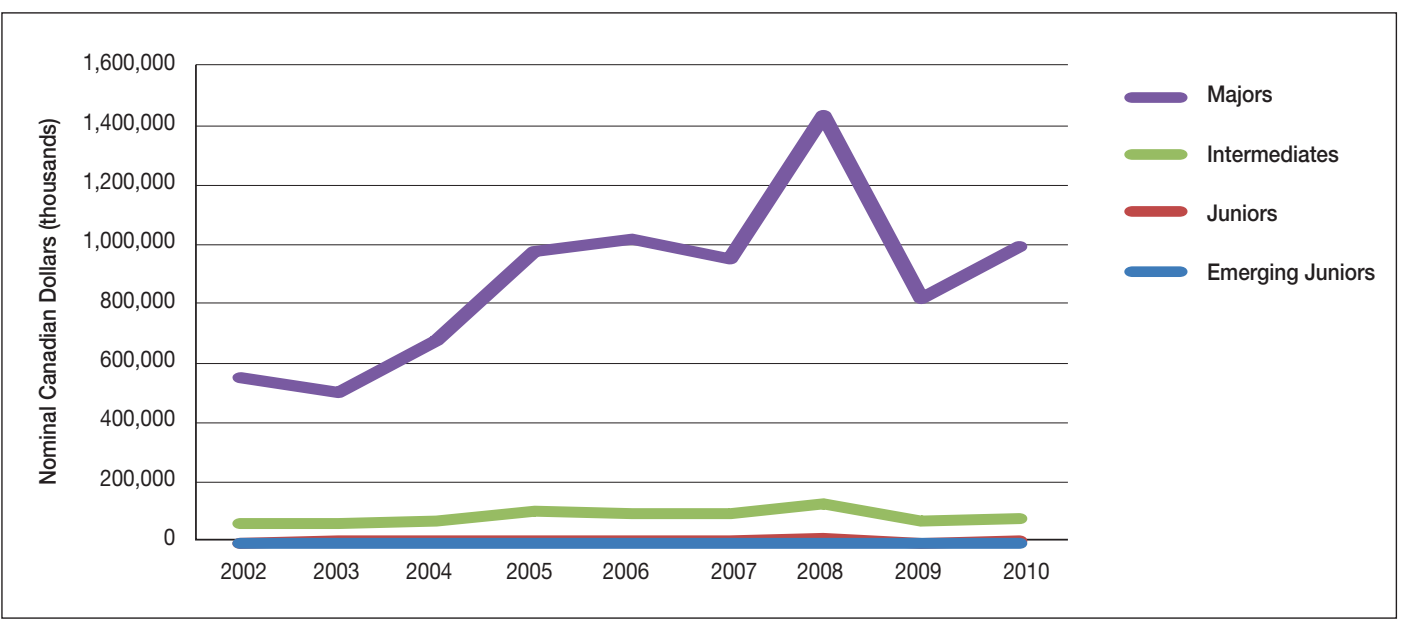

Source: Derived from database assembled by authors using CanOils data 
FIGURE 5.11: AVERAGE GROSS ROYALTIES PAID (II)

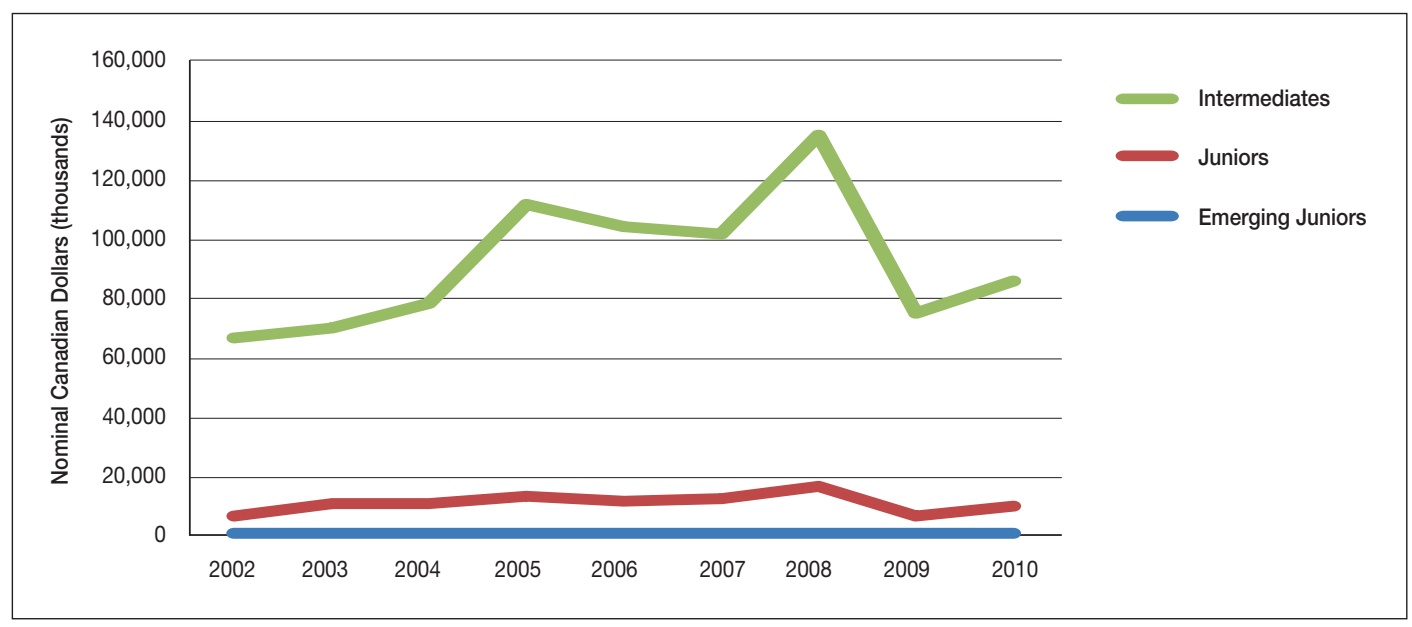

Source: Derived from database assembled by authors using CanOils data

FIGURE 5.12: ALBERTA ROYALTY TAX CREDIT AMOUNT

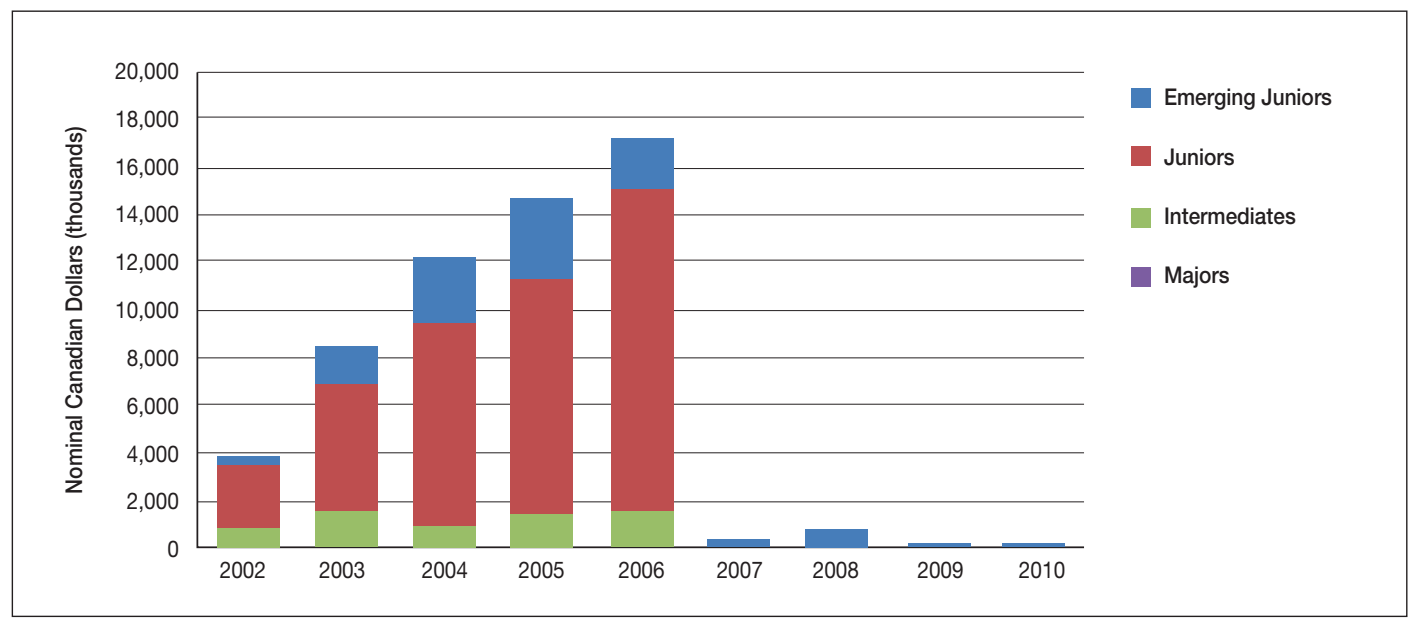

Source: Derived from database assembled by authors using CanOils data

\subsection{Differences in Income and Income Taxes}

Average income before and after taxes per BOE by size category is presented in Figures 5.13 and 5.14. Several notable features stand out. First, EJs showed large and increasing losses over the period. As indicated earlier, the fact that they experience negative earnings likely reflects the expectation of a capital gain through being acquired rather than developing significant levels of production and operating revenues. Alternatively, it may reflect the fact that it takes greater than five years to become profitable at which point they become an attractive buyout by larger firms. Second, only the Ms have been able to maintain positive earnings over the entire period, albeit they were low at the beginning and end of the period. Third, since 2005, the earnings performance (measured in both before and after tax terms) of the Is and Js has diverged from that of the Ms, with the Js exhibiting negative earnings over this period. 


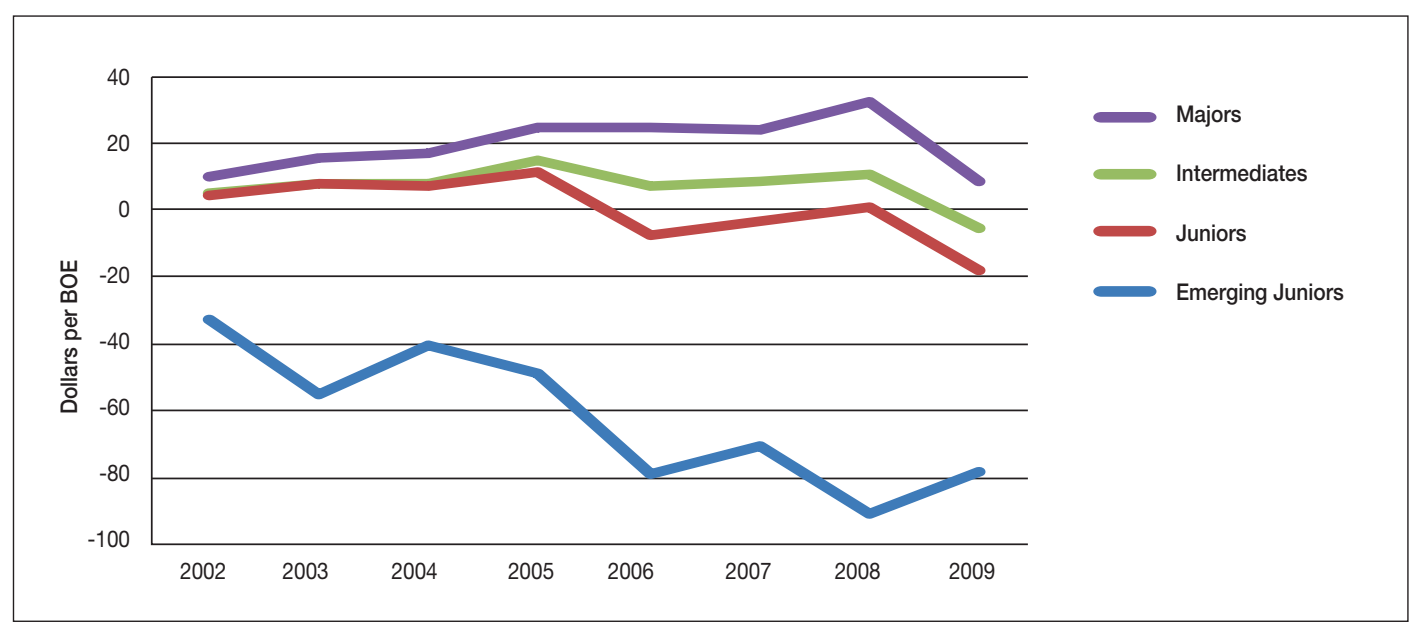

Source: Derived from database assembled by authors using CanOils data

FIGURE 5.14: AVERAGE NOMINAL NET INCOME PER BOE

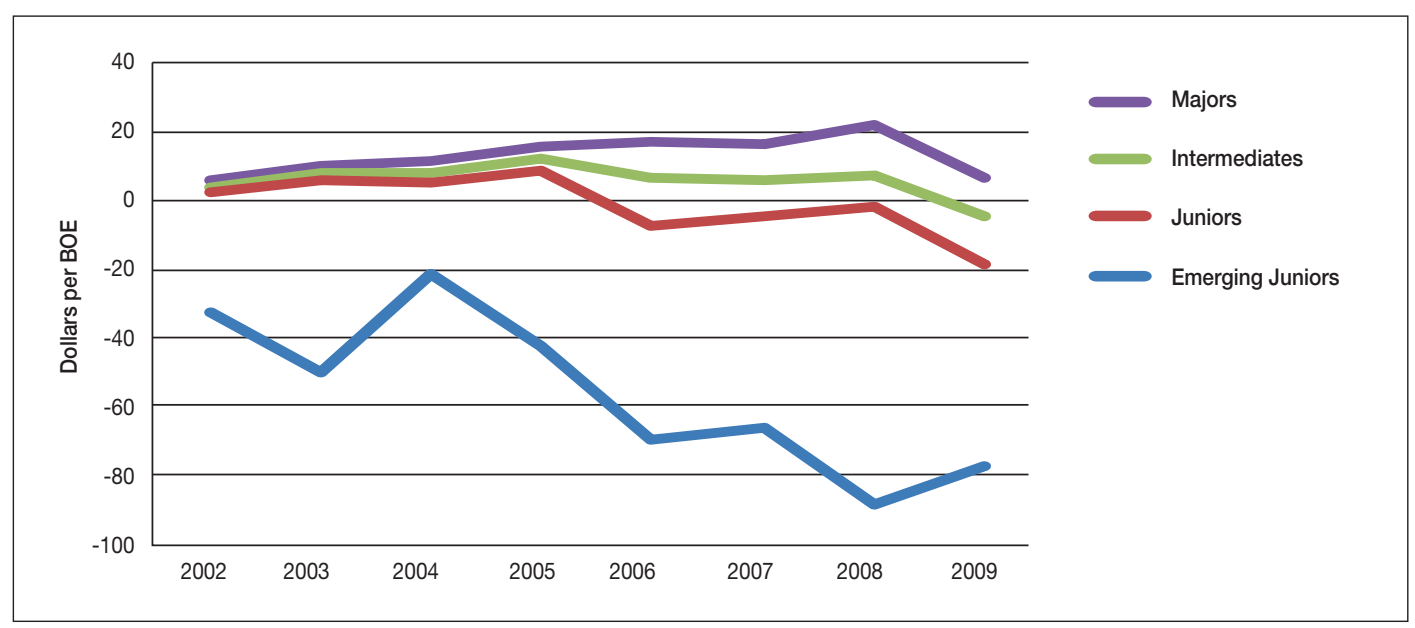

Source: Derived from database assembled by authors using CanOils data

Figures 5.15 through 5.17 show the cash tax burden (income plus capital taxes) on the four size categories. The Ms pay substantially more taxes than the three smaller categories. There is no discernible difference when comparing total taxes (Figure 5.15) to average taxes (Figure 5.16), as the tax burden on the Ms is simply too large to be comparable to that faced by even the Intermediate firms. Figure 5.17 is a repeat of Figure 5.16 without Ms to reduce the scale issue. We see a similar gap between the two smallest categories and the average tax burden of Is. 


\section{FIGURE 5.15: YEARLY GROSS TAXES PAID}

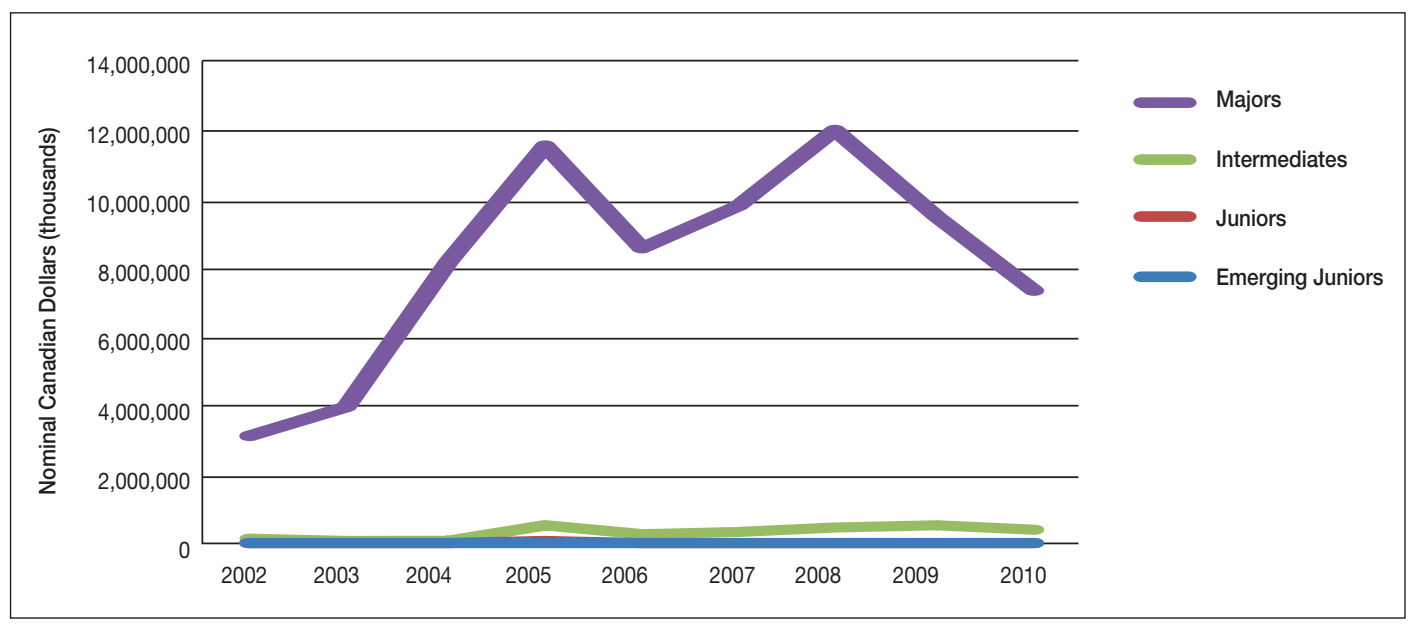

Source: Derived from database assembled by authors using CanOils data

\section{FIGURE 5.16: AVERAGE GROSS TAXES PAID}

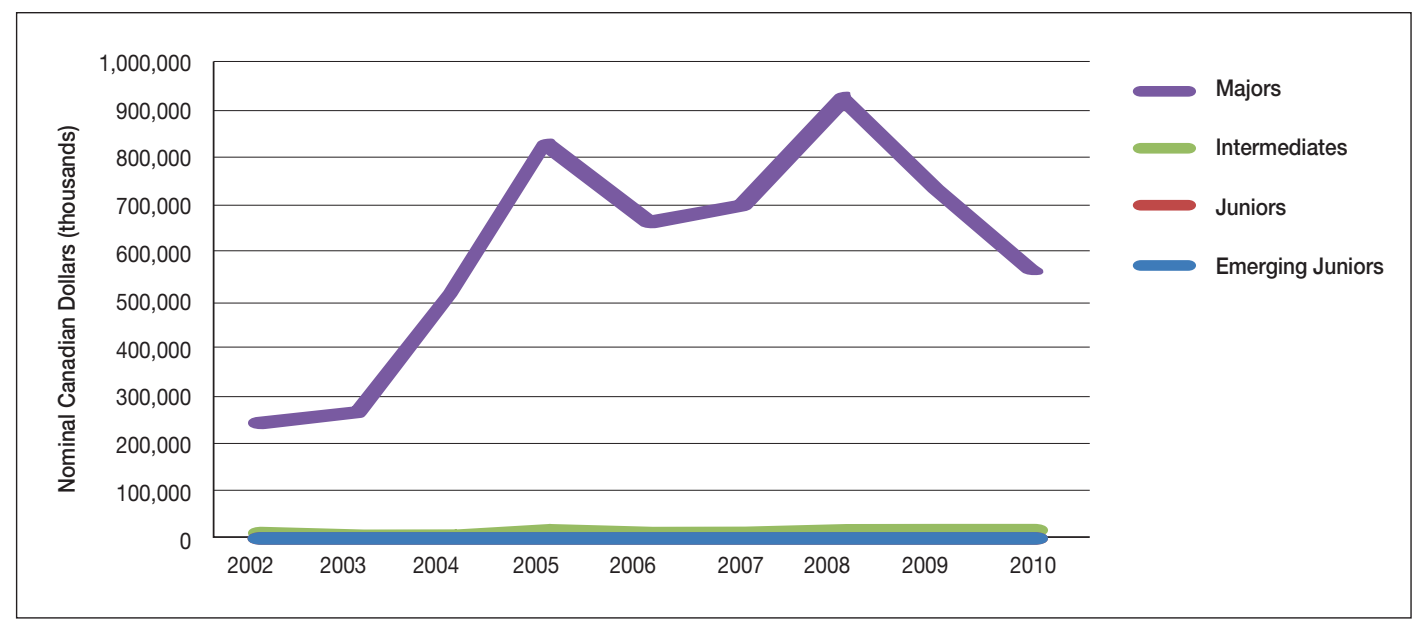

Source: Derived from database assembled by authors using CanOils data

\section{FIGURE 5.17: AVERAGE GROSS TAXES PAID (II)}

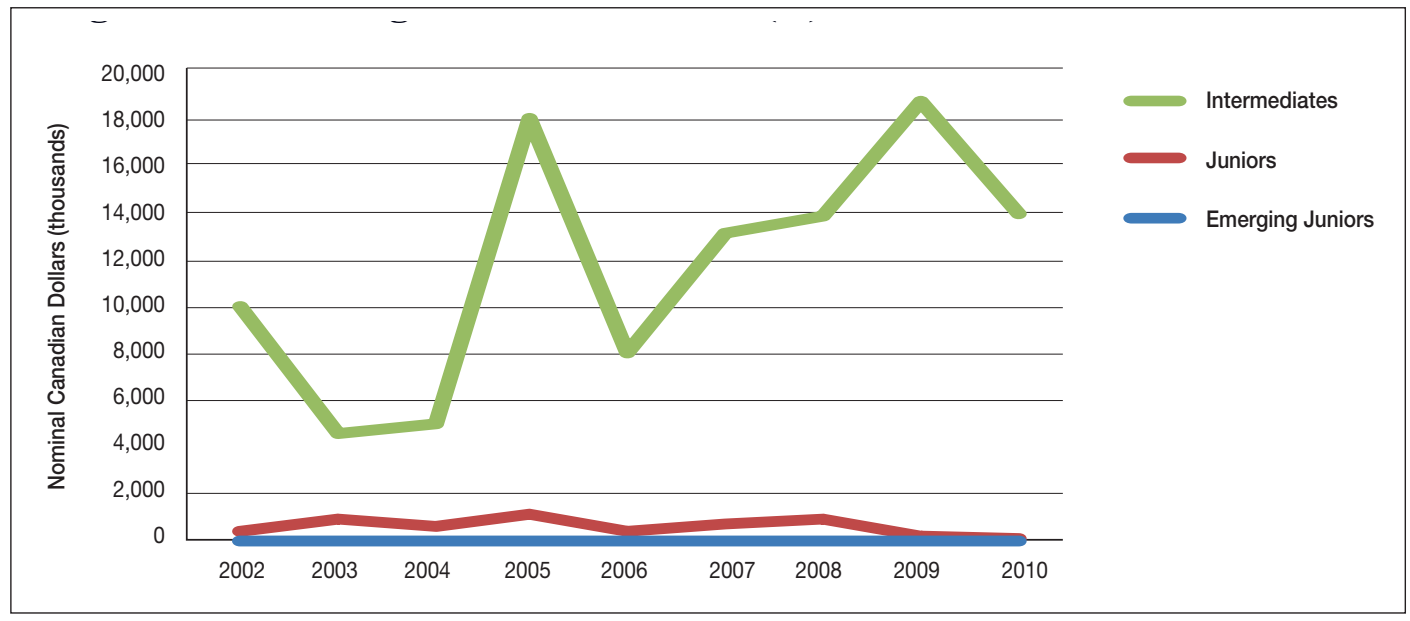

Source: Derived from database assembled by authors using CanOils data 
Figure 5.18 and Figure 5.19 display the calculated average tax rate, computed by dividing the tax paid by before-tax income. The simple average reveals a positive relationship between size and tax rate. Omitting firms with zero tax payments creates much more volatility in the average tax rate faced by EJs. This indicates that there are a considerable number of EJs that either have income close to zero, or pay very little income tax. Of interest is the spike in 2009 among the Ms and Is, with a corresponding decrease in the tax rate faced by Js and EJs.

FIGURE 5.18: CALCULATED AVERAGE TAX RATE

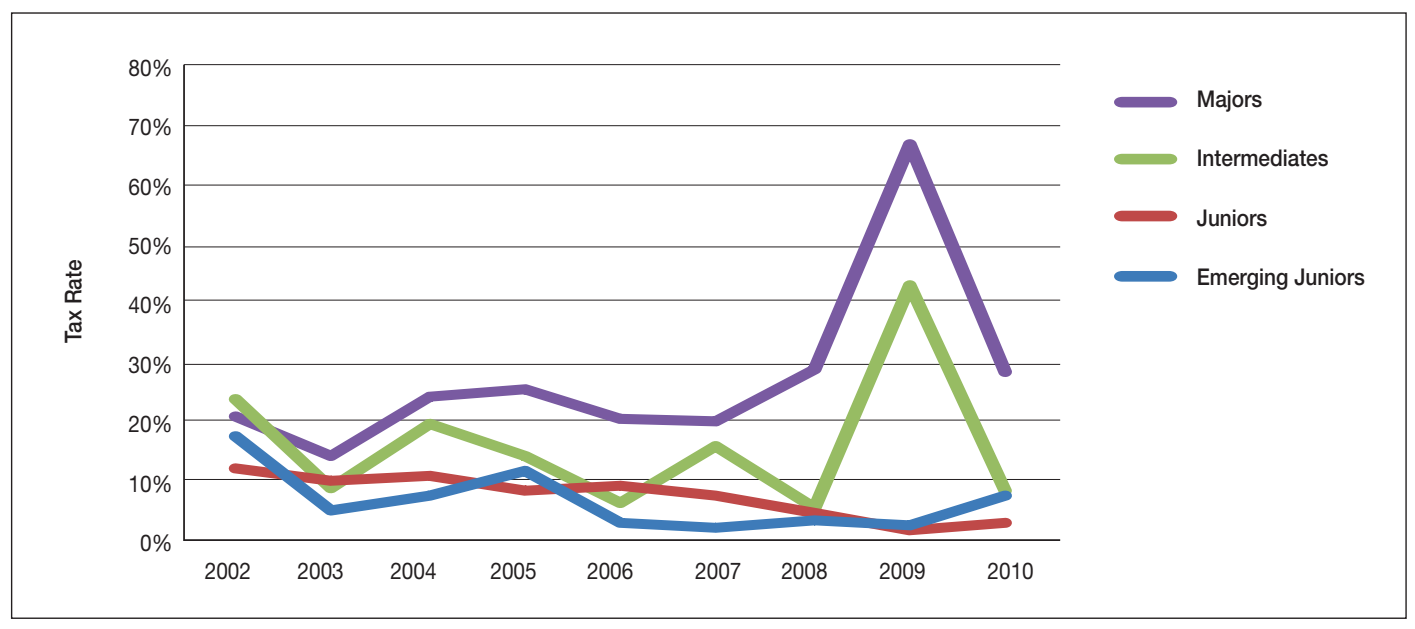

Source: Derived from database assembled by authors using CanOils data

\section{FIGURE 5.19: CALCULATED AVERAGE TAX RATE FOR NON-ZERO TAX PAYMENTS}

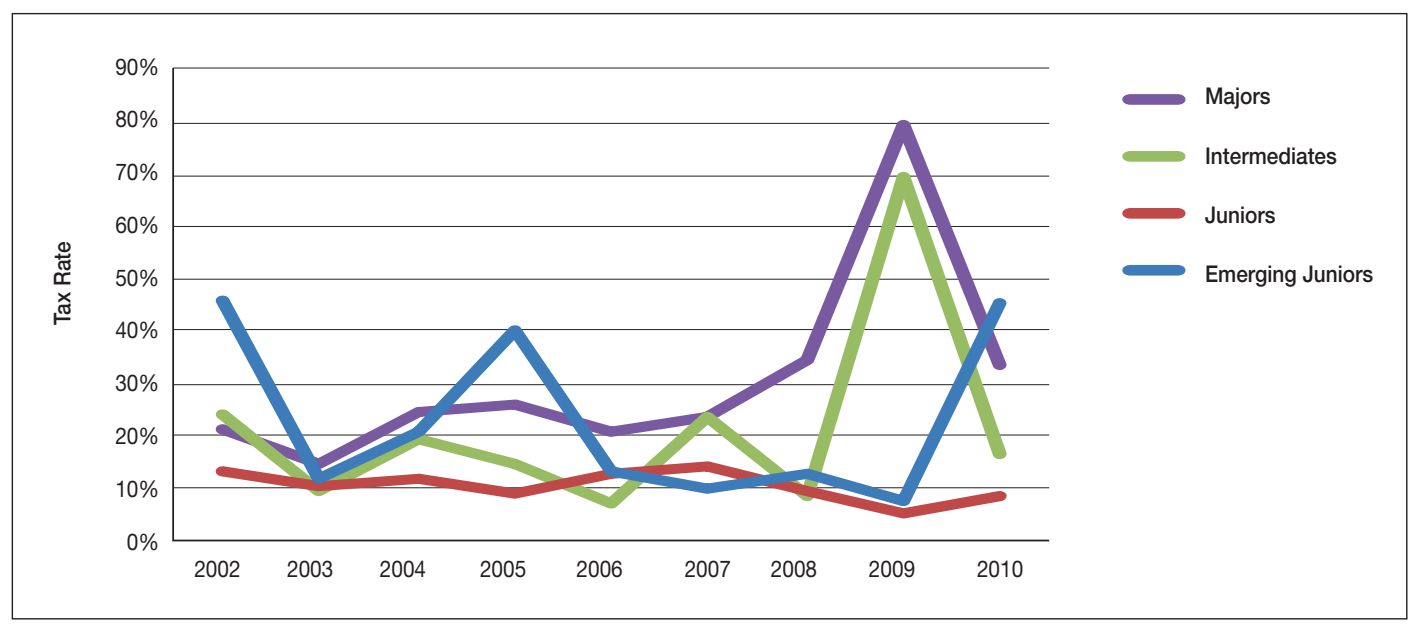

Source: Derived from database assembled by authors using CanOils data 


\subsection{Summary}

In this section we examined the differences across firm size categories in economic and financial performance. The focus was on various measures indicative of how activity is financed, debt levels, earnings, productivity of assets in generating revenues, operating costs, royalties paid and net income. The main conclusions are as follows.

- The Intermediates (Is) tend to be the most highly leveraged over the broad range of economic and market conditions captured over the period 2002-2009. They have the highest debt-to-equity ratios while, as expected, the Emerging Juniors (EJs) have the lowest ratios.

- The pattern for debt-to-capital ratios is similar with the Is at the upper range, the EJs and Juniors (Js) tending to have the lowest ratios and the Majors (Ms) typically having more stable ratios between the upper and lower range.

- Over the period examined, only the Ms have maintained substantial retained earnings relative to total equity. For the Js and Is, this ratio has tended to be close to zero and for the EJs, it is apparent that they were operating with large and growing losses. This would suggest that the key objective for EJs is, on average, to survive long enough to be acquired by larger firms. That is, the expectation appears to be that the capital gain through such acquisitions would exceed the accumulated operating losses.

- The EJs and Js tend to have the lowest ratio of liabilities to assets, reflecting in part the fact that these small firms are typically less reliant on debt for financing than is the case for the larger companies. However, it can be noted that the differences in this ratio among the four size categories are not large.

- There are large differences between small and large firms in the oil and gas sector in the revenue productivity of their assets. On average over the period, the Ms have a total revenue to asset ratio of about 60 percent, compared to 30 percent for Is and Js, and about 20 percent for EJs.

- When gross revenue is calculated on a per-BOE (barrel of oil equivalent) basis, the differences across size categories are surprisingly small - at least until 2006 when the Ms began showing a significant revenue advantage over firms in the smaller size categories.

- Data on operating costs suggests fairly consistent differences across size categories, with the Js and Is having the lowest operating costs per BOE, and EJs and Ms having the highest.

- In terms of total gross royalties paid to the provincial government and average gross royalties paid per firm, the Ms dominate, with the latter about 10 times higher than for the Is, the next largest contributors.

- The average royalties paid net of the Alberta Royalty Tax Credit (eliminated effective January 2007) show some significant differences across size categories for a limited period, but then a tendency toward convergence in recent years.

- In terms of income before and after taxes on a BOE basis, the EJs show large and increasing losses over the period. Only the Ms were able to maintain significant positive earning over the entire period. Since 2005, the earnings performance of the Is and Js has diverged from that of the Ms, with the Js exhibiting negative earnings over this period.

- In general, there is a positive relationship between size and tax burden, with the Ms and Is facing a substantially higher average (income and capital) tax rate. 


\section{CONCLUSION}

The main findings in this study relevant to public policy formation are as follows.

\section{Industry Structure}

- In general, it is frequently argued that small companies should be treated differently (typically preferentially) than large companies in areas such as tax policy, based on notions that it is the many small companies that, on average, have higher growth rates, create more jobs, are more innovative, and eventually become the large, dynamic companies of the future. Most of these arguments originated in the context of manufacturing, but even for that sector the research results do not consistently support the claims. For example, in the case of manufacturing, it is generally found that on a net basis (that is, after taking into account job creation by new small firms and job losses from small firms exiting the sector), small firms generally create fewer jobs than large firms.

- The results for the manufacturing sector are of limited applicability to the oil and gas sector, where there is higher capital and knowledge intensity, much higher values of production, greater market/price and regulatory/policy risks and a requirement of high levels of ongoing investment in order to maintain asset values and production levels.

- Data for a sample of 340 publicly traded oil and gas companies operating over the period 2002 to 2010 is assembled and used to evaluate differences among Emerging Juniors (EJs), Juniors (Js), Intermediates (Is) and Majors (Ms) in terms of relative roles, behaviour and performance. This sample covers approximately 90 percent of the activity of the oil and gas industry over this period.

- The variation in the number of active firms in the sample over the period 2002-2010, the average number of active firms over this period and the average daily production (in barrels of oil equivalent per day (BOE/d), averaged over the period 2002-2010 for each size category is shown below.

\begin{tabular}{|l|r|c|c|}
\hline Size Category & Number & Avg Number & Avg Daily Production \\
\hline EJ & $34-155$ & 107 & 251 \\
J & $28-69$ & 53 & 3,468 \\
I & $15-36$ & 27 & 29,614 \\
M & $13-15$ & 14 & 213,126 \\
\hline
\end{tabular}

- There are large swings over the short run in the number of active EJs, and to a lesser extent in Js and Is. The number of active EJs was from 37 in 2002, reached a high of 155 in 2006 and fell to 34 in 2010. In contrast, the number of active Ms has remained fairly constant, with only an increase from 13 to 15 in the period 2002-2004, and then remaining at 13 over the last half of the sample period.

- Averaged over the sample period, the Ms accounted for 74.6 percent of total Canadian oil and gas production, with the Is contributing 20.3 percent, the Js 4.5 percent and the EJs 0.6 percent. The respective contributions to total drilling over the sample period were: 75 percent, 15 percent, eight percent and two percent. 


\section{Employment}

- In general, the larger oil and gas firms (Ms and Is) dominate as well in terms of total employment. For example, in 2008, firms with more than 100 employees represented only three percent of the total number of firms but accounted for 71 percent of employment in the oil and gas sector.

- The largest firms (with over 500 employees) showed the highest rate of employment growth and accounted for almost 70 percent of the employment increase for the oil and gas sector over the period 2000-2008.

- Growth is also often related to the age of the firm, with newer firms showing the highest growth rates. Large firms have much higher survival rates and exhibit greater stability than small firms, typically pay higher wages and non-wage income and offer greater job satisfaction and job security, but demand more hours of work per week. Changes in tax rates tend to have a greater impact on larger firms than on smaller firms.

- Taken together, these findings would suggest larger firms have a competitive advantage in this sector, and that if the objective is employment or activity creation in this sector, it is unlikely that policies targeting smaller firms would be effective in achieving these objectives.

\section{Changes in Numbers of Firms by Size Category}

- It is variations in production by the Ms (majors) and Is (intermediates) that dominate overall changes in production in most years. Measured in percentage terms, the EJs (Emerging Juniors) and Js (Juniors) showed the greatest volatility and they exhibited declines in production over most of the period.

- There is a strong positive relationship between the number of firms in the oil and gas sector and overall economic conditions. High entry rates and low exit rates existed in the earlier part of the period. After 2006, with the combination of rising costs and a less attractive fiscal environment, entries dropped and exits increased significantly.

- Acquisition by other firms is the dominant strategy for growth and change among the EJs and Js.

- The Ms are the most stable firms over time.

- There are relatively few transitions from Is to Ms; such transitions to the next largest category are most common for EJs, with about one-third of these moving up to the J category over the 2002-2010 period.

- The five-year survival rates for EJs tend to be in the 50-75 percent range, which is higher than for most small businesses. These survival rates for Is and Ms are close to 100 percent. 


\section{Geographical Patterns of Activity}

- One objective in the analysis was to identify differences across firm size in the concentration and dispersion of activity, in propensities for drilling in deep vs. shallow formations, in geographical shifts in activity as conditions change and in costs and success rates. The analysis was based on detailed Alberta drilling and well data for 340 companies in each of the seven PSAC (Petroleum Services Association of Canada) areas for Alberta over the period 2002 to 2008, integrated with the data set outlined earlier.

- Average well depth is much greater in PSAC areas 1 and 2 (the mountain and foothills regions) than in other areas. Costs per well in these two areas are also much higher on average. PSAC regions 3-7 (non-mountain, non-foothills regions) generally support moderate, consistent drilling depths per well.

- The greatest concentrations of EJ (Emerging Junior) and J (Junior) companies occur in areas 3 and 5 (central and south-eastern areas). The Ms (Majors) and Intermediates (Is) tend to dominate in areas 1 and 2. The highest volume of drilling occurs in PSAC area 3 (generally the south and south-eastern corner of the province). The balance of the areas sees fairly consistent rates of drilling over time.

- The average well depth for Ms was lower than that for the other three categories. This average disguises the fact that while the Ms tend to dominate drilling in the deeper formations (such as PSAC areas 1 and 2), they also dominate drilling in the shallower formations to an extent that pulls the average depth down to levels below that for EJs, Js and Is.

- Ms tend to have the lowest average cost per well drilled. Costs over the study period have been generally increasing, faster for smaller firms than larger firms. For the smaller firms, the fact that costs generally exceed those of the Ms might be expected given economies of scale combined with larger and longer-term contracts with drilling companies.

- There is a significant increase in the frequency of horizontal and deviated drilling by firms in all size categories, suggesting the use of advanced drilling technology (also the most expensive) is not limited to the larger firms.

- Drilling activity of firms in all four size categories is fairly widely distributed, with the addition of significant clustering around key plays. The locations of these clusters appear fairly stable over the period analyzed. It would appear that the smaller firms (EJs and Js) tend to follow major investments and commitments of larger firms in areas that are relatively well-characterized and discovered, although with gaps in terms of actual leases secured.

- The Ms and Is have similar average success rates and these tend to be about 10 percentage points above the average success rates for Js and roughly 20 percentage points above average success rates for EJs. However, these differences vary widely across PSAC areas, with both EJs and Js achieving average success rates close to or comparable to those for the Ms and Is in the shallower, more heavily explored areas. 


\section{Economic and Financial Performance}

- An examination of differences across firm size categories in economic and financial performance was based on various measures indicative of how activity is financed, debt levels, earnings, productivity of assets in generating revenues, operating costs, royalties paid and net income.

- The Is tend to be the most highly leveraged over the broad range of economic and market conditions captured over the period 2002-2009. They have the highest debt-to-equity ratios while the EJs have the lowest ratios. The pattern for debt-to-capital ratios is similar with the Is at the upper range, with the EJs and Juniors (Js) tending to have the lowest ratios and the Majors (Ms) typically having more stable ratios between the upper and lower range.

- Over the period examined, only the Ms have maintained substantial retained earnings relative to total equity. For the Js and Is, this ratio has tended to be close to zero and for the EJs it is apparent that they were operating with large and growing losses. This would suggest that the key objective for EJs is, on average, to survive long enough to be acquired by larger firms.

- The EJs and Js tend to have the lowest ratio of liabilities to assets, reflecting in part the fact that these small firms are typically less reliant on debt for financing than is the case for the larger companies. The differences in this ratio among the four size categories are not large.

- There are large differences between small and large firms in the oil and gas sector in the productivity (measured in terms of revenue) of their assets. On average over the period, the Ms have a total revenue to asset ratio of about 60 percent, compared to 30 percent for Is and Js, and about 20 percent for EJs. When gross revenue is calculated on a per BOE (barrel of oil equivalent) basis, the differences across size categories are surprisingly small, at least until 2006 when the Ms began showing a significant revenue advantage over firms in the smaller size categories.

- Data on operating costs suggests fairly consistent differences across size categories, with the Js and Is having the lowest operating costs per BOE, and EJs and Ms having the highest.

- In terms of total gross royalties paid to the provincial government and average gross royalties paid per firm, the Ms dominate, with the latter about 10 times higher than for the Is, the next largest contributors. The average royalties paid net of the Alberta Royalty Tax Credit (eliminated effective January 2007) show some significant differences across size categories for the limited period, but then a tendency toward convergence in recent years.

- In terms of income before and after taxes on a BOE basis, the EJs show large and increasing losses over the period. Only the Ms were able to maintain significant positive earning over the entire period.

- Since 2005, the earnings performance of the Is and Js has diverged from that of the Ms, with the Js exhibiting negative earnings over this period.

- As with royalties, Ms face the largest income and capital tax burden. Moreover, there is a strong positive relationship between size and average tax rate. 


\section{Qualifications}

- The large information base, and its use to evaluate the differences across firm sizes with respect to the role, behaviour and performance, involved considerable effort and it provides a significant factual base. Nevertheless, some deficiencies remain and should be noted. In particular, while a relatively small component of the sector, no information is provided on non-public companies. Further, although care has been used to ensure consistent measurement for the multitude of variables, there remain some unresolved variations particularly in the financial data due to uneven reporting. As well, many of the results are provided in the form of averages and, as with all averages, care in interpretation is required. Finally, it must be recognized that not all decisions involving differential policy treatment based on size is or should be based entirely on measures of roles, behaviour and performance. For example, a commitment to a vibrant market economy and the wide provision of opportunity may call for policies that encourage entry even when the probability of success is low. Clearly, the large number of EJs and Js do represent an important entrepreneurial element of the oil and gas sector, and over the longer term the potential for the formation of new Is and Ms. 


\section{APPENDIX I - LIST OF FIRMS IN SAMPLE}

\begin{tabular}{|c|c|c|c|c|c|c|c|}
\hline & $\begin{array}{l}\text { Entry } \\
\text { Type }\end{array}$ & $\begin{array}{l}\text { Exit } \\
\text { Type }\end{array}$ & $\begin{array}{l}\text { Entry } \\
\text { Year }\end{array}$ & $\begin{array}{l}\text { Last Year } \\
\text { Producing }\end{array}$ & Duration & $\begin{array}{c}\text { Type of } \\
\text { Exit }\end{array}$ & $\begin{array}{c}\text { Type of } \\
\text { Entry }\end{array}$ \\
\hline Abenteuer Resources Corp. & EJ & EJ & 2004 & 2009 & 6 & & START \\
\hline Accrete Energy Inc. & E & $\mathrm{J}$ & 2004 & 2007 & 4 & BOUGHT & ENTER \\
\hline Action Energy Inc. & E & J & 2006 & 2008 & 3 & BANK & TAKEOVER \\
\hline Advantage Oil \& Gas Ltd. & I & I & 2002 & 2009 & 8 & & \\
\hline Alberta Clipper Energy Inc. & EJ & $\mathrm{J}$ & 2005 & 2008 & 4 & BOUGHT & ENTER \\
\hline Alberta Oilsands Inc. & E & EJ & 2004 & & 7 & & ENTER \\
\hline Algonquin Oil \& Gas Limited & E & E & 2004 & & 7 & & START \\
\hline Alpetro Resources Ltd. & EJ & EJ & 2003 & & 8 & & START \\
\hline Alston Ventures Inc. & E & EJ & 2009 & 2009 & 1 & & PROD \\
\hline AltaCanada Energy Corporation & E & EJ & 2002 & 2009 & 8 & BANK & \\
\hline Anadarko Petroleum Corp. & M & M & 2002 & 2006 & 5 & EXIT CAN & \\
\hline Anderson Energy Ltd. & E & J & 2004 & & 7 & & START \\
\hline Angle Energy Inc. & J & J & 2007 & 2009 & 3 & & START \\
\hline Anterra Energy Inc & E & EJ & 2003 & & 8 & & ACQUIRE \\
\hline Apache Corporation & M & M & 2002 & 2009 & 8 & & \\
\hline Arbour Energy Inc. & E & E & 2003 & 2005 & 3 & BANK & PROD \\
\hline ARC Resources Ltd. & I & I & 2002 & 2009 & 8 & & \\
\hline Arcan Resources Ltd & E & J & 2006 & & 5 & & MERGER \\
\hline Argosy Energy Inc. & EJ & EJ & 2008 & & 3 & & ENTER \\
\hline Arsenal Energy Inc. & EJ & J & 2003 & & 8 & & PROD \\
\hline Artek Exploration Ltd. & E & J & 2006 & & 5 & & PROD \\
\hline Aspen Group Resources Corp. & J & E & 2002 & 2008 & 7 & STOP & \\
\hline Athlone Energy Ltd & E & EJ & 2004 & 2007 & 4 & BOUGHT & START \\
\hline Atlas Energy Ltd. & J & J & 2002 & 2005 & 4 & BOUGHT & \\
\hline AvenEx Energy Corp. & E & J & 2003 & & 8 & & TAKEOVER \\
\hline Aztek Energy Ltd. & E & E & 2005 & 2008 & 4 & BOUGHT & ACQUIRE \\
\hline Barnwell Industries Inc. & J & J & 2002 & 2009 & 8 & & \\
\hline Base Oil \& Gas Ltd. & E & E & 2007 & 2009 & 3 & & PROD \\
\hline Baytex Energy Corp. & I & 1 & 2002 & 2009 & 8 & & \\
\hline Bear Ridge Resources Ltd. & E & J & 2005 & 2006 & 2 & BOUGHT & SPUN \\
\hline Bellamont Exploration Ltd. & E & E & 2006 & & 5 & & ENTER \\
\hline Bellatrix Exploration Ltd. & J & J & 2002 & 2009 & 8 & & \\
\hline Bengal Energy Ltd. & EJ & EJ & 2005 & & 6 & & START \\
\hline Berens Energy Ltd. & EJ & J & 2002 & 2008 & 7 & BOUGHT & \\
\hline Berkana Energy Corp & E & EJ & 2002 & 2005 & 4 & BOUGHT & \\
\hline Berkley Resources Inc. & E & E & 2004 & & 7 & & START \\
\hline Birchcliff Energy Ltd. & J & I & 2005 & 2009 & 5 & & TAKEOVER \\
\hline Blackdog Resources Ltd. & E & EJ & 2006 & & 5 & & MERGER \\
\hline BlackPearl Resources Inc. & J & J & 2006 & 2009 & 4 & & PROD \\
\hline Blacksteel Energy Inc. & EJ & EJ & 2009 & 2009 & 1 & & ACQUIRE \\
\hline Blue Mountain Energy Ltd. & J & J & 2003 & 2005 & 3 & BOUGHT & REORG \\
\hline Bonavista Energy Corporation & I & 1 & 2002 & 2009 & 8 & & \\
\hline Bonterra Energy Corp. & J & J & 2002 & 2009 & 8 & & \\
\hline Bow Valley Energy Ltd. & J & J & 2002 & 2007 & 6 & BOUGHT & \\
\hline Breaker Energy Ltd. & E & J & 2004 & 2008 & 5 & BOUGHT & ENTER \\
\hline Brixton Energy Corp. & E & EJ & 2006 & 2008 & 3 & NON & START \\
\hline Bronco Energy Ltd. & E & J & 2006 & 2009 & 4 & & PROD \\
\hline Bucking Horse Energy Inc. & E & J & 2007 & 2009 & 3 & & PROD \\
\hline Buffalo Resources Corp. & E & J & 2003 & 2008 & 6 & BOUGHT & START \\
\hline Bulldog Resources Inc. & EJ & EJ & 2005 & 2006 & 2 & BOUGHT & SPUN \\
\hline Burmis Energy Inc. & E & J & 2003 & 2007 & 5 & BOUGHT & ENTER \\
\hline C1 Energy Ltd. & EJ & EJ & 2004 & 2006 & 3 & BOUGHT & ENTER \\
\hline Cadence Energy Inc. & J & J & 2005 & 2007 & 3 & BOUGHT & ENTER \\
\hline Calvalley Petroleum Inc. & E & J & 2002 & 2006 & 5 & EXIT CAN & \\
\hline Canacol Energy Ltd. & E & E & 2005 & & 6 & & ENTER \\
\hline Canada Energy Partners Inc. & E & EJ & 2008 & & 3 & & PROD \\
\hline
\end{tabular}




\begin{tabular}{|c|c|c|c|c|c|c|c|}
\hline & $\begin{array}{l}\text { Entry } \\
\text { Type }\end{array}$ & $\begin{array}{l}\text { Exit } \\
\text { Type }\end{array}$ & $\begin{array}{l}\text { Entry } \\
\text { Year }\end{array}$ & $\begin{array}{l}\text { Last Year } \\
\text { Producing }\end{array}$ & Duration & $\begin{array}{c}\text { Type of } \\
\text { Exit }\end{array}$ & $\begin{array}{c}\text { Type of } \\
\text { Entry }\end{array}$ \\
\hline Canadian Energy Exploration Inc. & E & E & 2009 & 2009 & 1 & & PROD \\
\hline Canadian Natural Resources Limited & M & M & 2002 & 2009 & 8 & & \\
\hline Canadian Oil Sands Limited & I & M & 2002 & 2009 & 8 & & \\
\hline Canadian Phoenix Resources Corp. & EJ & E & 2004 & & 7 & & MERGER \\
\hline Canetic Resources Trust & I & 1 & 2006 & 2006 & 1 & BOUGHT & MERGER \\
\hline Canext Energy Ltd. & EJ & E & 2006 & & 5 & & ENTER \\
\hline Cannon Oil \& Gas Ltd. & EJ & E & 2002 & 2005 & 4 & BOUGHT & \\
\hline Capitol Energy Resources Ltd. & EJ & J & 2004 & 2006 & 3 & BOUGHT & ENTER \\
\hline Caribou Resources Corp. & E & J & 2003 & 2006 & 4 & BOUGHT & ENTER \\
\hline Castle Rock Petroleum Ltd. & EJ & E & 2005 & 2006 & 2 & BOUGHT & QUAL \\
\hline Celtic Exploration Ltd. & E & 1 & 2002 & & 9 & & \\
\hline Cenovus Energy Inc. & M & M & 2009 & 2009 & 1 & & SPUN \\
\hline Cequence Energy Ltd. & J & J & 2007 & 2009 & 3 & & START \\
\hline CGX Energy Inc. & EJ & EJ & 2002 & 2003 & 2 & EXIT CAN & \\
\hline Challenger Energy Corp. & E & E & 2007 & 2008 & 2 & BOUGHT & PROD \\
\hline Chamaelo Exploration Ltd. & J & J & 2005 & 2005 & 1 & BOUGHT & REORG \\
\hline Cheyenne Energy Incorporated & EJ & E & 2003 & 2006 & 4 & BANK & START \\
\hline Churchill Energy Inc. & EJ & EJ & 2004 & 2008 & 5 & BOUGHT & ENTER \\
\hline Cinch Energy Corp. & EJ & J & 2004 & & 7 & & START \\
\hline Circumpacific Energy Corporation & E & E & 2005 & 2009 & 5 & & START \\
\hline Cobalt Energy Ltd. & EJ & E & 2008 & 2008 & 1 & BOUGHT & PROD \\
\hline Compton Petroleum Corporation & I & I & 2002 & 2009 & 8 & & \\
\hline Connacher Oil and Gas Limited & EJ & J & 2002 & & 9 & & \\
\hline Contact Exploration Inc. & EJ & E & 2003 & & 8 & & START \\
\hline Cordero Energy Inc. & J & J & 2005 & 2007 & 3 & BOUGHT & ENTER \\
\hline Cork Exploration Inc. & EJ & E & 2005 & 2006 & 2 & MERGER & ENTER \\
\hline Corridor Resources Inc. & EJ & J & 2003 & & 8 & & START \\
\hline COSTA Energy Inc. & E & EJ & 2006 & 2008 & 3 & BOUGHT & REORG \\
\hline Crescent Point Energy Corp & J & 1 & 2002 & 2009 & 8 & & \\
\hline Crew Energy Inc. & J & 1 & 2003 & 2009 & 7 & & ENTER \\
\hline Crocotta Energy Inc. & E & J & 2006 & & 5 & & REORG \\
\hline Cruiser Oil \& Gas Ltd. & EJ & E & 2005 & 2007 & 3 & BOUGHT & TAKEOVER \\
\hline Culane Energy Corp. & E & J & 2003 & & 8 & & TAKEOVER \\
\hline Cumberland Oil \& Gas Ltd. & E & E & 2009 & 2009 & 1 & & PROD \\
\hline CYGAM Energy Inc. & EJ & E & 2005 & & 6 & & TAKEOVER \\
\hline Cypress Hills Resource Corp. & EJ & E & 2005 & & 6 & & REORG \\
\hline Cyries Energy Inc. & J & J & 2004 & 2006 & 3 & BOUGHT & ENTER \\
\hline Daylight Energy Ltd. & I & 1 & 2004 & 2009 & 6 & & ENTER \\
\hline DeeThree Exploration Ltd. & EJ & EJ & 2009 & 2009 & 1 & & ACQUIRE \\
\hline Defiant Resources Corporation & E & J & 2004 & 2007 & 4 & BOUGHT & ENTER \\
\hline Dejour Energy Inc. & E & EJ & 2008 & & 3 & & START \\
\hline Delphi Energy Corp. & J & J & 2003 & 2009 & 7 & & TAKEOVER \\
\hline Desmarais Energy Corporation & EJ & E & 2002 & & 9 & & \\
\hline Detector Exploration Ltd. & E & E & 2002 & & 9 & & \\
\hline Devon Energy Corporation & M & M & 2002 & 2009 & 8 & & \\
\hline Diamond Tree Energy Ltd & J & J & 2004 & 2006 & 3 & BOUGHT & START \\
\hline Diaz Resources Ltd. & EJ & E & 2002 & & 9 & & \\
\hline Drake Energy Ltd. & EJ & EJ & 2002 & 2009 & 8 & BANK & \\
\hline Dual Exploration Inc. & E & E & 2005 & 2005 & 1 & BOUGHT & ENTER \\
\hline DualEx Energy International Inc. & EJ & EJ & 2007 & & 4 & & PROD \\
\hline Duvernay Oil Corp. & J & 1 & 2003 & 2007 & 5 & BOUGHT & START \\
\hline E4 Energy Inc. & E & E & 2003 & 2006 & 4 & BOUGHT & START \\
\hline Eastshore Energy Ltd. & E & E & 2003 & 2006 & 4 & BOUGHT & ENTER \\
\hline Elkwater Resources Ltd. & EJ & E & 2003 & & 8 & & ENTER \\
\hline Ember Resources Inc. & EJ & J & 2005 & & 6 & & SPUN \\
\hline Emerald Bay Energy Inc. & E & E & 2002 & & 9 & & \\
\hline Emerge Oil \& Gas Inc. & EJ & J & 2008 & & 3 & & REORG \\
\hline
\end{tabular}




\begin{tabular}{|c|c|c|c|c|c|c|c|}
\hline & $\begin{array}{l}\text { Entry } \\
\text { Type }\end{array}$ & $\begin{array}{l}\text { Exit } \\
\text { Type }\end{array}$ & $\begin{array}{l}\text { Entry } \\
\text { Year }\end{array}$ & $\begin{array}{l}\text { Last Year } \\
\text { Producing }\end{array}$ & Duration & $\begin{array}{c}\text { Type of } \\
\text { Exit }\end{array}$ & $\begin{array}{l}\text { Type of } \\
\text { Entry }\end{array}$ \\
\hline EMM Energy Inc. & EJ & EJ & 2003 & 2009 & 7 & & QUAL \\
\hline EnCana Corporation & M & M & 2003 & 2009 & 7 & & TAKEOVER \\
\hline Endev Energy Inc. & J & J & 2002 & 2007 & 6 & BOUGHT & \\
\hline Enerplus Corporation & 1 & 1 & 2002 & 2009 & 8 & & \\
\hline Equal Energy Ltd. & J & J & 2002 & 2009 & 8 & & \\
\hline Eurogas Corporation & E & E & 2002 & 2004 & 3 & EXIT CAN & \\
\hline EurOmax Resources Ltd. & E & E & 2002 & 2007 & 6 & EXIT CAN & \\
\hline Exall Energy Corporation & E & E & 2006 & & 5 & & ENTER \\
\hline Exall Resources Limited & E & E & 2003 & 2005 & 3 & BOUGHT & START \\
\hline ExAlta Energy Inc. & J & J & 2004 & 2006 & 3 & BOUGHT & START \\
\hline Exceed Energy Inc. & E & E & 2004 & 2008 & 5 & BOUGHT & PROD \\
\hline Excelsior Energy Limited & E & E & 2006 & 2009 & 4 & & TAKEOVER \\
\hline Expedition Energy Inc. & E & E & 2003 & 2006 & 4 & BOUGHT & MERGER \\
\hline Fair Sky Resources Inc. & E & EJ & 2006 & 2006 & 1 & BANK & ACQUIRE \\
\hline Fairborne Energy Ltd. & J & 1 & 2002 & 2009 & 8 & & \\
\hline Fairmount Energy Inc. & E & EJ & 2004 & 2008 & 5 & BOUGHT & ACQUIRE \\
\hline Fairquest Energy Limited & J & $\mathrm{J}$ & 2005 & 2006 & 2 & BOUGHT & ENTER \\
\hline FairWest Energy Corp. & E & E & 2005 & & 6 & & TAKEOVER \\
\hline Falcon Oil \& Gas Ltd. & E & E & 2006 & & 5 & & START \\
\hline Flagship Energy Inc. & $E$ & J & 2005 & 2007 & 3 & MERGER & TAKEOVER \\
\hline Focus Energy Trust & J & 1 & 2002 & 2006 & 5 & BOUGHT & \\
\hline Forent Energy Ltd. & E & E & 2008 & & 3 & & ACQUIRE \\
\hline Forest Oil Corporation & 1 & I & 2002 & 2009 & 8 & & \\
\hline Fortress Energy Inc. & E & J & 2004 & & 7 & & REORG \\
\hline Freehold Royalties Ltd. & J & J & 2002 & 2009 & 8 & & \\
\hline G2 Resources Inc & E & E & 2005 & 2007 & 3 & BOUGHT & ENTER \\
\hline Galleon Energy Inc. & E & I & 2003 & & 8 & & ENTER \\
\hline Gentry Resources Ltd. & J & J & 2002 & 2007 & 6 & BOUGHT & \\
\hline Geocan Energy Inc. & E & J & 2002 & 2007 & 6 & BOUGHT & \\
\hline Grand Banks Energy Corporation & E & J & 2002 & 2007 & 6 & BOUGHT & \\
\hline Grand Petroleum Inc. & E & J & 2003 & 2006 & 4 & BOUGHT & TAKEOVER \\
\hline Great Plains Exploration Inc. & E & J & 2004 & 2009 & 6 & & ENTER \\
\hline Greentree Gas \& Oil Ltd. & E & E & 2002 & 2008 & 7 & BANK & \\
\hline Grey Wolf Exploration Inc. & E & J & 2003 & 2008 & 6 & BOUGHT & ENTER \\
\hline Guardian Exploration Inc. & E & EJ & 2006 & & 5 & & TAKEOVER \\
\hline Harvest Operations Corp. & J & I & 2002 & 2009 & 8 & & \\
\hline Hawk Exploration Ltd. & EJ & EJ & 2009 & 2009 & 1 & & ENTER \\
\hline Hermes Financial Inc. & E & E & 2009 & 2009 & 1 & & QUAL \\
\hline Highpine Oil \& Gas Limited & J & 1 & 2004 & 2008 & 5 & BOUGHT & START \\
\hline Husky Energy Inc. & M & M & 2002 & 2009 & 8 & & \\
\hline Imperial Oil Limited & M & M & 2002 & 2009 & 8 & & \\
\hline Innova Exploration Ltd. & J & J & 2004 & 2006 & 3 & BOUGHT & ENTER \\
\hline Insignia Energy Ltd. & E & J & 2008 & & 3 & & TAKEOVER \\
\hline $\begin{array}{l}\text { International Frontier Resources } \\
\text { Corporation }\end{array}$ & E & EJ & 2004 & & 7 & & PROD \\
\hline International Sovereign Energy Corp. & EJ & EJ & 2002 & & 9 & & \\
\hline Ironhorse Oil \& Gas Inc. & E & J & 2004 & & 7 & & PROD \\
\hline Iteration Energy Ltd. & J & I & 2002 & 2009 & 8 & & \\
\hline Ivory Energy Inc & E & E & 2006 & 2007 & 2 & BOUGHT & TAKEOVER \\
\hline Javelin Energy Inc. & E & E & 2006 & 2007 & 2 & BANK & REORG \\
\hline Kallisto Energy Corp. & E & EJ & 2004 & & 7 & & ACQUIRE \\
\hline Keeper Resources Inc. & E & EJ & 2004 & 2007 & 4 & BOUGHT & PROD \\
\hline Kootenay Energy Inc. & E & EJ & 2005 & 2007 & 3 & BOUGHT & PROD \\
\hline Kulczyk Oil Ventures Inc. & E & E & 2002 & 2007 & 6 & EXIT CAN & \\
\hline Legacy Oil + Gas Inc. & E & J & 2006 & & 5 & & ENTER \\
\hline Long View Resources Corporation & E & E & 2004 & 2006 & 3 & BOUGHT & ACQUIRE \\
\hline Longbow Resources Inc & E & E & 2003 & 2007 & 5 & BOUGHT & START \\
\hline Longford Energy Inc. & E & EJ & 2005 & & 6 & & PROD \\
\hline
\end{tabular}




\begin{tabular}{|c|c|c|c|c|c|c|c|}
\hline & $\begin{array}{l}\text { Entry } \\
\text { Type }\end{array}$ & $\begin{array}{l}\text { Exit } \\
\text { Type }\end{array}$ & $\begin{array}{l}\text { Entry } \\
\text { Year }\end{array}$ & $\begin{array}{l}\text { Last Year } \\
\text { Producing }\end{array}$ & Duration & $\begin{array}{c}\text { Type of } \\
\text { Exit }\end{array}$ & $\begin{array}{c}\text { Type of } \\
\text { Entry }\end{array}$ \\
\hline Madalena Ventures Inc. & E & E & 2006 & 2009 & 4 & & REORG \\
\hline Madison Energy Corp. & E & E & 2004 & 2008 & 5 & NON & REORG \\
\hline Magnum Energy Inc. & E & EJ & 2006 & & 5 & & PROD \\
\hline Magnus Energy Inc. & E & E & 2006 & 2006 & 1 & BOUGHT & START \\
\hline Mahalo Energy Ltd. & E & J & 2005 & 2008 & 4 & BANK & START \\
\hline Masters Energy Inc. & E & J & 2004 & 2008 & 5 & BOUGHT & TAKEOVER \\
\hline McChip Resources Inc. & EJ & EJ & 2008 & 2008 & 1 & NON & START \\
\hline MEG Energy Corp. & $\mathrm{J}$ & J & 2009 & 2009 & 1 & & START \\
\hline Midnight Oil Exploration Ltd. & $\mathrm{J}$ & J & 2005 & 2009 & 5 & & SPUN \\
\hline Midway Energy Ltd. & E & EJ & 2006 & & 5 & & MERGER \\
\hline Milagro Energy Inc. & E & EJ & 2002 & 2007 & 6 & BANK & \\
\hline Mission Oil \& Gas Inc. & J & J & 2005 & 2005 & 1 & BOUGHT & ENTER \\
\hline Monterey Exploration Ltd. & $\mathrm{J}$ & $\mathrm{J}$ & 2007 & 2009 & 3 & & START \\
\hline Mountainview Energy Ltd. & EJ & EJ & 2002 & & 9 & & \\
\hline Murphy Oil Corporation & M & M & 2002 & 2009 & 8 & & \\
\hline Mystique Energy, Inc. & E & E & 2003 & 2007 & 5 & BANK & START \\
\hline NAL Energy Corporation & J & 1 & 2002 & 2009 & 8 & & \\
\hline Netco Energy Inc. & EJ & EJ & 2007 & 2008 & 2 & NON & START \\
\hline Nexen Inc. & M & M & 2002 & 2009 & 8 & & \\
\hline Nexstar Energy Ltd. & E & E & 2006 & 2008 & 3 & BOUGHT & PROD \\
\hline Niko Resources Ltd. & 1 & 1 & 2004 & 2007 & 4 & EXIT CAN & START \\
\hline Nordic Oil and Gas Ltd. & E & E & 2004 & & 7 & & PROD \\
\hline Northern Sun Exploration Company Inc. & E & EJ & 2005 & 2007 & 3 & BANK & START \\
\hline Novus Energy Inc. & EJ & E & 2006 & & 5 & & TAKEOVER \\
\hline NuLoch Resources Inc. & E & E & 2005 & & 6 & & ENTER \\
\hline NuVista Energy Ltd. & J & 1 & 2002 & 2009 & 8 & & ENTER \\
\hline Open Range Energy Corp. & E & J & 2005 & & 6 & & SPUN \\
\hline OPTI Canada Inc. & $\mathrm{J}$ & J & 2008 & 2009 & 2 & & START \\
\hline Orion Oil \& Gas Corporation & J & J & 2009 & 2009 & 1 & & REORG \\
\hline Orleans Energy Ltd. & E & J & 2004 & & 7 & & TAKEOVER \\
\hline Painted Pony Petroleum Ltd. & E & $\mathrm{J}$ & 2007 & 2009 & 3 & & ENTER \\
\hline Palliser Oil \& Gas Corporation & E & EJ & 2008 & & 3 & & START \\
\hline PanTerra Resource Corp. & E & E & 2009 & 2009 & 1 & & START \\
\hline Panwestern Energy Inc. & E & EJ & 2006 & 2009 & 4 & & START \\
\hline Paramount Resources Ltd. & I & 1 & 2002 & 2009 & 8 & & \\
\hline Paris Energy Inc & E & E & 2002 & & 9 & & \\
\hline Patch International Inc. & EJ & EJ & 2003 & 2007 & 5 & BANK & START \\
\hline Peerless Energy Inc. & E & J & 2005 & 2006 & 2 & BOUGHT & ENTER \\
\hline Pegasus Oil \& Gas & E & EJ & 2006 & 2008 & 3 & BOUGHT & TAKEOVER \\
\hline Pengrowth Energy Corporation & 1 & 1 & 2002 & 2009 & 8 & & \\
\hline Penn West Petroleum Ltd. & I & M & 2002 & 2009 & 8 & & \\
\hline Pennant Energy Inc. & EJ & EJ & 2005 & & 6 & & START \\
\hline Perpetual Energy Inc. & 1 & 1 & 2003 & 2009 & 7 & & START \\
\hline Petro Andina Resources Inc. & $\mathrm{J}$ & I & 2007 & 2008 & 2 & BOUGHT & START \\
\hline Petro Uno Resources Ltd. & E & E & 2008 & & 3 & & QUAL \\
\hline PetroBakken Energy Ltd. & 1 & 1 & 2009 & 2009 & 1 & & TAKEOVER \\
\hline Petrobank Energy and Resources Ltd. & J & 1 & 2002 & 2009 & 8 & & \\
\hline Petro-Canada & M & M & 2002 & 2008 & 7 & STOP PROD & \\
\hline Petroflow Energy Ltd. & E & J & 2004 & 2008 & 5 & BANK & START \\
\hline PetroGlobe Inc. & EJ & EJ & 2005 & & 6 & & START \\
\hline Petromin Resources Ltd. & E & E & 2005 & & 6 & & START \\
\hline Petro-Reef Resources Ltd. & E & EJ & 2004 & & 7 & & START \\
\hline Peyto Exploration \& Development Corp. & J & I & 2002 & 2009 & 8 & & \\
\hline Pilot Energy Ltd & E & E & 2004 & 2006 & 3 & BOUGHT & ACQUIRE \\
\hline Pine Cliff Energy Ltd. & E & EJ & 2005 & & 6 & & PROD \\
\hline Pioneer Natural Resources Company & M & M & 2002 & 2007 & 6 & EXIT CAN & \\
\hline Pogo Producing Company & 1 & 1 & 2005 & 2006 & 2 & BOUGHT & START \\
\hline
\end{tabular}




\begin{tabular}{|c|c|c|c|c|c|c|c|}
\hline & $\begin{array}{l}\text { Entry } \\
\text { Type }\end{array}$ & $\begin{array}{l}\text { Exit } \\
\text { Type }\end{array}$ & $\begin{array}{l}\text { Entry } \\
\text { Year }\end{array}$ & $\begin{array}{l}\text { Last Year } \\
\text { Producing }\end{array}$ & Duration & $\begin{array}{c}\text { Type of } \\
\text { Exit }\end{array}$ & $\begin{array}{c}\text { Type of } \\
\text { Entry }\end{array}$ \\
\hline Point North Energy Ltd. & $\mathrm{J}$ & $\mathrm{J}$ & 2002 & 2005 & 4 & BANK & \\
\hline PRD Energy Inc. & E & E & 2006 & 2008 & 3 & NON & REORG \\
\hline Primary Petroleum Corporation & E & EJ & 2006 & & 5 & & PROD \\
\hline PrimeWest Energy Trust & 1 & 1 & 2002 & 2006 & 5 & BOUGHT & \\
\hline ProEx Energy Ltd. & J & I & 2004 & 2008 & 5 & BOUGHT & ENTER \\
\hline Profound Energy Inc. & E & J & 2007 & 2008 & 2 & BOUGHT & TAKEOVER \\
\hline Progress Energy Resources Corp. & J & I & 2002 & 2009 & 8 & & \\
\hline ProspEx Resources Ltd. & $\mathrm{J}$ & J & 2004 & 2009 & 6 & & ENTER \\
\hline Provident Energy Ltd. & 1 & 1 & 2002 & 2009 & 8 & & \\
\hline Questerre Energy Corporation & $E$ & E & 2003 & & 8 & & START \\
\hline Quicksilver Resources Inc & 1 & I & 2004 & 2009 & 6 & & START \\
\hline Radius Resources Corp. & E & EJ & 2006 & 2008 & 3 & BOUGHT & ENTER \\
\hline Raimount Energy Inc & E & E & 2004 & & 7 & & START \\
\hline Real Resources Inc. & J & I & 2002 & 2006 & 5 & BOUGHT & \\
\hline Redcliffe Exploration Inc. & E & E & 2007 & & 4 & & TAKEOVER \\
\hline RedStar Oil \& Gas Inc. & EJ & J & 2005 & 2007 & 3 & BOUGHT & TAKEOVER \\
\hline Reece Energy Exploration Corp. & E & J & 2005 & 2008 & 4 & BOUGHT & QUAL \\
\hline Relentless Resources Ltd. & E & E & 2006 & & 5 & & ACQUIRE \\
\hline Reliable Energy Ltd. & E & EJ & 2008 & & 3 & & ACQUIRE \\
\hline Renegade Petroleum Ltd. & E & E & 2005 & & 6 & & ENTER \\
\hline Result Energy Inc. & E & EJ & 2003 & 2008 & 6 & BOUGHT & START \\
\hline Ria Resources Corp. & E & E & 2003 & & 8 & & TAKEOVER \\
\hline Riata Resources Corp. & EJ & EJ & 2005 & & 6 & & REORG \\
\hline Richards Oil \& Gas Limited & E & E & 2005 & 2008 & 4 & BANK & PROD \\
\hline Rider Resources Ltd. & J & J & 2002 & 2006 & 5 & BOUGHT & \\
\hline Ripper Oil and Gas Inc. & E & EJ & 2002 & & 9 & & \\
\hline Rival Energy Ltd. & E & E & 2002 & 2006 & 5 & BOUGHT & \\
\hline Rock Energy Inc. & EJ & J & 2004 & & 7 & & TAKEOVER \\
\hline Rockbridge Resources Inc. & $E$ & E & 2008 & & 3 & & PROD \\
\hline Rockyview Energy Inc. & J & J & 2005 & 2006 & 2 & BOUGHT & ENTER \\
\hline Rolling Thunder Exploration Ltd & E & E & 2005 & 2006 & 2 & BOUGHT & ENTER \\
\hline Rosetta Exploration Inc. & E & E & 2002 & 2005 & 4 & BOUGHT & \\
\hline RSX Energy Inc. & E & E & 2003 & 2006 & 4 & BOUGHT & START \\
\hline $\begin{array}{l}\text { Sagres Energy Inc. } \\
\text { (pre reverse-takeover) }\end{array}$ & E & E & 2003 & 2009 & 7 & & START \\
\hline Sahara Energy Ltd. & E & E & 2006 & & 5 & & ACQUIRE \\
\hline Sawtooth International Resources Inc. & E & E & 2003 & 2004 & 2 & BOUGHT & START \\
\hline Seaview Energy Inc. & E & J & 2007 & & 4 & & ENTER \\
\hline Second Wave Petroleum Inc. & E & EJ & 2005 & & 6 & & PROD \\
\hline Sharon Energy Ltd. & E & E & 2002 & & 9 & & \\
\hline Shell Canada Limited & M & M & 2002 & 2006 & 5 & BOUGHT & \\
\hline Shiningbank Energy Income Fund & 1 & I & 2002 & 2006 & 5 & BOUGHT & \\
\hline Silverwing Energy Ltd. & E & EJ & 2004 & 2007 & 4 & BOUGHT & PROD \\
\hline Solara Exploration Ltd. & E & E & 2005 & & 6 & & START \\
\hline Sonde Resources Corp. & E & J & 2002 & & 9 & & \\
\hline Sound Energy Trust & $\mathrm{J}$ & $\mathrm{J}$ & 2002 & 2006 & 5 & BOUGHT & \\
\hline Southern Pacific Resource Corp. & E & E & 2009 & 2009 & 1 & & START \\
\hline Spartan Exploration Ltd. & EJ & EJ & 2009 & 2009 & 1 & & START \\
\hline Spry Energy Ltd. (private) & E & J & 2004 & & 7 & & REORG \\
\hline StarPoint Energy Trust & J & J & 2003 & 2004 & 2 & BOUGHT & ENTER \\
\hline Stealth Ventures Ltd. & E & E & 2004 & & 7 & & START \\
\hline Steen River Oil \& Gas Ltd. & $E$ & E & 2004 & 2007 & 4 & BANK & ACQUIRE \\
\hline Stetson Oil \& Gas Ltd & EJ & EJ & 2004 & & 7 & & MERGER \\
\hline Stonefire Energy Corp. & E & EJ & 2006 & 2008 & 3 & BOUGHT & PROD \\
\hline Storm Exploration Inc. & J & J & 2004 & 2009 & 6 & & SPUN \\
\hline Strategic Oil \& Gas Ltd. & E & E & 2006 & & 5 & & TAKEOVER \\
\hline Strike Petroleum Ltd. & E & E & 2005 & 2006 & 2 & BOUGHT & ACQUIRE \\
\hline Stylus Energy Inc. & E & $\mathrm{J}$ & 2003 & 2006 & 4 & BOUGHT & START \\
\hline
\end{tabular}




\begin{tabular}{|c|c|c|c|c|c|c|c|}
\hline & $\begin{array}{l}\text { Entry } \\
\text { Type }\end{array}$ & $\begin{array}{l}\text { Exit } \\
\text { Type }\end{array}$ & $\begin{array}{l}\text { Entry } \\
\text { Year }\end{array}$ & $\begin{array}{l}\text { Last Year } \\
\text { Producing }\end{array}$ & Duration & $\begin{array}{c}\text { Type of } \\
\text { Exit }\end{array}$ & $\begin{array}{l}\text { Type of } \\
\text { Entry }\end{array}$ \\
\hline Suncor Energy Inc. & M & M & 2002 & 2009 & 8 & & \\
\hline Sure Energy Inc & E & E & 2006 & & 5 & & SPUN \\
\hline Surge Energy Inc. & J & J & 2002 & 2009 & 8 & & \\
\hline Suroco Energy Inc. & E & E & 2005 & & 6 & & ENTER \\
\hline Talisman Energy Inc. & M & M & 2002 & 2009 & 8 & & \\
\hline Tamarack Valley Energy Ltd. & EJ & EJ & 2003 & & 8 & & PROD \\
\hline Terra Energy Corp. & J & J & 2004 & 2009 & 6 & & MERGER \\
\hline Texalta Petroleum Ltd. & E & EJ & 2003 & & 8 & & START \\
\hline TG World Energy Corp. & E & EJ & 2002 & 2002 & 1 & NON & \\
\hline The Buffalo Oil Corporation & EJ & J & 2004 & 2006 & 3 & BOUGHT & TAKEOVER \\
\hline Thunder Energy Trust & J & J & 2002 & 2006 & 5 & BOUGHT & \\
\hline Titan Exploration Ltd. & EJ & J & 2004 & 2006 & 3 & BOUGHT & ENTER \\
\hline Tiverton Petroleums Ltd. & E & EJ & 2002 & 2004 & 3 & BOUGHT & \\
\hline TKE Energy Trust & J & J & 2002 & 2004 & 3 & MERGER & \\
\hline Torque Energy Inc. & EJ & EJ & 2004 & & 7 & & START \\
\hline TRAFINA Energy Ltd. & EJ & EJ & 2002 & & 9 & & \\
\hline TransGlobe Energy Corporation & J & J & 2002 & 2008 & 7 & EXIT CAN & \\
\hline Traverse Energy Ltd. & EJ & EJ & 2002 & & 9 & & \\
\hline Trilogy Energy Corp. & I & I & 2005 & 2009 & 5 & & SPUN \\
\hline Trimox Energy Inc. & E & E & 2005 & 2006 & 2 & BOUGHT & ENTER \\
\hline TriOil Resources Ltd. & EJ & EJ & 2006 & & 5 & & REORG \\
\hline TriStar Oil \& Gas Ltd. & J & I & 2006 & 2008 & 3 & BOUGHT & ENTER \\
\hline Tuscany Energy Ltd. & E & EJ & 2005 & & 6 & & START \\
\hline TUSK Energy Corporation & EJ & J & 2004 & 2008 & 5 & BOUGHT & ENTER \\
\hline Twin Butte Energy Ltd. & E & J & 2006 & & 5 & & START \\
\hline Twoco Petroleums Ltd. & EJ & J & 2004 & & 7 & & START \\
\hline Upper Lake Oil and Gas Ltd. & E & EJ & 2007 & 2007 & 1 & BOUGHT & ENTER \\
\hline Valparaiso Energy Inc. & EJ & E & 2002 & & 9 & & \\
\hline Vangold Resources Ltd. & EJ & EJ & 2005 & 2007 & 3 & NON & START \\
\hline Vast Exploration Inc. & E & EJ & 2005 & & 6 & & REORG \\
\hline Vault Energy Trust & E & J & 2004 & 2006 & 3 & BOUGHT & ENTER \\
\hline Vecta Energy Corporation & EJ & EJ & 2002 & & 9 & & \\
\hline Vermilion Energy Inc. & 1 & I & 2002 & 2009 & 8 & & \\
\hline Vero Energy Inc. & E & J & 2005 & & 6 & & ENTER \\
\hline Veteran Resources Inc. & E & EJ & 2002 & 2004 & 3 & BOUGHT & \\
\hline Vision 2000 Exploration Ltd. & E & EJ & 2002 & 2007 & 6 & BOUGHT & \\
\hline Waldron Energy Corporation & EJ & EJ & 2006 & & 5 & & START \\
\hline Welton Energy Corporation & EJ & E & 2003 & 2007 & 5 & BOUGHT & MERGER \\
\hline West Energy Ltd. & J & J & 2004 & 2009 & 6 & & TAKEOVER \\
\hline West Isle Energy Inc. & EJ & EJ & 2002 & & 9 & & \\
\hline Westbow Energy Inc. & EJ & EJ & 2003 & 2007 & 5 & BOUGHT & PROD \\
\hline Westchester Resources Inc. & E & EJ & 2005 & 2005 & 1 & NON & START \\
\hline Western Canada Energy Ltd. & EJ & E & 2003 & 2008 & 6 & BANK & START \\
\hline Western Oil Sands Inc. & I & 1 & 2003 & 2006 & 4 & BOUGHT & START \\
\hline Western Plains Petroleum Ltd. & E & EJ & 2008 & & 3 & & ACQUIRE \\
\hline WestFire Energy Ltd. & E & J & 2007 & & 4 & & ENTER \\
\hline $\begin{array}{l}\text { Whitecap Resources Inc. } \\
\text { (Pre-reverse takeover) }\end{array}$ & EJ & EJ & 2005 & & 6 & & START \\
\hline Wild Stream Exploration Inc. & E & E & 2006 & & 5 & & ACQUIRE \\
\hline Winslow Resources Inc. & E & EJ & 2005 & 2006 & 2 & BOUGHT & START \\
\hline Winstar Resources Ltd. & EJ & J & 2005 & & 6 & & START \\
\hline Wrangler West Energy Corp. & EJ & J & 2003 & & 8 & & ACQUIRE \\
\hline XXL Energy Corp & EJ & EJ & 2003 & 2008 & 6 & EXIT CAN & START \\
\hline Yangarra Resources Ltd. & E & EJ & 2004 & & 7 & & REORG \\
\hline Yoho Resources Inc. & E & J & 2005 & & 6 & & TAKEOVER \\
\hline Zargon Oil \& Gas Ltd. & J & J & 2002 & 2009 & 8 & & \\
\hline Zenas Energy Corp. & EJ & EJ & 2005 & 2005 & 1 & BOUGHT & ENTER \\
\hline
\end{tabular}


APPENDIX II - AGGREGATE DRILLING LOCATIONS

BY PSAC AREA AND FIRM SIZE, 2002 TO 2008*

YEAR 2002

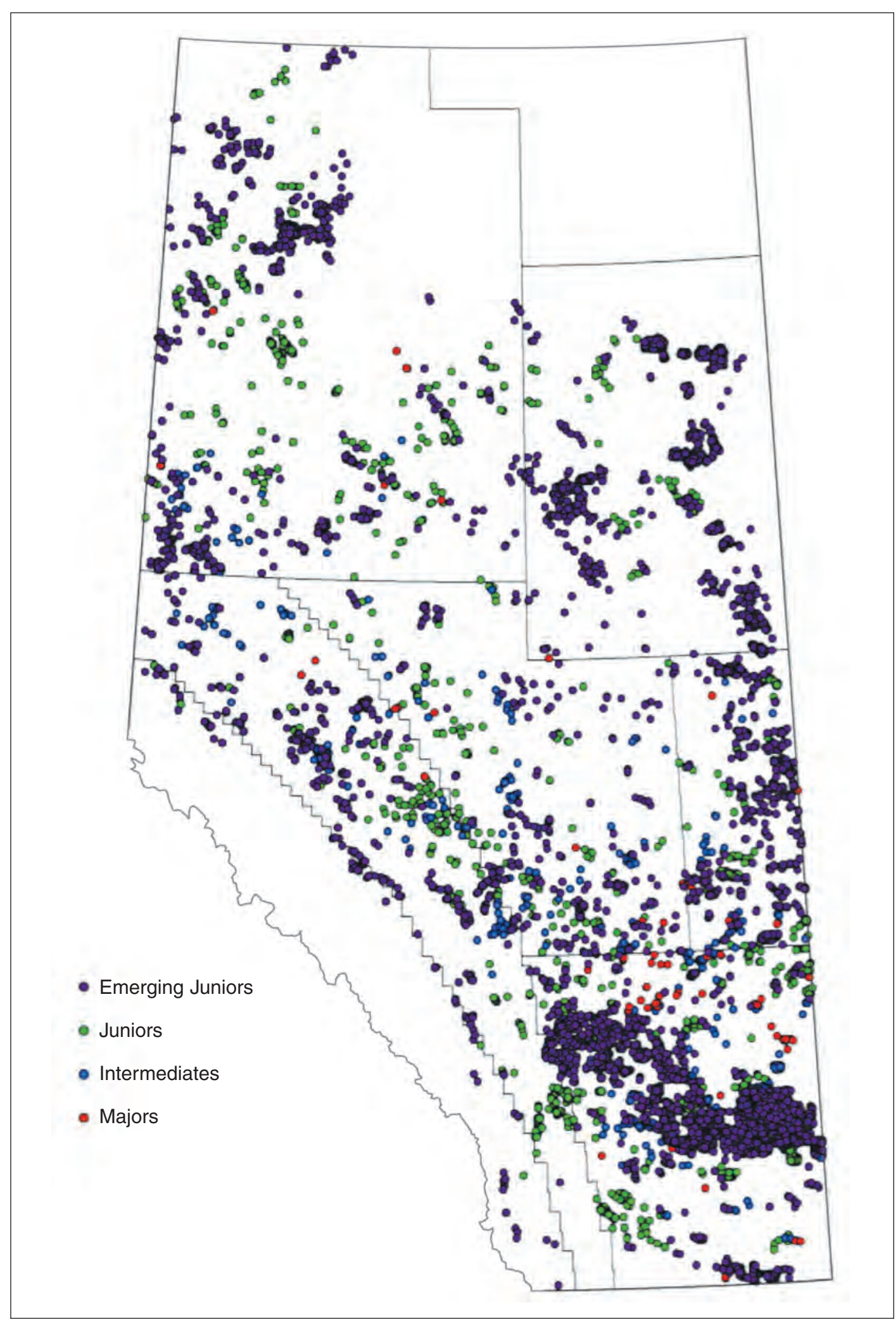

* See Figures 4.8 and 4.9 in text for years 2003 and 2007 
YEAR 2004

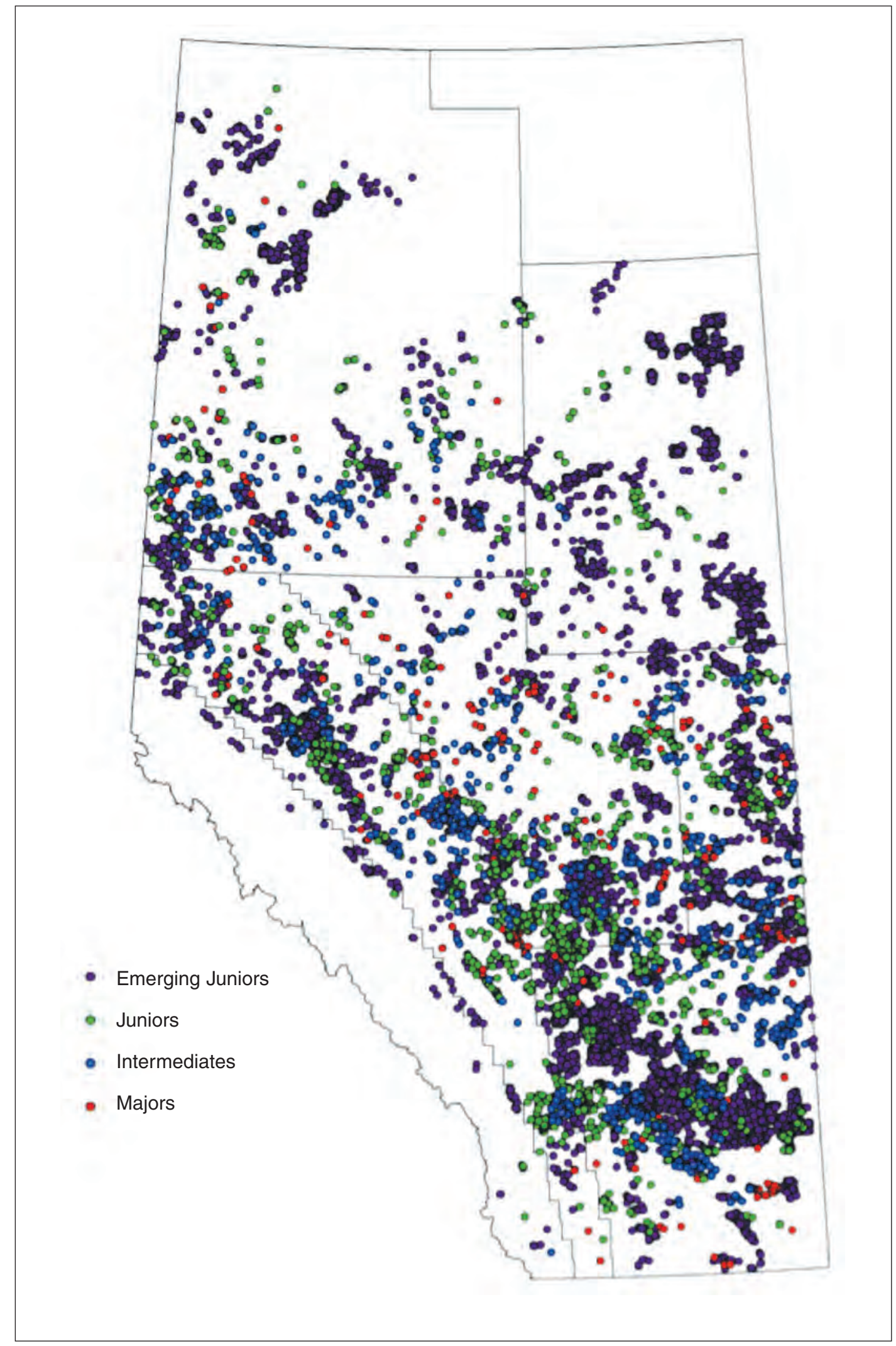


YEAR 2005

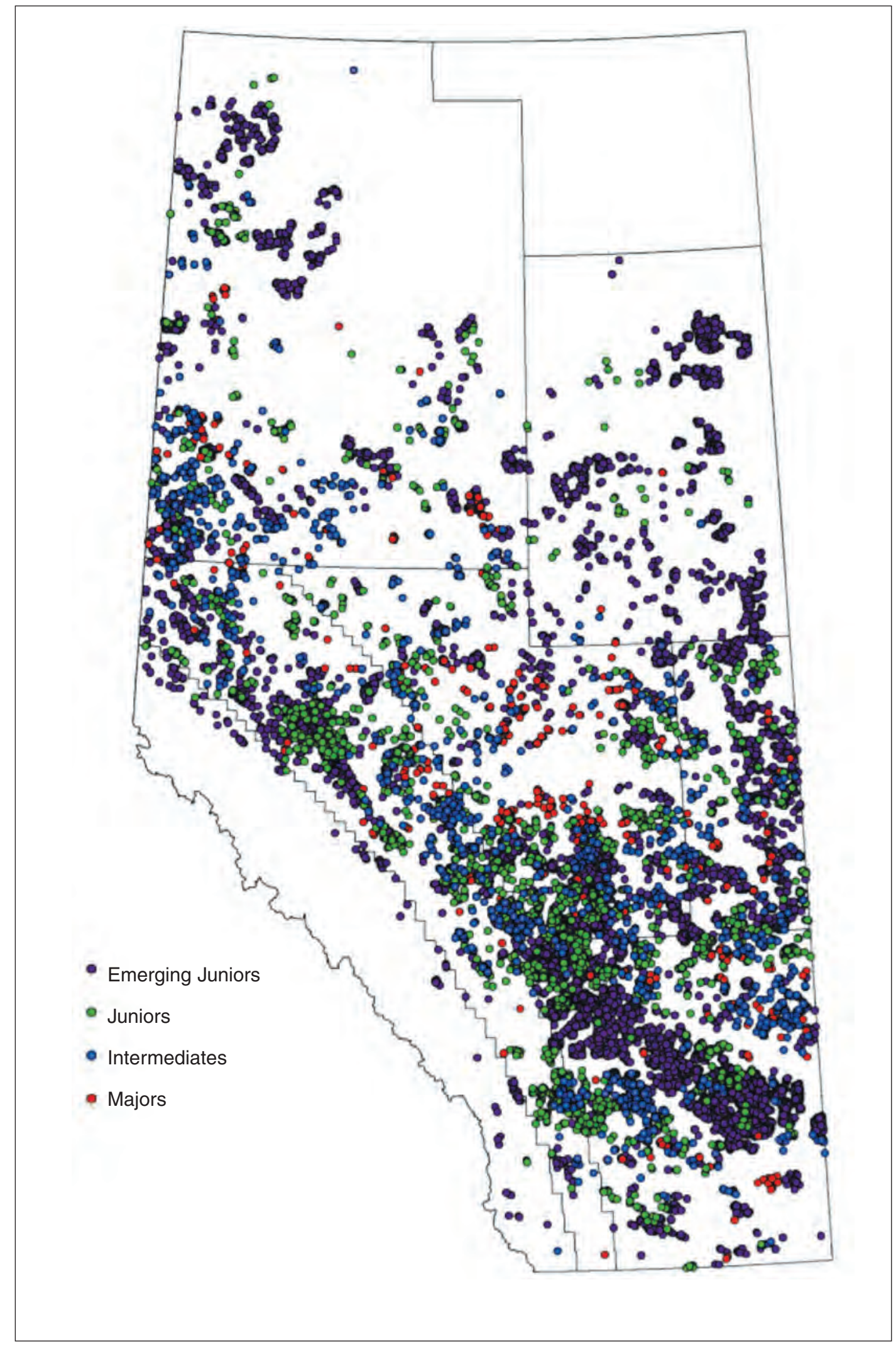


YEAR 2006

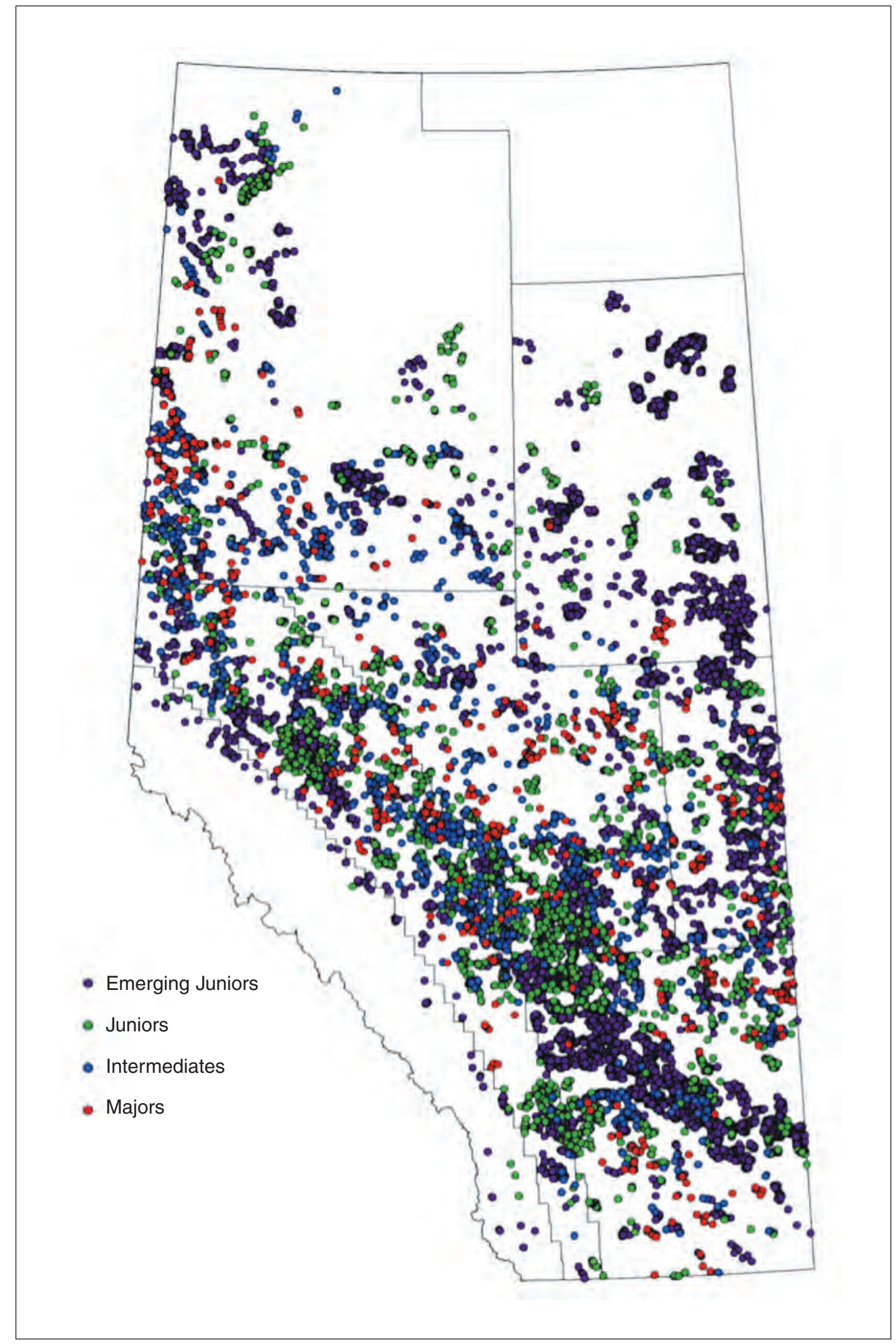




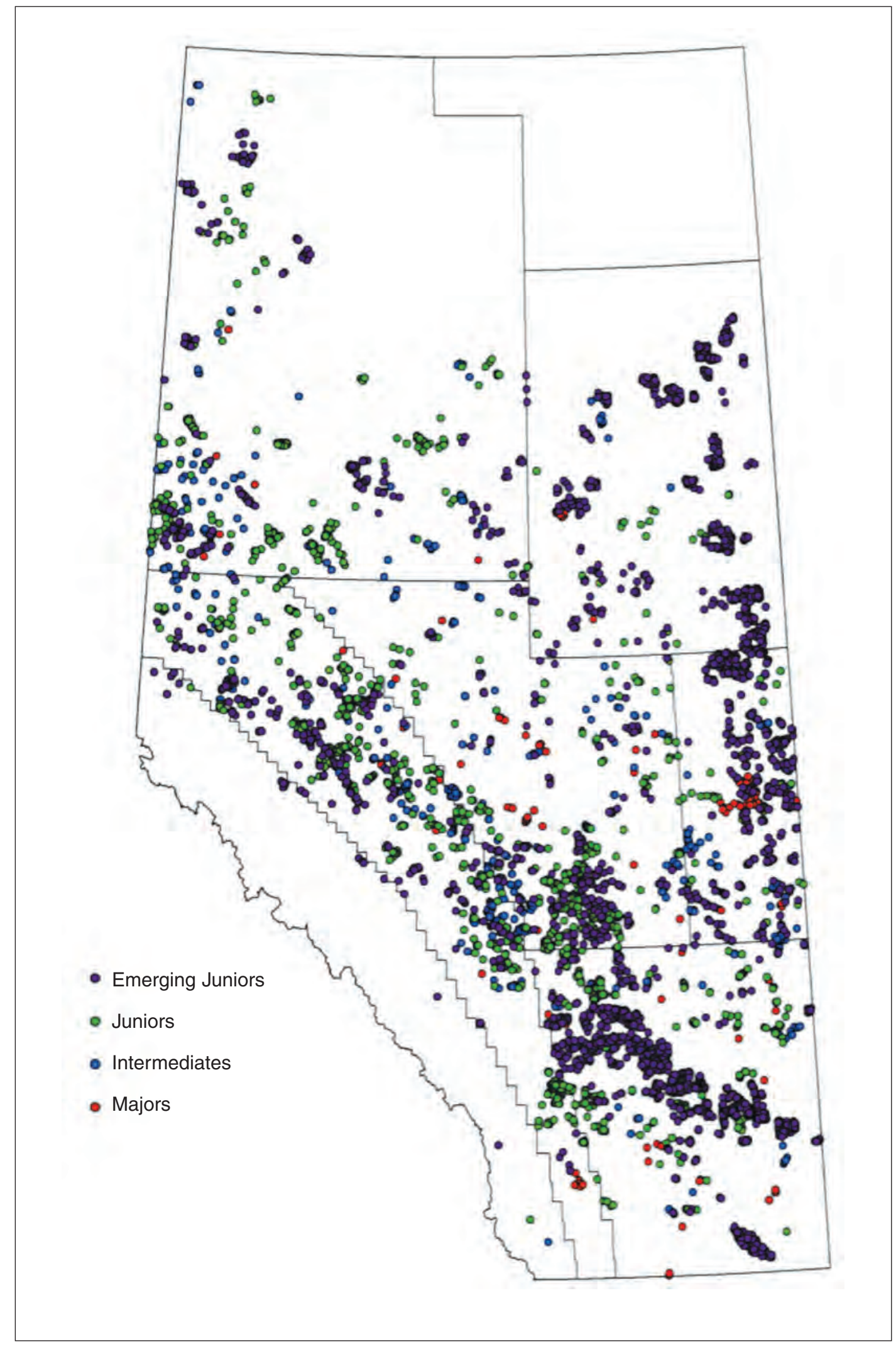




\section{APPENDIX III - TRANSITIONS AND FIRM SURVIVAL RATES}

EMERGING JUNIOR TRANSITION AND SURVIVAL

\begin{tabular}{|l|r|r|r|r|r|r|r|}
\hline & $\mathbf{2 0 0 2}$ & $\mathbf{2 0 0 3}$ & $\mathbf{2 0 0 4}$ & $\mathbf{2 0 0 5}$ & $\mathbf{2 0 0 6}$ & $\mathbf{2 0 0 7}$ & $\mathbf{2 0 0 8}$ \\
\hline Base & 37 & 71 & 108 & 136 & 156 & 135 & 118 \\
Continue & 33 & 62 & 86 & 115 & 120 & 103 & 89 \\
New & 38 & 44 & 49 & 38 & 11 & 13 & 10 \\
Enter Down & 0 & 0 & 1 & 2 & 2 & 1 & 3 \\
Exit Up & 2 & 7 & 18 & 11 & 16 & 10 & 7 \\
Exit Out & 2 & 1 & 4 & 9 & 18 & 21 & 22 \\
Total & $\mathbf{7 1}$ & $\mathbf{1 0 8}$ & $\mathbf{1 3 6}$ & $\mathbf{1 5 6}$ & $\mathbf{1 3 5}$ & $\mathbf{1 1 8}$ & $\mathbf{1 0 2}$ \\
\hline
\end{tabular}

JUNIOR TRANSITION AND SURVIVAL

\begin{tabular}{|l|r|r|r|r|r|r|r|}
\hline & $\mathbf{2 0 0 2}$ & $\mathbf{2 0 0 3}$ & $\mathbf{2 0 0 4}$ & $\mathbf{2 0 0 5}$ & $\mathbf{2 0 0 6}$ & $\mathbf{2 0 0 7}$ & $\mathbf{2 0 0 8}$ \\
\hline Base & 28 & 32 & 49 & 68 & 69 & 67 & 58 \\
Continue & 24 & 31 & 42 & 56 & 47 & 47 & 42 \\
New & 6 & 11 & 8 & 2 & 4 & 1 & 2 \\
Enter Down & 0 & 0 & 0 & 0 & 0 & 0 & 2 \\
Enter Up & 2 & 7 & 18 & 11 & 16 & 10 & 7 \\
Exit Up & 3 & 1 & 4 & 5 & 2 & 7 & 0 \\
Exit Down & 0 & 0 & 1 & 2 & 2 & 1 & 3 \\
Exit Out & 1 & 0 & 2 & 5 & 18 & 12 & 13 \\
Total & $\mathbf{3 2}$ & $\mathbf{4 9}$ & $\mathbf{6 8}$ & $\mathbf{6 9}$ & $\mathbf{6 7}$ & $\mathbf{5 8}$ & $\mathbf{5 3}$ \\
\hline
\end{tabular}

INTERMEDIATE TRANSITION AND SURVIVAL

\begin{tabular}{|l|r|r|r|r|r|r|r|}
\hline & $\mathbf{2 0 0 2}$ & $\mathbf{2 0 0 3}$ & $\mathbf{2 0 0 4}$ & $\mathbf{2 0 0 5}$ & $\mathbf{2 0 0 6}$ & $\mathbf{2 0 0 7}$ & $\mathbf{2 0 0 8}$ \\
\hline Base & 15 & 19 & 23 & 30 & 36 & 29 & 34 \\
Continue & 14 & 19 & 23 & 29 & 27 & 27 & 28 \\
New & 2 & 3 & 2 & 1 & 0 & 0 & 1 \\
Enter Down & 0 & 0 & 1 & 1 & 0 & 0 & 0 \\
Enter Up & 3 & 1 & 4 & 5 & 2 & 7 & 0 \\
Exit Up & 1 & 0 & 0 & 1 & 2 & 0 & 0 \\
Exit Down & 0 & 0 & 0 & 0 & 0 & 0 & 2 \\
Exit Out & 0 & 0 & 0 & 0 & 7 & 2 & 4 \\
Total & $\mathbf{1 9}$ & $\mathbf{2 3}$ & $\mathbf{3 0}$ & $\mathbf{3 6}$ & $\mathbf{2 9}$ & $\mathbf{3 4}$ & $\mathbf{2 9}$ \\
\hline
\end{tabular}

MAJOR TRANSITION AND SURVIVAL

\begin{tabular}{|l|r|r|r|r|r|r|r|}
\hline & $\mathbf{2 0 0 2}$ & $\mathbf{2 0 0 3}$ & $\mathbf{2 0 0 4}$ & $\mathbf{2 0 0 5}$ & $\mathbf{2 0 0 6}$ & $\mathbf{2 0 0 7}$ & $\mathbf{2 0 0 8}$ \\
\hline Base & 13 & 15 & 15 & 14 & 13 & 14 & 13 \\
Continue & 13 & 15 & 14 & 12 & 12 & 13 & 12 \\
New & 1 & 0 & 0 & 0 & 0 & 0 & 1 \\
Enter Up & 1 & 0 & 0 & 1 & 2 & 0 & 0 \\
Exit Down & 0 & 0 & 1 & 1 & 0 & 0 & 0 \\
Exit Out & 0 & 0 & 0 & 1 & 1 & 1 & 1 \\
Total & $\mathbf{1 5}$ & $\mathbf{1 5}$ & $\mathbf{1 4}$ & $\mathbf{1 3}$ & $\mathbf{1 4}$ & $\mathbf{1 3}$ & $\mathbf{1 3}$ \\
\hline
\end{tabular}




\section{APPENDIX IV - PERCENTAGES OF DRILLING ACTIVITY BY FIRM SIZE CATEGORY AND PSAC AREA}

Activity by Firm Type in PSAC 1 as $\%$ of Yearly Total Wells in PSAC 1

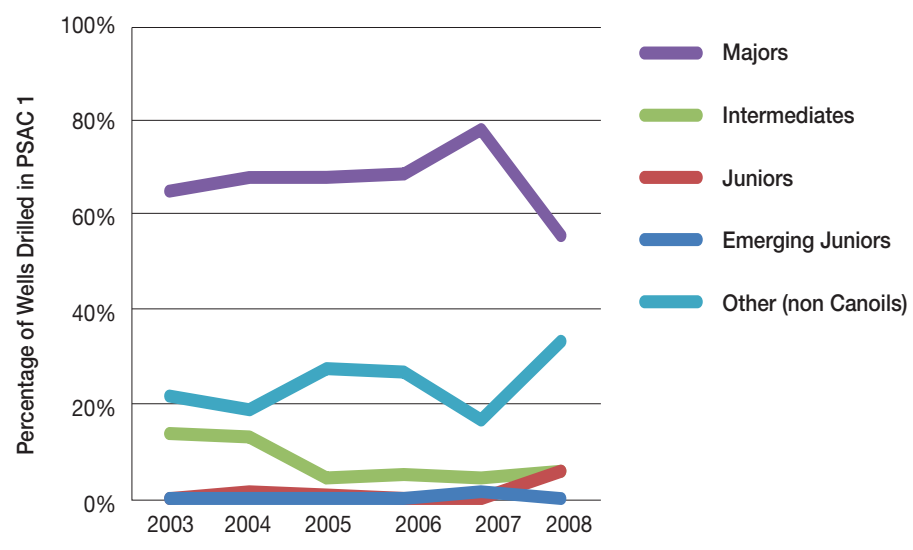

Activity by Firm Type in PSAC 2 as \% of Yearly Total Wells in PSAC 2

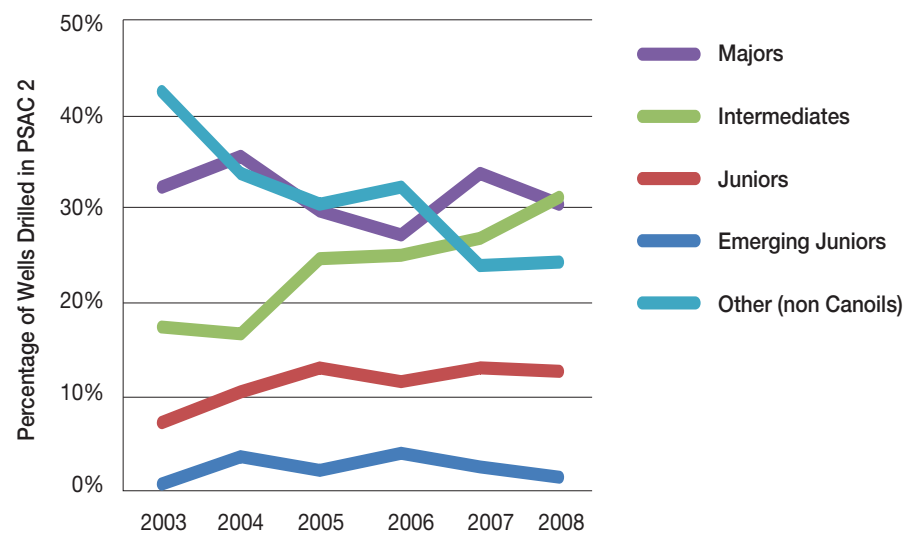


Activity by Firm Type in PSAC 3 as \% of Yearly Total Wells in PSAC 3

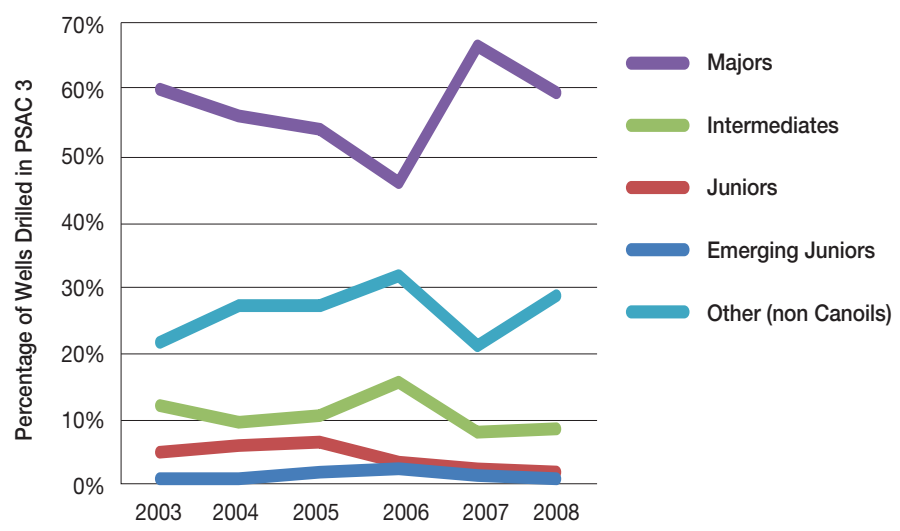

Activity by Firm Type in PSAC 4 as \% of Yearly Total Wells in PSAC 4

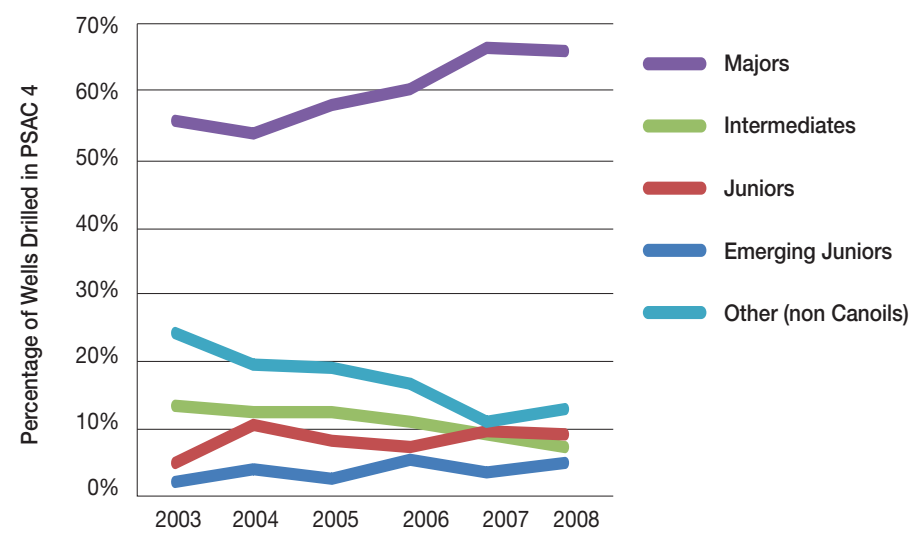

Activity by Firm Type in PSAC 5 as $\%$ of Yearly Total Wells in PSAC 5

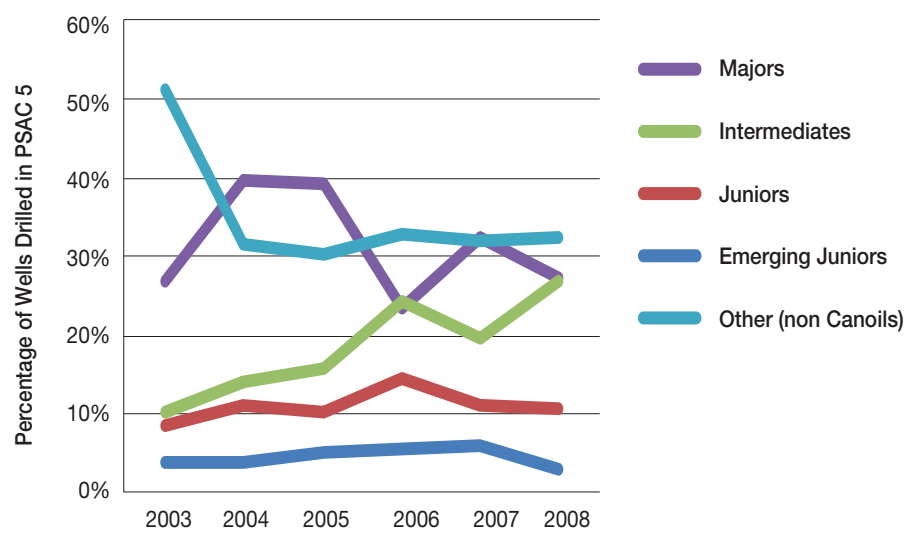


Activity by Firm Type in PSAC 6 as $\%$ of Yearly Total Wells in PSAC 6

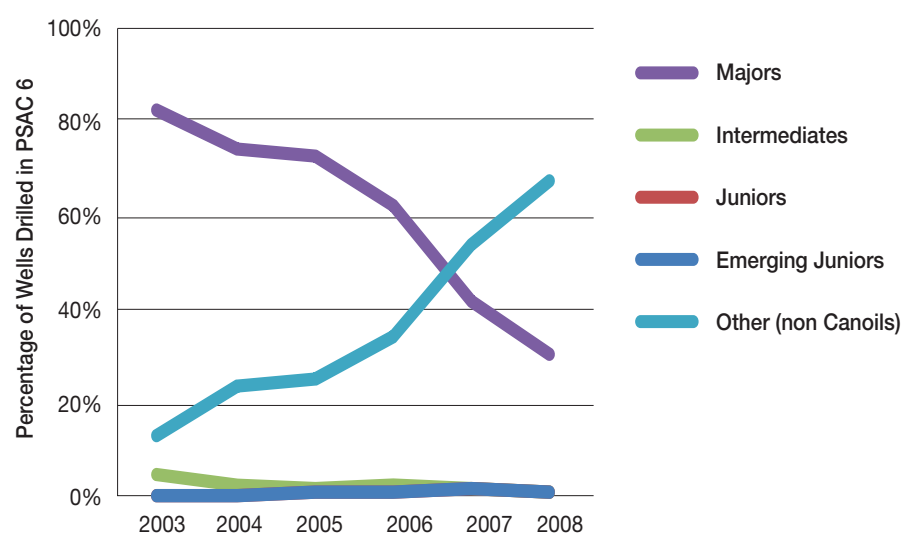

Activity by Firm Type in PSAC 7 as $\%$ of Yearly Total Wells in PSAC 7

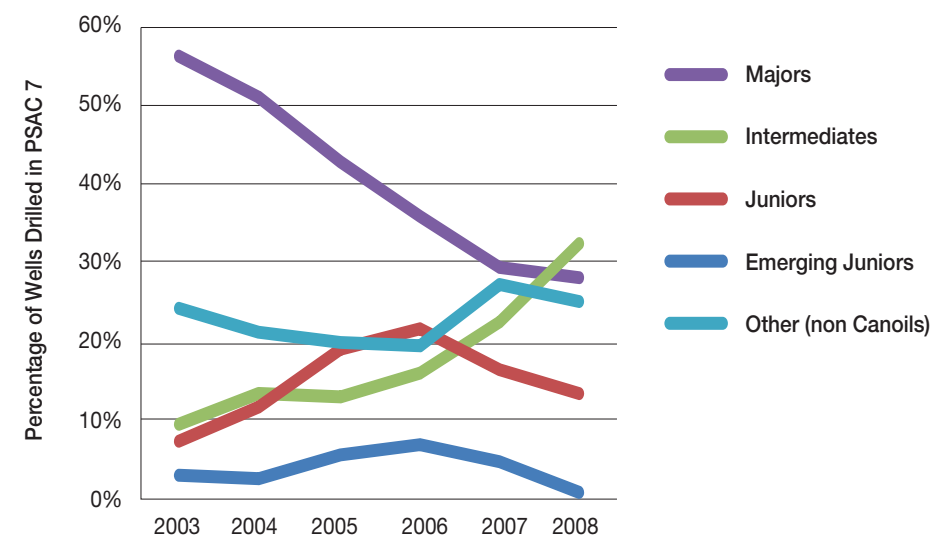




\section{APPENDIX V - DRILLING SUCCESS RATES BY PSAC AREA AND SIZE OF FIRM*}
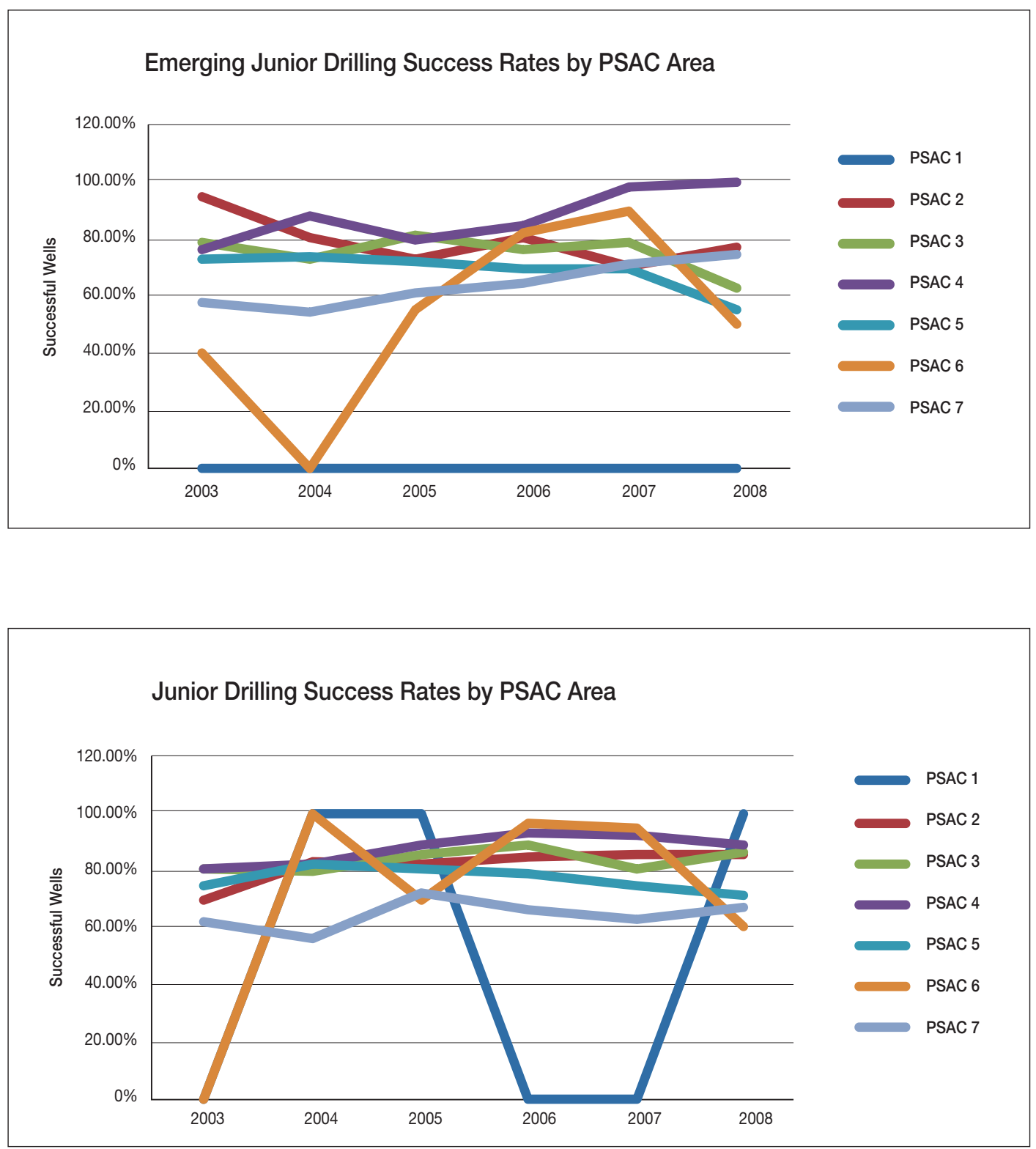

Note that in the cases where success rates are shown as zero, this is because there were no wells drilled in that PSAC area by firms in the particular size category. 

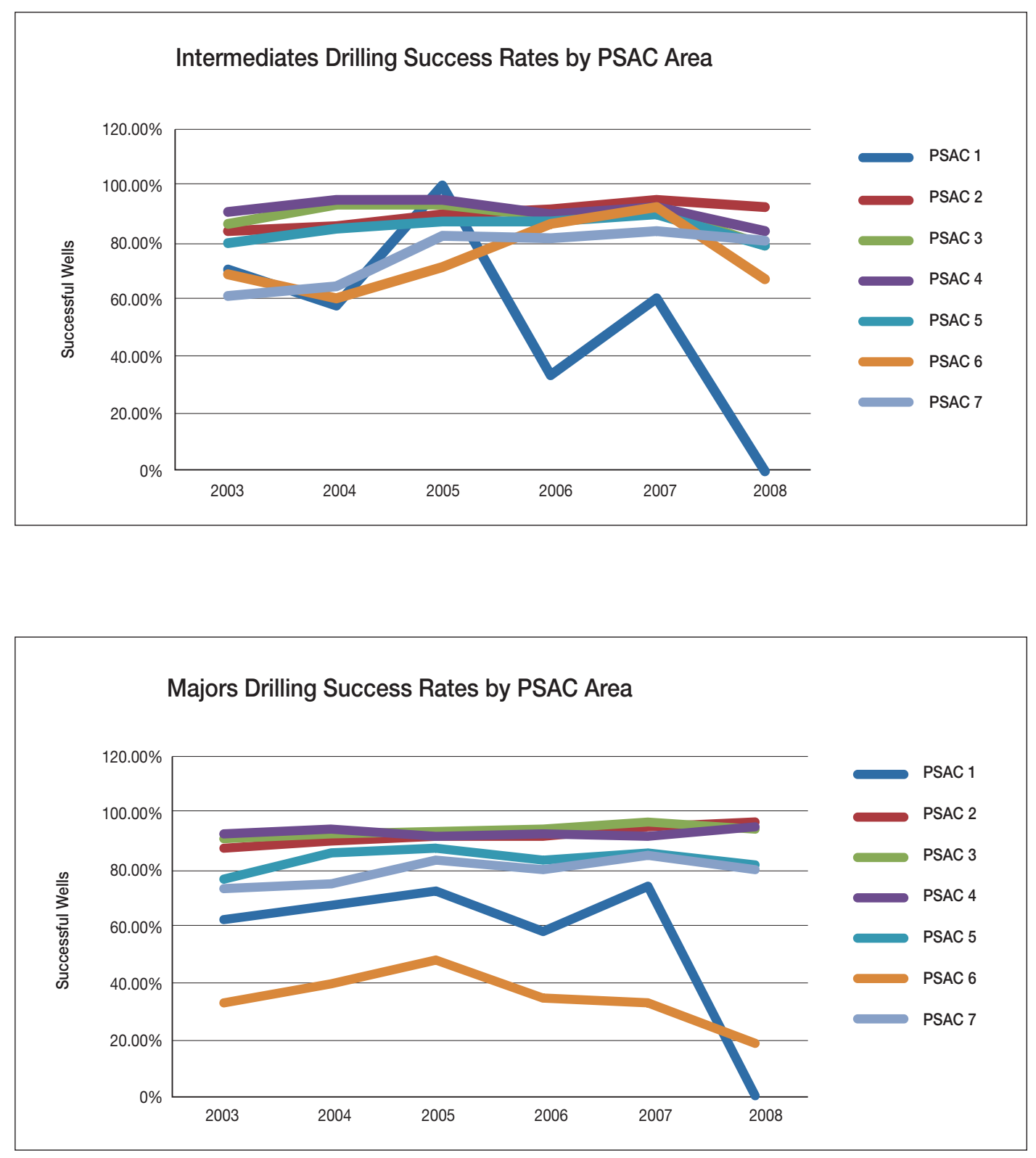


\section{ABOUT THIS PUBLICATION}

The School of Public Policy Research Papers provide in-depth, evidence-based assessments and recommendations on a range of public policy issues. Research Papers are put through a stringent peer review process prior to being made available to academics, policy makers, the media and the public at large. Views expressed in The School of Public Policy Research Papers are the opinions of the author(s) and do not necessarily represent the view of The School of Public Policy.

\section{OUR MANDATE}

The University of Calgary is home to scholars in 16 faculties (offering more than 80 academic programs) and 36 Research Institutes and Centres including The School of Public Policy. Under the direction of Jack Mintz, Palmer Chair in Public Policy, and supported by more than 100 academics and researchers, the work of The School of Public Policy and its students contributes to a more meaningful and informed public debate on fiscal, social, energy, environmental and international issues to improve Canada's and Alberta's economic and social performance.

The School of Public Policy achieves its objectives through fostering ongoing partnerships with federal, provincial, state and municipal governments, industry associations, NGOs, and leading academic institutions internationally. Foreign Investment Advisory Committee of the World Bank, International Monetary Fund, Finance Canada, Department of Foreign Affairs and International Trade Canada, and Government of Alberta, are just some of the partners already engaged with the School's activities.

For those in government, The School of Public Policy helps to build capacity and assists in the training of public servants through degree and non-degree programs that are critical for an effective public service in Canada. For those outside of the public sector, its programs enhance the effectiveness of public policy, providing a better understanding of the objectives and limitations faced by governments in the application of legislation.

\section{DISTRIBUTION}

Our publications are available online at www.policyschool.ca.

\section{DISCLAIMER}

The opinions expressed in these publications are the authors' alone and therefore do not necessarily reflect the opinions of the supporters, staff, or boards of The School of Public Policy.

\section{COPYRIGHT}

Copyright (C) 2012 by The School of Public Policy.

All rights reserved. No part of this publication may be reproduced in any manner whatsoever without written permission except in the case of brief passages quoted in critical articles and reviews.

\section{ISSN}

1919-112x SPP Research Papers (Print)

1919-1138 SPP Research Papers (Online)

\section{DATE OF ISSUE}

July 2012

\section{MEDIA INQUIRIES AND INFORMATION}

For media inquiries, please contact Morten Paulsen at 403-453-0062.

Our web site, www.policyschool.ca, contains more information about The School's events, publications, and staff.

\section{DEVELOPMENT}

For information about contributing to The School of Public Policy, please contact Courtney Murphy by telephone at 403-210-7201 or by e-mail at cmurphy@ucalgary.ca.

\section{EDITOR}

Timothy Giannuzzi 


\section{RECENT PUBLICATIONS BY THE SCHOOL OF PUBLIC POLICY}

HOW YOU PAY DETERMINES WHAT YOU GET: ALTERNATIVE FINANCING OPTIONS AS A DETERMINANT OF PUBLICLY FUNDED HEALTH CARE IN CANADA

http:/ / policyschool.ucalgary.ca/?q=content/ how-you-pay-determines-what-you-get-alternative-financingoptions-determinant-publicly-funded-health-care-canada.pdf

Ronald Kneebone | June 2012

SUPPLY MANAGEMENT: PROBLEMS, POLITICS - AND POSSIBILITIES

http:/ / policyschool.ucalgary.ca/?q=content/ supply-management-problems-politics-and-possibilities.pdf Martha Hall Findlay | June 2012

POLICY OPTIONS FOR REDUCING DIETARY SODIUM INTAKE

http:/ / policyschool.ucalgary.ca/ ?q=content/ policy-options-reducing-dietary-sodium-intake.pdf Lindsay McLaren | June 2012

A WHITE PAPER* ON REFORMING CANADA'S TRANSPORTATION POLICIES FOR THE 21ST CENTURY http:/ / policyschool.ucalgary.ca/ ?q=content/ white-paper-reforming-canadas-transportation-policies-21scentury.pdf

Brian Flemming | June 2012

PREVENTING DOMESTIC VIOLENCE IN ALBERTA: A COST SAVINGS PERSPECIVE http:/ / policyschool.ucalgary.ca/?q=content/ preventing-domestic-violence-alberta-cost-savingsperspective.pdf Lana Wells, Casey Boodt and Herb Emery | June 2012

NEGOTIATED SETTLEMENTS: LONG-TERM PROFITS AND COSTS

http:/ / policyschool.ucalgary.ca/ ?q=content/negotiated-settlements-long-term-profits-and-costs.pdf G Kent Fellows | May 2012

REFORMING THE TAX MIX IN CANADA

http:/ / policyschool.ucalgary.ca/?q=content/ reforming-tax-mix-canada.pdf

Bev Dahlby | April 2012

TAXING CONSUMPTION OR INCOME: DU PAREIL AU MÊME?

http:/ / policyschool.ucalgary.ca/sites/default/files/research/cnossen-taxing-consumption.pdf Sijbren Cnossen | April 2012

THE GST/HST: CREATING AN INTEGRATED SALES TAX IN A FEDERAL COUNTRY http:/ / policyschool.ucalgary.ca/ sites/default/ files/research/bird-gst-hst.pdf Richard M. Bird | April 2012

A PROPOSAL TO CREATE A PAN-CANADIAN ENERGY INFORMATION ORGANIZATION (CEIO) http:/ / policyschool.ucalgary.ca/ sites/default/files/research/m-moore-pancanadian.pdf Michal C. Moore | April 2012

ASSISTED REPRODUCTION POLICY IN FEDERAL STATES: WHAT CANADA SHOULD LEARN FROM AUSTRALIA http:/ / policyschool.ucalgary.ca/ sites/default/ files/research/dave-snow-art-final.pdf Dave Snow and Rainer Knopff | April 2012 